Pontifícia Universidade $_{\text {do Rio de Janeiro }}^{\text {Católica }}$

THIAGO ABREU PEREIRA PEIXOTO

Interação entre aspectos microestruturais e iniciação de trincas de fadiga em aços estruturais

Dissertação de Mestrado

Dissertação apresentada como requisito parcial para obtenção do grau de Mestre pelo programa de Pós-graduação em Engenharia de Materiais e de Processos Químicos e Metalúrgicos da PUC-Rio.

Orientador: Prof. Marcos Venicius Soares Pereira

Rio de Janeiro

Agosto de 2018 


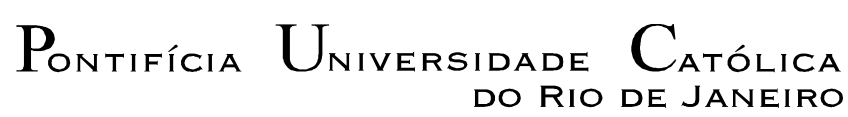

THIAGO ABREU PEREIRA PEIXOTO

\section{Interação entre aspectos microestruturais e iniciação de trincas de fadiga em aços estruturais}

Dissertação apresentada como requisito parcial para obtenção do grau de Mestre pelo Programa de Pós-graduação em Engenharia de Materiais e de Processos Químicos e Metalúrgicos da PUC-Rio. Aprovado pela Comissão Examinadora abaixo assinada.

Prof. Marcos Venicius Soares Pereira

Orientador

Departamento de Engenharia Química e de Materiais - PUC-Rio

Prof. Fathi Aref Ibrahim Darwish

Universidade Federal Fluminense

Prof. Felipe José da Silva

Instituto Federal de Educação, Ciência e Tecnologia do Rio de Janeiro

Prof. Marcio da Silveira Carvalho Coordenador Setorial do Centro Técnico Científico - PUC-Rio 
Todos os direitos reservados. É proibida a reprodução total ou parcial do trabalho sem autorização da universidade, da autora e do orientador.

Thiago Abreu Pereira Peixoto Graduou-se em Engenharia Mecânica na Universidade Federal do Rio de Janeiro. Profissional com carreira desenvolvida na área da Engenharia, atuando em empresas nacionais e multinacionais de médio e grande porte nos segmentos de Projetos, Construção Civil e Prestação de Serviços. Atuação em grandes projetos como Angra 3, Comperj e Rnest como responsável pela verificação de materiais de Tubulação.

Ficha Catalográfica

Peixoto, Thiago Abreu Pereira

Interação entre aspectos microestruturais e iniciação de trincas de fadiga em aços estruturais / Thiago Abreu Pereira Peixoto ; orientador: Marcos Venicius Soares Pereira. - 2018.

105 f. : il. color. ; $30 \mathrm{~cm}$

Dissertação (mestrado)-Pontifícia Universidade Católica do Rio de Janeiro, Departamento de Engenharia Química e de Materiais, 2018.

Inclui bibliografia

1. Engenharia Química e de Materiais - Teses. 2. Eixos virabrequins. 3. Usinas termoelétricas. 4. Curva da/dN versus $\Delta \mathrm{K} .5$. Limiar de propagação. 6. Inclusões. I. Pereira, Marcos Venicius Soares. II. Pontifícia Universidade Católica do Rio de Janeiro. Departamento de Engenharia Química e de Materiais. III. Título. 


\section{Agradecimentos}

À minha esposa e a minha mãe que sempre estiveram ao meu lado e foram as principais incentivadoras para que eu fizesse o mestrado, me dando forças em cada etapa vencida, comemorando em cada pequena vitória conquistada.

À minha filha, que é o maior presente que Deus me deu, e me impulsiona a querer ser uma pessoa cada vez melhor.

Ao meu orientador, Marcos Venicius Soares Pereira, pelos ricos ensinamentos passados a mim, não só na execução dessa tese, mas em todas as disciplinas ministradas por ele, sempre buscando desenvolver o nosso raciocínio na solução de problemas diversos.

A CAPES e a Puc-Rio, pelos auxílios concedidos, sem os quais esta pesquisa não poderia ter sido realizada.

Ao engenheiro Adrian Giovani pelo auxílio nos ensaios experimentais, assim como ao José Marques pela confecção dos corpos de prova e Asafe Bittencourt pela ajuda na preparação das amostras e microscopia óptica.

A todos os amigos do mestrado, em especial Ana Paula, Francisco José, Felipe Roballo, Maria Clara e Tiago Castro, pelo convívio, estímulo e apoio constante durante o mestrado.

A todos os professores do DEQM pelos ensinamentos.

A todos aqueles, que embora não citados nominalmente, contribuíram direta e indiretamente para a execução deste trabalho. 
Este trabalho foi desenvolvido no âmbito do Programa de Pesquisa e Desenvolvimento Tecnológico do Setor de Energia Elétrica regulado pela ANEEL, com o apoio das empresas da ENEVA - Pecém II Geração de Energia S.A., Itaqui Geração de Energia S.A. Parnaíba I, II e III Geração de Energia S.A. 


\section{Resumo}

Peixoto, Thiago Abreu Pereira; Soares Pereira, Marcos Venicius. Interação entre aspectos microestruturais e iniciação de trincas de fadiga em aços estruturais. Rio de Janeiro, 2018. 105p. Dissertação de Mestrado - Departamento de Engenharia de Materiais e Processos Químicos e Metalúrgicos, Pontifícia Universidade Católica do Rio de Janeiro.

O presente trabalho teve como objetivos avaliar a influência de heterogeneidades metalúrgicas sobre o limiar de propagação de trincas de fadiga e apresentar alternativas de materiais para a fabricação de eixos virabrequins de motores Diesel / gás natural de unidades geradoras de plantas termoelétricas, uma vez que tais componentes mecânicos fabricados com aço DIN 34CrNiMo6 vêm apresentando falhas por fadiga com baixo número de ciclos de carregamento. Corpos de prova foram usinados de aços SAE 4140, SAE 4340 e DIN 42CrMo4. Inicialmente, conduziram-se ensaios de tração para a determinação das propriedades mecânicas dos materiais. Ensaios de propagação de trincas de fadiga foram realizados em espécimes do tipo $\mathrm{C}(\mathrm{T})$ entalhados, submetidos a um carregamento cíclico. Pré-trincas de fadiga, com comprimentos variando entre 1,3 $\mathrm{mm}$ e $1,6 \mathrm{~mm}$, foram induzidas nos corpos de prova de acordo com a norma ASTM E647. Em sequência, foram levantadas as curvas $\mathrm{d} a / \mathrm{dN}$ versus $\Delta \mathrm{K}$ dos materiais, com ênfase para a determinação da variação do fator de intensidade de tensão do limiar de propagação $\left(\Delta \mathrm{K}_{\text {th }}\right)$ de cada aço. Neste contexto, o aço SAE 4140 apresentou um valor de $\left(\Delta K_{\text {th }}\right)$ superior aos demais, o que significa que suporta maiores tamanhos de trinca antes do início da propagação. Análises por técnicas de microscopia evidenciaram a presença de inclusões na região de propagação das trincas, dando origem a um caminho preferencial para o crescimento das mesmas. Os resultados destas análises indicaram a presença de uma menor quantidade de inclusões no aço SAE 4140, permitindo uma associação desta característica microestrutural com o valor do $\Delta \mathrm{K}_{\text {th }}$ do material. Desta maneira, no que se refere à iniciação de trincas de fadiga, o aço SAE 4140 
apresenta-se como alternativa viável para substituição do aço 34CrNiMo6 na fabricação de eixos virabrequins para motores de usinas termoelétricas.

\section{Palavras-chave}

Eixos virabrequins; Usinas termoelétricas; Curva $\mathrm{d} a / \mathrm{dN}$ versus $\Delta \mathrm{K}$; Limiar de propagação; Inclusões. 


\section{Abstract}

Peixoto, Thiago Abreu Pereira; Soares Pereira, Marcos Venicius (Advisor). Interaction between microstructural aspects and initiation of fatigue cracks in structural steels. Rio de Janeiro, 2018. 105p. Dissertação de Mestrado - Departamento de Engenharia de Materiais e Processos Químicos e Metalúrgicos, Pontifícia Universidade Católica do Rio de Janeiro.

The present study had as objectives to evaluate the influence of metallurgical heterogeneities on the fatigue cracking propagation threshold and to present alternative materials for the manufacture of crankshafts of diesel / natural gas engines of thermoelectric plants generating units, since such components mechanics manufactured with DIN 34CrNiMo6 steel has been presenting faults due to fatigue with a low number of loading cycles. Test specimens were machined from SAE 4140, SAE 4340 and DIN 42CrMo4 steels. Initially, tensile tests were conducted to determine the mechanical properties of the materials. Fatigue crack propagation tests were performed on $\mathrm{C}(\mathrm{T})$ specimens subjected to cyclic loading. Fatigue pre-cracks, with lengths ranging from $1.3 \mathrm{~mm}$ to $1.6 \mathrm{~mm}$, were induced in the test specimens according to ASTM E647. In sequence, $\mathrm{d} a / \mathrm{dN}$ versus $\Delta \mathrm{K}$ curves of the materials were raised, with emphasis on the determination of the tensile strength factor of the propagation threshold ( $\Delta \mathrm{K}$ th) of each steel. In this context, the steel SAE 4140 presented a value of $\left(\Delta \mathrm{K}_{\text {th }}\right)$ superior to the others, which means to support larger crack sizes before the beginning of the propagation. Analysis by microscopy techniques evidenced the presence of inclusions in the region of crack propagation, giving rise to a preferential path for their growth. The results of these analyzes indicated the presence of a smaller number of inclusions in the steel SAE 4140, allowing an association of this microstructural characteristic with the value of the $\Delta \mathrm{K}_{\text {th }}$ of the material. In this way, with regard to the initiation of fatigue cracks, the SAE 4140 steel is presented as a viable alternative for the replacement of 34CrNiMo6 steel in the manufacture of crankshafts for motors of thermoelectric power plants. 


\section{Keywords}

Crankshafts; Thermoelectric power plants; $\mathrm{d} a / \mathrm{dN}$ versus $\Delta \mathrm{K}$ curve; Threshold; Inclusions. 


\section{Sumário}

1. Introdução

2. Revisão bibliográfica 20

2.1. Fratura 20

2.1.1. Conceito 20

2.1.2. Resistência teórica dos materiais 22

2.1.2.1. Análise de Inglis 23

2.1.2.2. Análise de Grifftith 24

2.1.2.3. Análise de Irwin 25

2.1.3. Crescimento real versus crescimento virtual da trinca 26

2.1.4. Mecânica da fratura linear elástica e elastoplástica 27

2.1.4.1. Modos de carregamento 29

2.2. Fadiga 30

2.2.1. Conceito 30

2.2.2. Curva SN 30

2.2.2.1. Fadiga de baixo ciclo 31

2.2.2.2. Fadiga de alto e altíssimo ciclo 34

2.2.3. Curva de propagação de trincas por fadiga 35

2.2.4. Características macroscópicas e microscópicas da superficie de fratura 42

2.3. Aspectos microestruturais $\quad 45$

3. Materiais e Métodos 51

3.1. Caracterização dos materiais 51

3.1.1. Composição química 52

3.1.2. Tratamento térmico 52

3.2. Ensaios mecânicos 54

3.2.1. Ensaio de tração 54

3.2.2. Ensaio de propagação das trincas por fadiga 56 
3.3. Microscopia 62

3.3.1. Microscopia óptica 62

3.3.2. Microscopia eletrônica de varredura 65

4. Resultados e discussão $\quad \mathbf{7 0}$

4.1. Composição química 70

4.2. Tratamento térmico 70

4.3. Ensaios mecânicos 70

4.3.1 Ensaios de tração

4.3.2. Ensaios de propagação das trincas de fadiga 72

4.4. Microscopia 83

$\begin{array}{ll}\text { 5. Conclusões } & 98\end{array}$

6. Sugestões para trabalhos futuros 99

7. Referências bibliográficas 100 


\section{Lista de Figuras}

Figura 1 - Relação K versus Espessura.

Figura 2 - Redistribuição de tensões devido à existência de um defeito.

Figura 3 - Placa infinita sujeita a um esforço de tração remoto 24

Figura 4 - Balanço energético de Griffith.

Figura 5 - Tamanho da zona plástica no ligamento do corpo de provas.

Figura 6 - Abertura da ponta da trinca.

Figura 7 - Curva JR.

Figura 8 - Modos de carregamento.

29

Figura 9 - Curva S-N "Duplex".

Figura 10 - Ciclo de Histerese.

Figura 11 - Parâmetros da equação de Coffin-Mason p/ algumas ligas.

Figura 12 - Tipos de Nucleação de trincas dependendo da região da curva S-N.

Figura 13 - Formação de intrusões e exclusões devido ao carregamento cíclico em fadiga de baixo ciclo.

Figura 14 - Curva $\mathrm{d} a / \mathrm{dN}$ versus $\Delta \mathrm{K}$. 37

Figura 15 - Propagação de uma trinca na fase 2.

Figura 16 - Superfícies características de uma fratura, evidenciando as etapas de nucleação, propagação e ruptura

Figura 17 - Representação esquemática dos modelos analisados em um diagrama de tipo Kitagawa-Takahashi.

Figura 18 - "Frente" da trinca com relação ao nível de carregamento.

Figura 19 - Representação das zonas cisalhadas, radial e fibrosa na fratura de um corpo cilíndrico liso.

Figura 20 - Local de iniciação da fratura marcada com uma flecha. 
Figura 21 - Aspecto das facetas de clivagem com "rios"

característicos que indicam o sentido de propagação da fratura.

Figura 22 - Estricção de um corpo de prova cilíndrico, coalescimento das cavidades vai diminuindo a seção resistente do corpo.

Figura 23 - Diagramas de Kitagawa para ambas as microestruturas (defeito = trinca calculada com $3 \mathrm{MPa} \mathrm{m}^{1 / 2}$ threshold efetivo).

Figura 24 - Curva de valor estimado para limiar de propagação para S45C.

Figura 25 - Efeito do R sobre o threshold de um aço com microestrutura austenítica.

Figura 26 - Efeito do R sobre o threshold para diferentes microestruturas.

Figura 27 - Ciclo de têmpera + revenimento.

Figura 28 - Corpo de prova de tração: (a) Dimensões em mm,

(b) Corpo de prova de tração usinado.

Figura 29 - Máquina Instron 5500R: (a) Visão geral da máquina;

(b) Detalhe do corpo de prova e extensômetro fixados durante ensaio.

Figura 30 - Dimensões do $C(T)$ para Ensaio de Propagação de trincas por fadiga.

Figura 31 - Máquina Servo-Hidráulica MTS 810-250kN.

Figura 32 - (a) "Garras" e Anéis de Pressão; (b) Fixação do corpo de prova $C(T)$ na Máquina Servo-Hidráulica MTS 810-250kN.

Figura 33 - Polimento das amostras: a) Politriz DPU-10 com abrasivo de $6 \mu \mathrm{m}$; b) Politriz Aropol VV com abrasivo de $1 \mu \mathrm{m}$.

Figura 34 - a) Corpo de prova do tipo $\mathrm{C}(\mathrm{T})$ com marcas

típicas de usinagem; b) Corpo de prova após polimento.

Figura 35 - a) Máquina Servo-Hidráulica Instron 8502 - 100 kN;

b) Microscópio Óptico acoplado à maquina.

Figura 36 - a) Microscópio Óptico Stereo Zeiss Discovery V8.

b) Lentes de magnificação do microscópio.

Figura 37 - Microscopia Óptica no cp do aço SAE 4340 - Aumento de $500 x$. 
Figura 38 - Microscopia Óptica no cp do aço DIN 42CrMo4 Aumento de 500x.

Figura 39 - Microscopia Óptica no cp do aço DIN 34CrNiMo6 Aumento de 200x.

Figura 40 - Microscopia Óptica no cp do aço SAE 4140 Aumento de 100x.

Figura 41 - Desenho esquemático para comparação entre microscópio óptico e microscópio eletrônico de varredura.

Figura 42 - a) MEV utilizado no ensaio; b) CP no porta amostras do MEV.

Figura 43 - MEV na amostra de DIN 42CrMo4 - Aumento de 500x. 68

Figura 44 - MEV na amostra de SAE 4340 - Aumento de 500x. 68

Figura 45 - MEV na amostra de DIN 34CrNiMo6 - Aumento de 500x. 69

Figura 46 - MEV na amostra de SAE 4140 - Aumento de 500x.

Figura 47- Display da Máquina Servo-Hidráulica indicando a carga máxima, carga mínima e número de ciclos realizados.

Figura 48 - Curva $\mathrm{d} a / \mathrm{dN}$ versus $\Delta \mathrm{K}$ do SAE 4340.

Figura 49 - Curva da/dN versus $\Delta \mathrm{K}$ do SAE 4140.

Figura 50 - Curva da/dN versus $\Delta \mathrm{K}$ do DIN $42 \mathrm{CrMo} 4$.

Figura 51 - Curva da/dN versus $\Delta \mathrm{K}$ do DIN34CrNiMo6.

Figura 52 - Limiar de propagação de trincas de fadiga dos quatro aços estruturais estudados.

Figura 53 - Nova curva da/dN versus $\triangle \mathrm{K}$ do SAE 4340.

Figura 54 - Nova curva da/dN versus $\triangle \mathrm{K}$ do SAE 4140.

Figura 55 - Nova curva da/dN versus $\Delta \mathrm{K}$ do DIN 42CrMo4. 82

Figura $56-\Delta K_{\text {th }}$ dos quatro aços estruturais estudados. 82

Figura 57 - Imagem de MEV da amostra do aço DIN 34CrNiM06 a ser analisada.

Figura 58 - Comando Analyze Particles do Fiji.

Figura 59 - Resultado do comando Analyze Particles

na imagem segmentada do aço DIN 34CrNiM06.

Figura 60 - Mosaico formado por 4 imagens do aço 34CrNiM06. 85

Figura 61 - Imagem do MEV onde foi feito EDS no 34CrNiM06. 86

Figura 62 - EDS na partícula 1 (Fig.61) no aço DIN 34CrNiM06. 86 
Figura 63 - EDS na partícula 2 (Fig.55) no aço DIN 34CrNiM06.

Figura 64 - Outra imagem de MEV onde foi feito EDS no aço DIN 34CrNiMo6.

Figura 65 - EDS na partícula 1 (Fig.64) no aço DIN 34CrNiM06. 87

Figura 66 - EDS na partícula 2 (Fig.64) no aço DIN 34CrNiM06. 88

Figura 67 - Área das partículas presente no aço DIN 34CrNiM06. 88

Figura 68 - Mosaico formado por 5 imagens do aço SAE 4340.

Figura 69 - Imagem do MEV onde foi feito EDS no aço SAE 4340. 90

Figura 70 - EDS na partícula 1 (Fig.69) indicando sulfetos

no aço SAE 4340.

90

Figura 71 - EDS na partícula 2 (Fig.69) indicando vazios no aço SAE 4340.

Figura 72 - Mosaico formado por 5 imagens do aço DIN 42CrMo4. 92

Figura 73 - Imagem de MEV da amostra do aço SAE 4140

indicando múltiplas nucleação de trincas de fadiga.

93

Figura 74 - Mosaico formado por 5 imagens do aço SAE 4140.

Figura 75 - MEV onde foi feito EDS no aço SAE 4140.

Figura 76 - EDS indicando a presença de sulfetos no aço $4140 . \quad 96$

Figura 77 - Outra imagem de MEV onde foi feito EDS no aço SAE 4140.

Figura 78 - EDS indicando a presença de vazios no aço 4140.

Figura 79 - EDS indicando a presença de mais vazios no aço SAE 4140.

Figura 80 - Comparação entre o $\Delta k_{\text {th }}$ teórico (Murakami) e o experimental para quatro diferentes aços estruturais. 


\section{Lista de Tabelas}

Tabela 1 - Valores de W e B utilizados. 56

Tabela 2 - Composição química das amostras dos aços estudados. 70

Tabela 3 - Valores de tensões obtidas através do ensaio de tração. 71

Tabela 4 - Parâmetros de ductilidade obtidos no ensaio de tração. 71

Tabela 5 - Valores de Pmáx críticos calculados para a pré trinca de fadiga.

Tabela 6 - Valores de Pmáx estimados para o cálculo da pré trinca fadiga.

Tabela 7 - Valores obtidos para levantamento da curva da/dN versus $\Delta \mathrm{K}$ para o aço SAE 4340

Tabela 8 - Valores obtidos para levantamento da curva da/dN versus $\Delta \mathrm{K}$ para o aço SAE 4140

Tabela 9 - Valores obtidos para levantamento da curva da/dN versus $\Delta \mathrm{K}$ para o aço DIN 42CrMo4

Tabela 10 - Valores obtidos para levantamento da curva da/dN versus $\Delta \mathrm{K}$ para o aço DIN 34CrNiMo6

Tabela 11 - Novos valores obtidos para levantamento da curva $\mathrm{d} a / \mathrm{dN}$ versus $\Delta \mathrm{K}$ para o aço SAE 4140

Tabela 12 - Novos valores obtidos para levantamento da curva $\mathrm{d} a / \mathrm{dN}$ versus $\Delta \mathrm{K}$ para o aço SAE 4340

Tabela 13 - Novos valores obtidos para levantamento da curva $\mathrm{d} a / \mathrm{dN}$ versus $\Delta \mathrm{K}$ para o aço DIN 42CrMo4

Tabela $14-\Delta \mathrm{K}_{\mathrm{th}}$ calculado e medido experimentalmente para os aços estruturais estudados. 


\section{Lista de Símbolos}

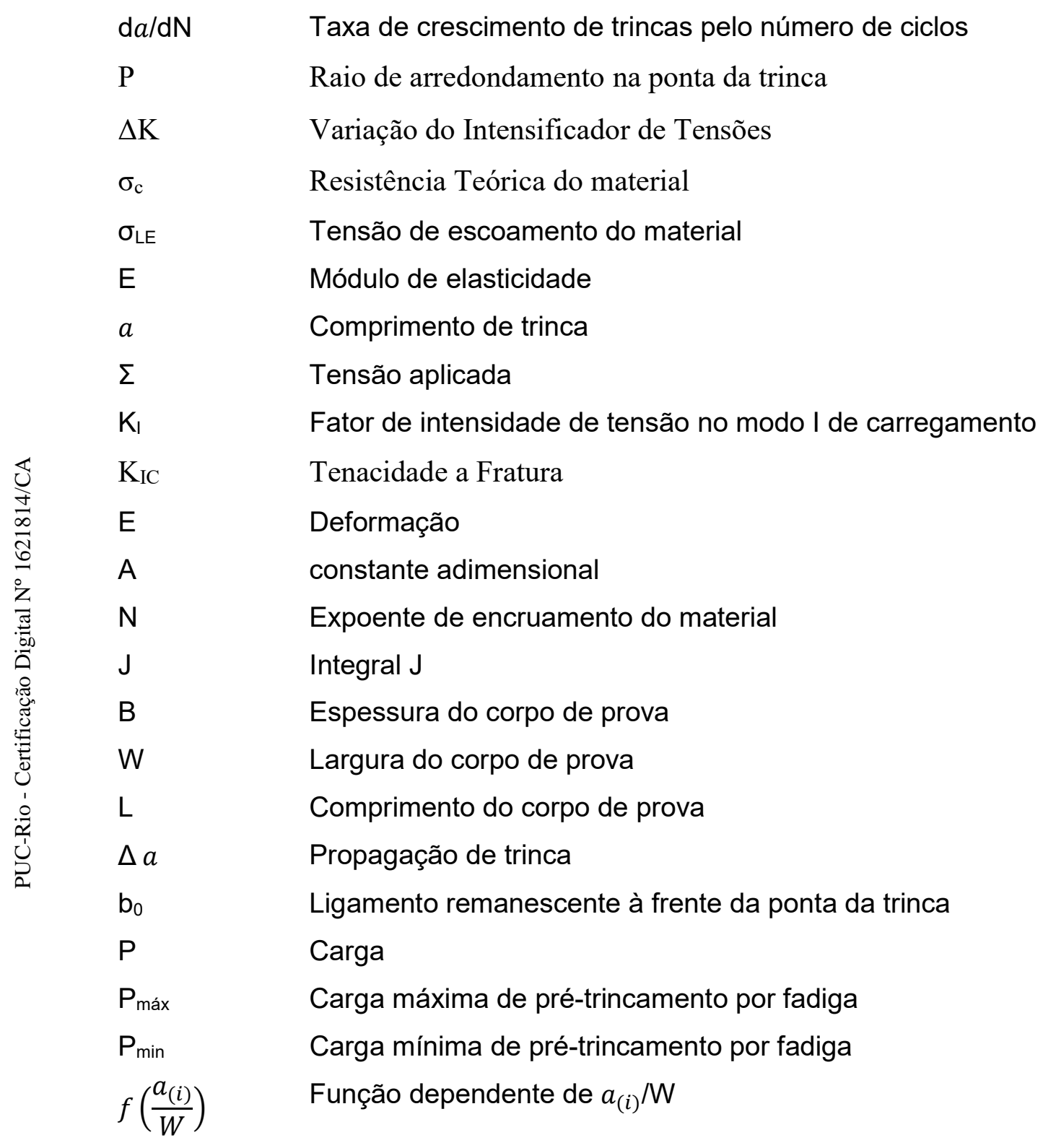




\section{Introdução}

Eixos virabrequins empregados em usinas termelétricas, quando fabricados com aço DIN 34CrNiMo6, vêm apresentando falhas por fadiga com baixo número de ciclos de carregamento. As causas dessas falhas prematuras podem estar relacionadas com heterogeneidades metalúrgicas presentes no material.

Equipamentos, componentes mecânicos e estruturas normalmente apresentam descontinuidades, trincas e outros defeitos que concentram tensões e que podem criar condições propícias para fraturas, muitas vezes catastróficas. Os materiais de alta resistência mecânica têm baixa resistência na presença de trincas, mesmo muito pequenas e, consequentemente, estruturas construídas com tais materiais podem fraturar em tensões abaixo daquelas de projeto.

A curva $\mathrm{d} a / \mathrm{dN}$ versus $\Delta \mathrm{K}$ permite a partir da detecção do tamanho do defeito, calcular a variação do intensificador de tensões $(\Delta K)$ que está atuando na ponta do "defeito" e ao compará-lo com o limiar de propagação $\left(\Delta \mathrm{K}_{\text {th }}-\right.$ que é uma função do tipo de material, mas não somente), saber se a trinca é incipiente, se sua propagação ocorre de maneira estável ou de maneira instável. Sendo assim, é considerada uma curva de tolerância ao dano.

O objetivo do trabalho é estudar a influência das heterogeneidades metalúrgicas em diferentes aços estruturais, realizando ensaios para levantamento do limiar de propagação de trincas de fadiga e acompanhamento visual da propagação das mesmas, para com isso ser capaz de traçar a curva $\mathrm{d} a / \mathrm{dN}$ versus $\Delta \mathrm{K}$ para diferentes materiais.

Além das curvas $\mathrm{d} a / \mathrm{dN}$ versus $\Delta \mathrm{K}$ dos diferentes aços estruturais, buscou-se através das microscopias óptica e eletrônica de varredura, visualizar o caminho preferencial de propagação das trincas e avaliar a influência dos aspectos microestruturais nessas curvas, tendo assim as condições necessárias para analisar qual aço seria o mais indicado para ser utilizado num eixo virabrequim que foi 
utilizado no motor de uma usina termelétrica, que apresentou falhas por fadiga com baixo número de ciclos de carregamento.

O presente estudo está dividido da seguinte maneira: No capítulo 2 realizam-se referências bibliográficas sobre a Mecânica da Fratura e Fadiga, introduzindo seus conceitos fundamentais e descrevendo as curvas de propagação de trincas de fadiga. Os Materiais e métodos utilizados para o desenvolvimento do estudo estão explicados no capítulo 3 e os resultados e as discussões a respeito dos ensaios encontram-se no capítulo 4. As conclusões e as sugestões para trabalhos futuros estão nos capítulos 5 e 6, respectivamente. Por fim, as referências bibliográficas aparecem no capítulo 7 . 


\section{Revisão Bibliográfica}

Na revisão bibliográfica a seguir são apresentados os principais conceitos da Mecânica da Fratura e Fadiga. São mostradas as características relacionadas aos diferentes tipos de Fratura, tanto com relação a aspectos macroscópicos como microscópicos. Em seguida são discutidos os aspectos relacionados à fadiga, evidenciando os fatores que influenciam as regiões presentes na curva de propagação de trincas por fadiga. O último tópico a ser discutido diz respeito aos aspectos microestruturais e a influência destes nas curvas $\mathrm{d} a / \mathrm{dN}$ versus $\Delta \mathrm{K}$.

\subsection{Fratura}

\subsubsection{Conceito}

Fratura é um problema que a sociedade vem enfrentando ao longo de muito tempo e seu estudo teve um impulso significativo a partir da Segunda Guerra Mundial, pois o entendimento sobre o porquê que os materiais falham e a habilidade de evitar tais falhas cresceu consideravelmente.

Falha é um não atendimento a um requisito de utilização e as causas podem ser diversas. Mas, basicamente houve negligência durante o projeto, construção ou operação da estrutura, ou ainda, a aplicação de um novo material que não tenha sido previamente testado e apresentou características indesejadas $[1]$.

Como especialista na seleção de materiais a serem utilizados num novo projeto o usual é a utilização de materiais que tenham um histórico de sucesso em projetos similares. Esses materiais já estão normatizados, foram testados, é conhecida de uma maneira eficiente a resposta que o material apresenta quando lhe for solicitado determinado esforço mecânico. 
A utilização de novos materiais deve ser precedida de um intenso estudo, contemplando diversos cenários possíveis que possam de fato testar se o que está sendo proposto corresponderá ao serviço a que é destinado e ainda, se esses novos materiais terão uma resposta superior com relação aos já utilizados em outras situações semelhantes.

Toda fratura ocorre a partir do que é conhecido como Zona de Processamento de Fratura e envolve a zona plástica na ponta da trinca e o aparecimento de novas superfícies no material [2].

Toda trinca concentra tensão na sua ponta e, à medida que a trinca vai aumentando de tamanho, a taxa com que ela cresce aumenta - mecanismo auto catalítico [3].

A fim de avaliar a existência de trincas iniciais e o comprimento das mesmas, os ensaios não destrutivos são uma forma eficiente de mapear esses defeitos, entretanto esses ensaios têm limitações que serão abordadas mais adiante.

As trincas presentes nos componentes mecânicos podem estar num tamanho que não inviabilize a utilização do mesmo, ou seja, o equipamento continua operando em segurança. Por exemplo, muitas soldas presentes em diversos equipamentos de Angra I possuem trincas e estes equipamentos estão operando há mais de 30 anos, ou seja, as trincas não crescem ou tem um crescimento incipiente, de modo que é relativamente "seguro" conviver com esses defeitos.

A fragilidade de um material é influenciada por três fatores externos, a saber: Temperatura, taxa ou velocidade de deformação (aumento faz com que as discordâncias não andem, limita a deformação plástica do material, fraturando-o de maneira frágil) e estado de tensões [4].

$\mathrm{Na}$ superfície é observado um estado de tensões planas, o que significa uma maior capacidade de deformação plástica (fig. 1). Internamente vai depender da espessura [5], e o caso mais crítico ocorre em chapas grossas, pois o estado de tensões é tri axial, o que significa uma falha frágil - uma vez que a deformação plástica é inibida nesta condição. 


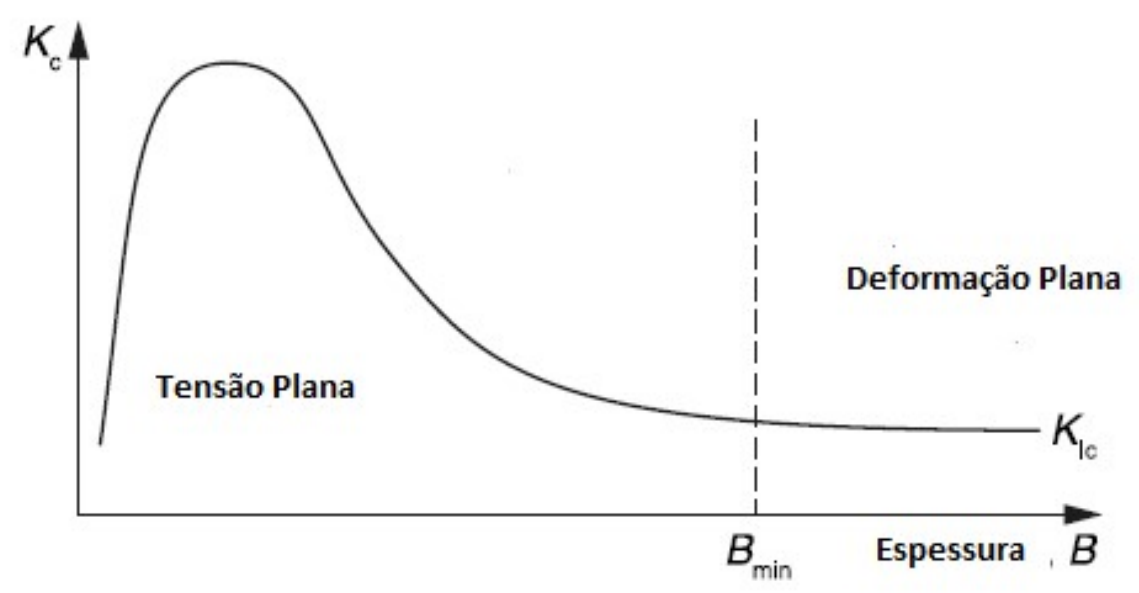

Figura 1: Relação K versus Espessura. Adaptado de [3].

\subsubsection{Resistência teórica dos materiais}

Para a mecânica clássica, fraturar o material significa afastar dois átomos, romper as ligações atômicas. Para inúmeros materiais a resistência teórica do componente mecânico encontra-se no intervalo de E/4 e E/15. Como valor médio teórico, considera-se que $\sigma_{\mathrm{c}}=\mathrm{E} / 10$. [6]

Na prática, os valores observados são cerca de 1/10 a 1/100 do valor teórico, ou seja, da ordem de E/100 até E/1000. Essa diferença pode ser atribuída à presença de defeitos que atuam no sentido de "amplificar" o efeito da tensão externa.

O valor de $\sigma_{c}$ pode ser calculado através da seguinte equação [3]:

$$
\sigma_{c}=\sqrt{\frac{E \gamma_{s}}{a_{0}}}
$$

onde:

$\gamma_{s}=$ Energia de Superfície

$a_{0}=$ Espaçamento da rede cristalina

A presença da trinca distorce as linhas de tensão no material, tendo impacto mais significativo o quanto mais próximo está do defeito conforme é observado na figura 2 [7]. 


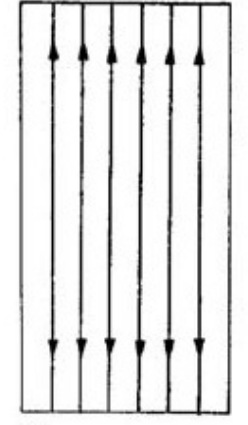

(a)

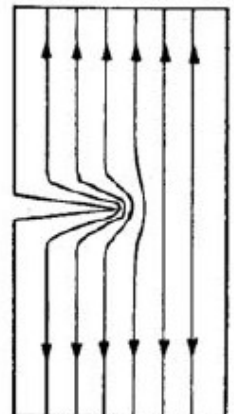

(b)

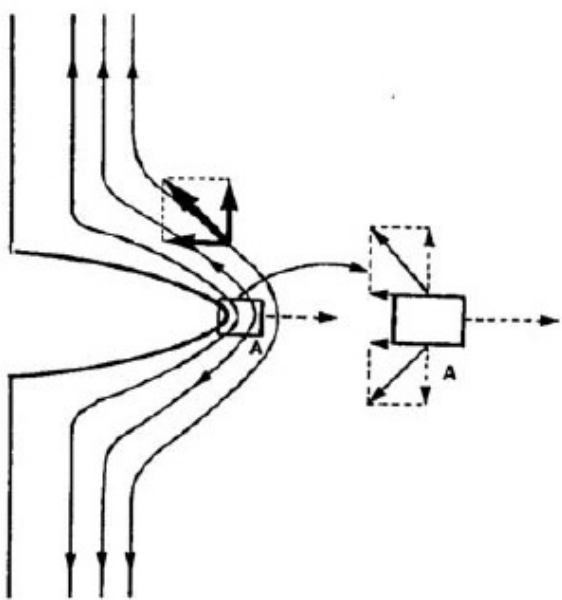

(c)

Figura 2: Redistribuição de tensões devido à existência de um defeito [7].

\subsubsection{Análise de Inglis}

Inglis (1913) foi pioneiro ao avaliar os efeitos da concentração de tensão, analisando entalhes elípticos em placas planas. Nesta análise a tensão é aplicada no infinito (muito longe do defeito) ou considera-se uma chapa infinita ou semi infinita. A tensão gera o campo de tensão na ponta do defeito, mas não interage com o mesmo. A equação proposta por Inglis indica que:

$$
\sigma_{\text {máx }}=\sigma\left(1+2 \sqrt{\frac{a}{\rho}}\right)
$$

Pela equação acima, o defeito será mais ativo se o tamanho da trinca $(a)$ for maior ou se o $(\rho)$ for menor - trinca mais aguda. Por exemplo, ao furar a ponta da trinca com uma broca, aumenta-se o $\rho$, "embotando" assim a trinca, diminuindo a efetividade da trinca.

Considerando a $>>>\rho$ e assumindo que a fratura ocorre quando $\sigma_{\text {máx }}=\sigma_{c}$ :

$$
\sigma_{\text {máx }}=2 \sigma \sqrt{\frac{a}{\rho}}=\sqrt{\frac{E \gamma_{s}}{a_{0}}}
$$


Ou em termos de tensão de fratura $\left(\sigma_{\mathrm{f}}\right)$ e considerando a trinca aguda $\mathrm{a}_{0} \approx \rho$ :

$$
\sigma f=\sqrt{\frac{E \gamma_{s} \rho}{4 a_{0} a}}=\sqrt{\frac{E \gamma_{s}}{4 a}}
$$

Esse enfoque considera que, mesmo na ponta da trinca, não há deformação plástica. Na realidade, essa condição não é atendida para metais, devendo assim a parcela devido à deformação plástica ser considerada no cálculo acima.

\subsubsection{Análise de Griffith}

Usando a análise de tensão de Inglis (1913) para um buraco elíptico em uma placa infinita ou semi-infinita, um critério de fratura foi apresentado por Griffith em 1920 e baseava-se no balanço termodinâmico da propagação [8].

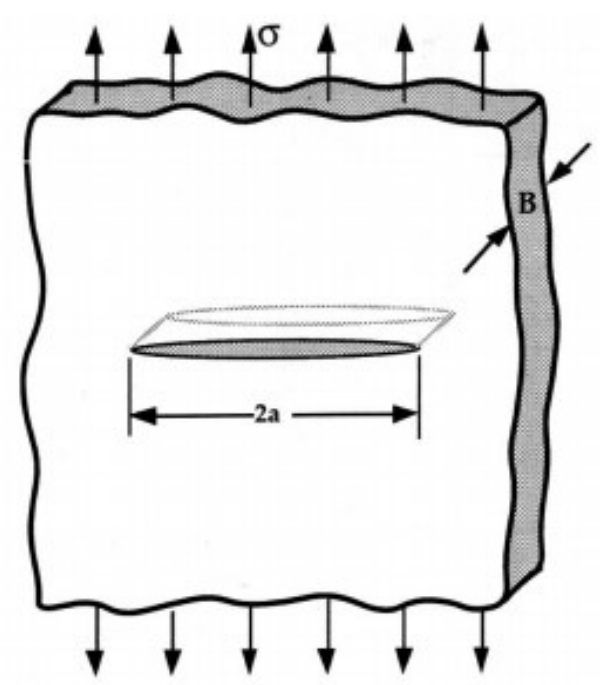

Figura 3: Placa infinita sujeita a um esforço de tração remoto. Em termos práticos,

"infinito" significa que a largura da placa é $>>2 a$. [1]

Seu postulado afirmava que: "a propagação instável da trinca só iria ocorrer quando o decréscimo de energia elástica com a propagação for ao menos igual à energia necessária para criar as novas superfícies de trinca". O que significa que a trinca se propaga de maneira estável até atingir o tamanho crítico $\left(a_{\mathrm{c}}\right)$ e a partir desse ponto a trinca se propaga de maneira instável (fig. 4). 


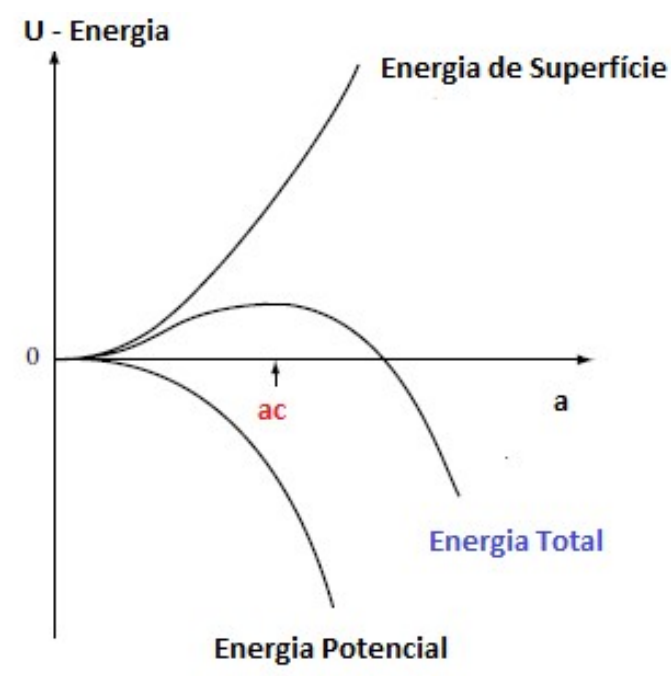

Figura 4: Balanço energético de Griffith [8]

Energia de deformação elástica (Potencial): Força motriz para o crescimento da trinca. Energia liberada (-).

Energia de Superfície: Aquela necessária para criar uma trinca de área $a \times 1$. Duas superfícies são criadas $(+)$.

$\mathrm{O}$ valor do $a_{\mathrm{c}}$ para materiais dúcteis é grande e para materiais frágeis é muito pequeno, ou seja, rapidamente a trinca muda o seu modo de propagação de estável para instável em materiais frágeis.

Isso pode levar a uma conclusão errônea de que propagação estável se relaciona com fratura dúctil e propagação instável com fratura frágil, o que não é verdade!

Como já mencionado anteriormente, uma parcela devido à deformação plástica deve ser adicionada a equação de Griffith, pois existe plastificação na ponta da trinca (materiais de engenharia).

\subsubsection{Análise de Irwin}

Orowan e Irwin sugeriram de forma independente que o equilíbrio termodinâmico de Griffith deve ser modificado para incluir essa parcela de deformação plástica $\left(\gamma_{p}\right)$, de modo que: 


$$
\sigma f=\sqrt{\frac{E\left(2 \gamma_{s}+\gamma_{p}\right)}{\pi a}}
$$

Mas, como $\gamma_{\mathrm{p}} \gg \gamma \mathrm{s}$, o termo de energia superficial pode ser ignorado completamente sem grande perda de precisão, portanto:

$$
\sigma f=\sqrt{\frac{E \gamma_{p}}{\pi a}}
$$

Esta simplificação indica que um valor para $\gamma_{\mathrm{p}}$ pode ser encontrado diretamente e usado como um meio de prever o início da fratura frágil sob outras condições de carga aplicada e comprimento de trinca.

$\mathrm{Na}$ prática, este tipo de procedimento raramente é realizado, uma vez que as condições em que os resultados de resistência à fratura podem ser medidos são mais bem compreendidas para a abordagem do fator de intensidade de tensão na fratura.

Em qualquer caso, o conceito de um valor crítico da taxa de liberação de energia potencial é uma abordagem mais rigorosa que proporciona um modelo melhor do processo de fratura, mas é bastante menos fácil de manipular do que àquela equivalente a um valor crítico de intensidade de tensão na fratura.

\subsubsection{Crescimento real versus crescimento virtual da trinca}

A trinca se arredonda num momento anterior àquele na qual que ela começa a se propagar de fato. Ela aumenta o raio de curvatura de sua ponta, mas não cresce, pois não cria novas superfícies [9]. Sendo assim, é um crescimento virtual com níveis de tensão entre a Tensão Limite de Escoamento $\left(\sigma_{\mathrm{y}}\right)$ e a Tensão Limite de Resistência a Tração (LRT) do material. Quanto mais dúctil for o material, mais a trinca consegue arredondar a ponta antes de começar a se propagar.

Quando a trinca atinge o máximo de arredondamento, ou seja, quando for exaurida na frente dela toda a capacidade de deformação plástica que o material possui (atinge o LRT na ponta da trinca) ela se propagará, haverá extensão da mesma, criando novas superfícies, apresentando crescimento real. 


\subsubsection{Mecânica da fratura linear elástica e elastoplástica}

A Mecânica da Fratura Linear Elástica (MFLE) está associada à fratura frágil, onde a zona plástica na ponta da trinca é desprezível, ou seja, a quantidade de plastificação no ligamento (parte não trincada) do corpo de prova é pequena (fig. 5). O parâmetro que rege esse comportamento é $\mathrm{K}_{\mathrm{IC}}$.

Já a Mecânica da Fratura Elastoplástica (MFEP) possui uma extensa zona plástica, grande quantidade de plastificação no ligamento do corpo de provas, estando associada à fratura dúctil, onde os métodos de Crack Tip Openening Displacement (CTOD) e Integral J são utilizados.

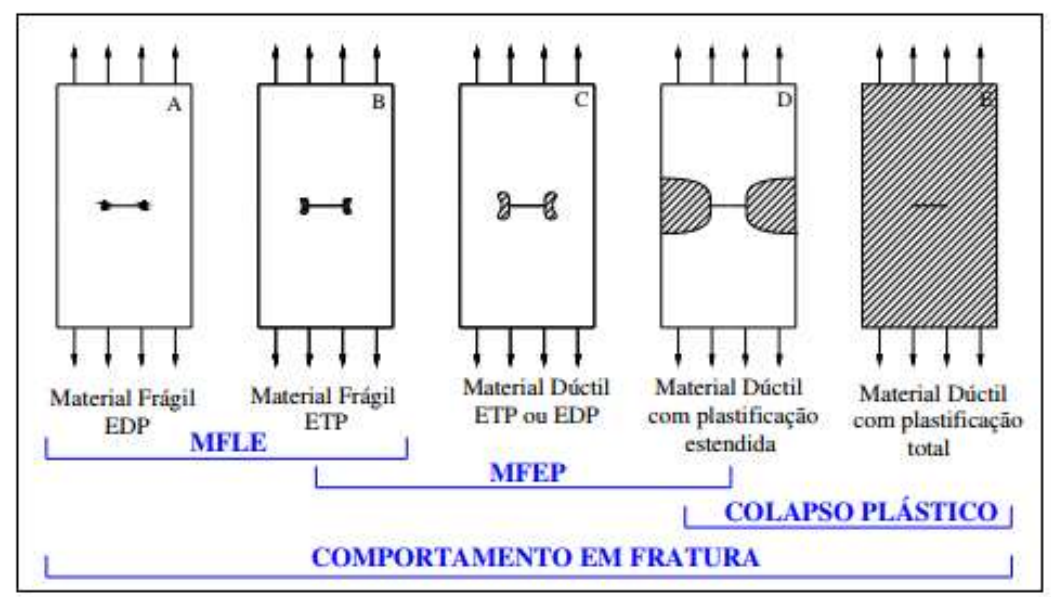

Figura 5: Tamanho da zona plástica no ligamento do corpo de prova [10].

$\mathrm{Na}$ indústria, algumas plantas de engenharia como a nuclear e aeronáutica, embora tenham materiais de altíssima ductilidade, são projetadas de acordo com a MFLE o que representa um método extremamente conservador.

Com isso, o equipamento é penalizado, pois a parada para a manutenção ocorre com um tamanho de defeito muito menor do que aquele que seria suportado na realidade. Entretanto, ao usar MFLE em materiais dúcteis busca-se uma maior segurança.

O CTOD mede o deslocamento da abertura da ponta da trinca, mensura o quanto de deformação plástica existe na ponta da trinca. Os conceitos básicos desse método foram desenvolvidos, de forma independente, por Wells [11] e Cottrell [12].

Quando a deformação plástica atinge o valor máximo a trinca cresce e quanto maior a ductilidade do material, maior será a abertura da ponta da trinca (fig.6). 


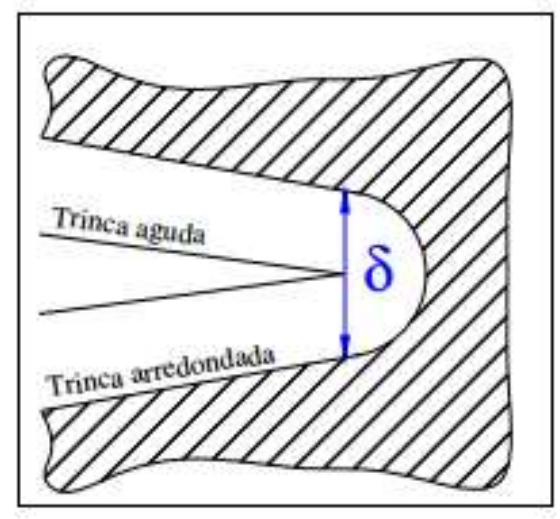

Figura 6: Abertura da ponta da trinca [10].

Existe um valor crítico da abertura da ponta da trinca que depende do critério de falha adotado, podendo ser o CTOD de iniciação da propagação estável da trinca, CTOD de iniciação da propagação instável da trinca ou CTOD de carga máxima.

A Integral $\mathbf{J}$ ou simplesmente $\mathbf{J}$ é uma integral de linha, independente do caminho, que ao integrar uma região mede a quantidade de energia presente na mesma, sendo assim um parâmetro que relaciona quantidade de energia $(\mathrm{J})$ por unidade de área $\left(\mathrm{m}^{2}\right)$.

A curva $J_{R}$ expressa a relação entre a propagação estável da trinca $(\Delta a)$ e a integral J. Inicialmente, a curva $J_{R}$ (fig.7) foi utilizada somente para determinar $\mathrm{J}_{\mathrm{IC}}$, que é o valor de J para o início da propagação estável da trinca. Mas, utilizar $\mathrm{J}_{\mathrm{IC}}$ como critério de projeto é excessivamente conservativo, já que desta maneira não se considera o aumento da resistência com o crescimento da trinca.

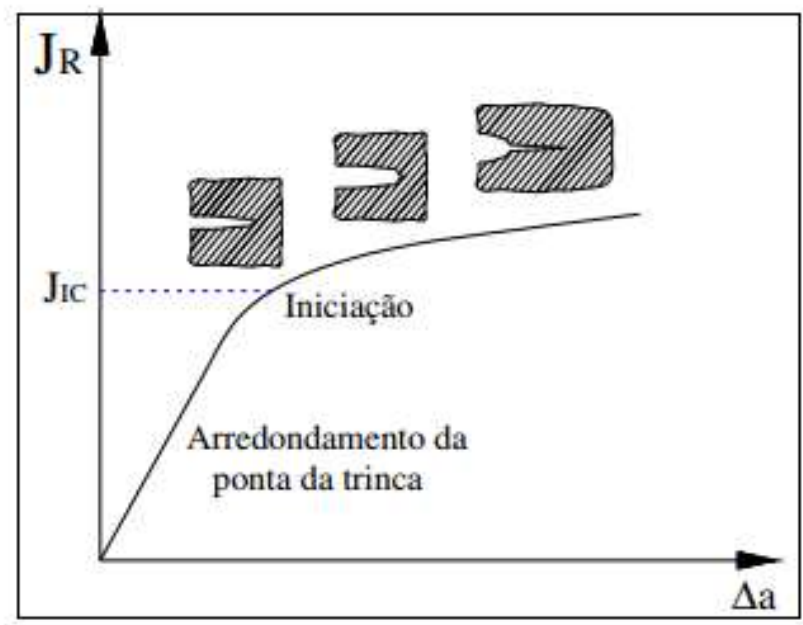

Figura 7: Curva $J_{R}[10]$. 
Diferentemente de $\mathrm{K}_{\mathrm{IC}}$ que é uma propriedade dos materiais que relaciona tensão com tamanho de defeito, permitindo assim calcular o valor do $a_{\mathrm{c}}$, os valores medidos por CTOD ou $\mathrm{J}$ devem ser parametrizados através dos Engineering Critical Assessement (ECA) para fornecer um valor de tensão capaz de medir a trinca na estrutura real.

Materiais de engenharia só "conhecem" dois tipos de tensões: normais e cisalhantes. A maior resistência do material é sempre a tração (esforço normal), os esforços cisalhantes equivalem a $60 \%$ do limite de resistência de esforços normais e isso ocorre porque para tracionar é necessário afastar planos cristalinos, enquanto no cisalhamento ocorre o deslizamento dos planos.

\subsubsection{Modos de carregamento}

Existem três formas fundamentais, segundo as quais a carga pode operar sobre uma trinca, e cada uma irá afetar um deslocamento diferente da superfície da trinca. No modo I de carregamento a tensão aplicada é perpendicular ao plano de propagação da trinca, no modo II a tensão é paralela ao plano de propagação da trinca (cisalhamento no plano, $\mathrm{K}_{\mathrm{II}}$ ) e no modo III a trinca propaga por torção (como material não "entende" torção, o que temos é um cisalhamento fora do plano).

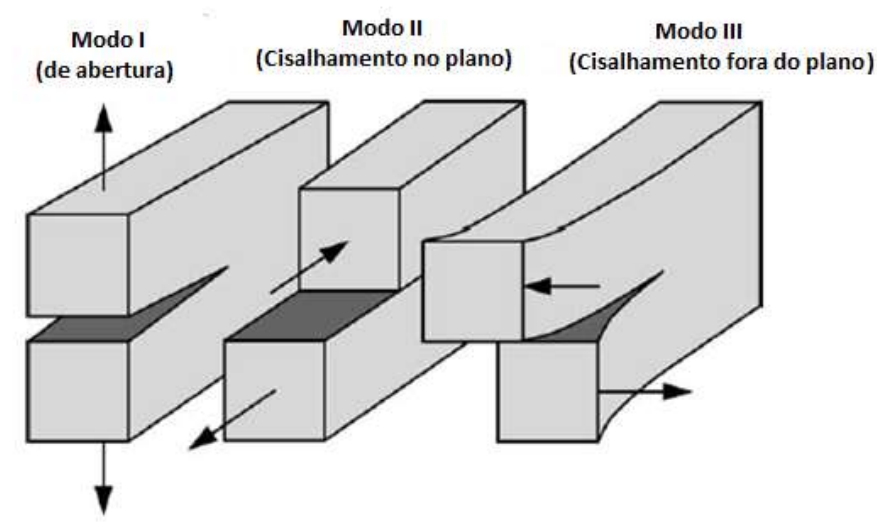

Figura 8: Modos de carregamento [1].

O modo I é o mais crítico para a propagação da trinca, pois não precisa de deformação (associada à componente cisalhante) para acontecer.

O parâmetro K pode ser entendido como a ação de uma tensão agindo sob o tamanho de um defeito, ou seja, como a tensão interage com o material, correlacionando a tensão global com a tensão local. 


\subsection{Fadiga}

\subsubsection{Conceito}

Fadiga é um processo de acúmulo de danos, onde o material rompe geralmente por tração [9], associada a carregamento cíclico. As trincas são os defeitos mais agudos e, portanto, mais críticos para os componentes mecânicos.

\subsubsection{Curva $S-N$}

Curva de vida em fadiga do material, desenvolvida a partir dos trabalhos pioneiros de Wöhler em meados do século XIX. É um método que não reconhece a presença de trincas, e em princípio só deve ser usado para evitar ou prever a iniciação de trincas por fadiga quando as tensões atuantes no ponto crítico da peça são menores do que a resistência ao escoamento cíclico do material, as quais são associadas a vidas longas [13].

$\mathrm{Na}$ indústria, frequentemente o tempo de vida de projeto requerido de muitos componentes excede $10^{7}$ ciclos de carregamento, o que significa que os componentes sofrem fadiga de altíssimo ciclo (Very High Cycle Fatigue - VHCF). Neste regime de fadiga, as inclusões não metálicas [14,15] têm um efeito muito prejudicial no desempenho de fadiga de aços de alta resistência.

Wang et al. [16], Paris et al. [17] e Marines et al. [18] relataram que no regime VHCF, a vida em fadiga é principalmente devido ao processo de iniciação. A figura 9 apresenta a curva S-N contemplando as regiões de fadiga de baixo ciclo, fadiga de alto ciclo e fadiga de altíssimo ciclo. 


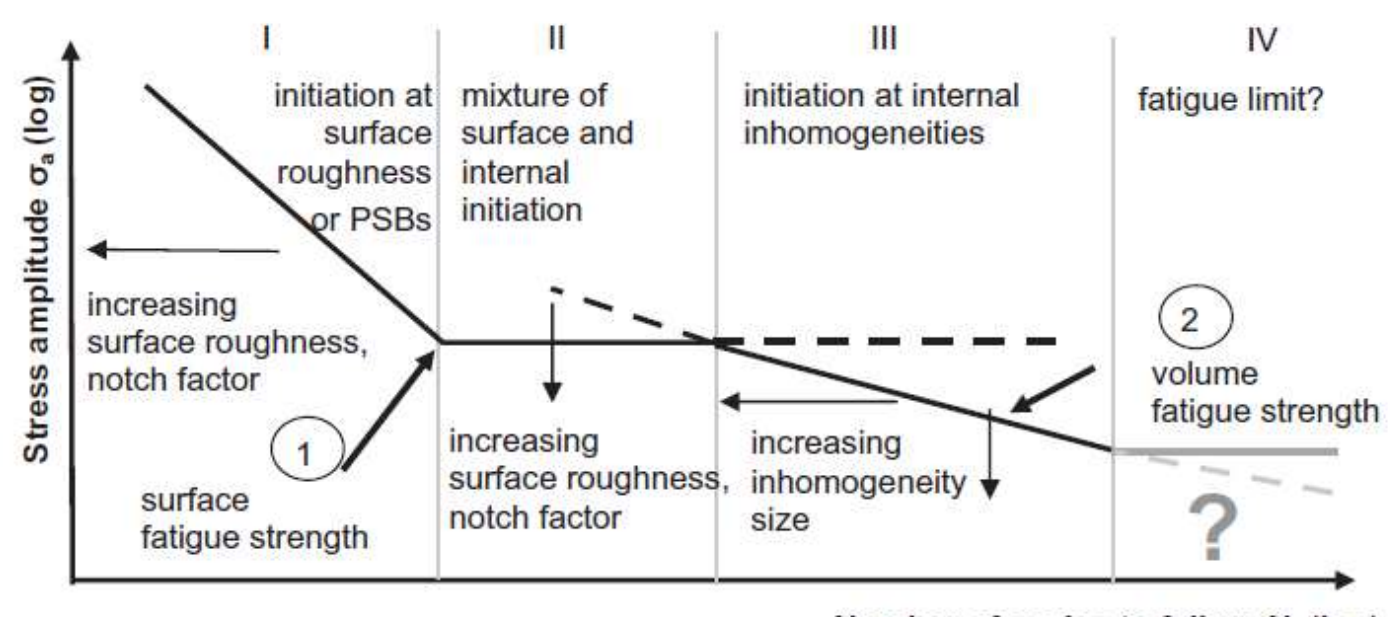

Number of cycles to failure $\mathbf{N}_{\mathrm{f}}(\log )$

Figura 9: Curva S-N "Duplex" [19].

\subsubsection{Fadiga de baixo ciclo}

Fadiga associada a um nível de tensão muito alto, número baixo de ciclos, ocasionando uma deformação cíclica (plastificação localizada no material). [20]

Em projetos com variação de temperatura muito grande podem aparecer deformações de origem térmica. Se um vaso de pressão está restrito a outros equipamentos e sofre uma variação de temperatura, ele sofre uma deformação térmica e pela Lei de Hooke aparece uma tensão de origem térmica.

Caso ocorra deformação plástica, há a formação de um ciclo de histerese (ao ser carregado novamente há um loop de deformação). A largura do ciclo (deformação plástica) depende do nível de deformação aplicado [21].

A noção de que as tensões plásticas são responsáveis pelo dano cíclico (fig.10) foi estabelecida por Coffin e Manson, onde trabalhando de forma independente em problemas associados à fadiga devido ao carregamento térmico e de alta amplitude de tensão, propuseram uma relação empírica entre o número de reversões de carga para a falha de fadiga e a amplitude da deformação plástica [9]. 


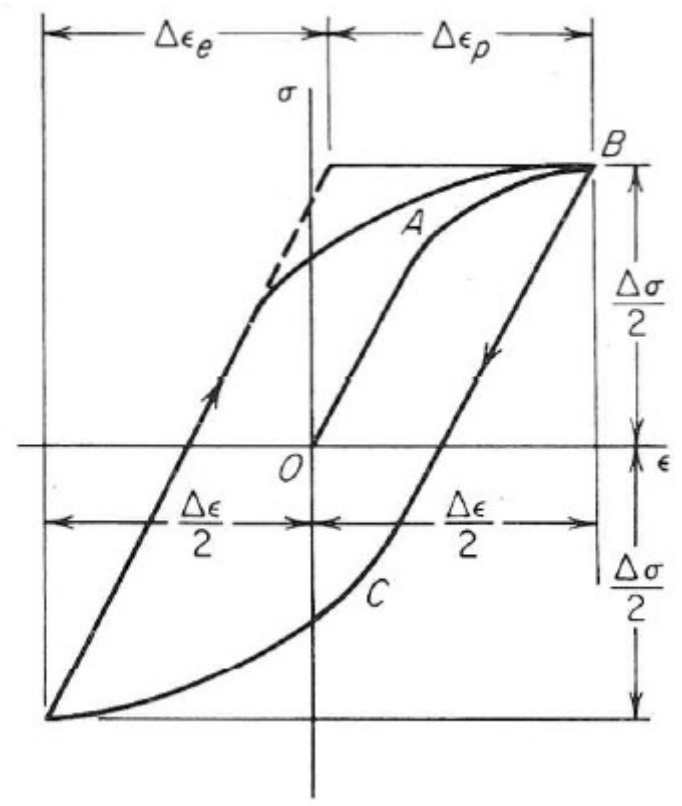

Figura 10: Ciclo de Histerese [3].

A equação de Coffin e Mason é dada por:

$$
\frac{\Delta \epsilon \mathrm{p}}{2}=\epsilon_{\mathrm{f}}^{\prime}\left(2 \mathrm{~N}_{\mathrm{f}}\right)^{\mathrm{c}}
$$

Onde:

$\Delta_{\epsilon \mathrm{p}} / 2$ é a amplitude de deformação plástica;

$\epsilon_{\text {f }}^{\prime}$ é o coeficiente de ductilidade em fadiga;

$\mathrm{N}_{\mathrm{f}}=$ Número de ciclos para a falha e;

c é o expoente da ductilidade em fadiga.

Em geral, o valor de $\epsilon_{\mathrm{f}}^{\prime}$ é aproximadamente igual àquele que indica a fratura dúctil na tensão monotônica $\left(\epsilon_{\mathrm{f}}\right)$, e c está na faixa de - 0,5 a - 0,7 para a maioria

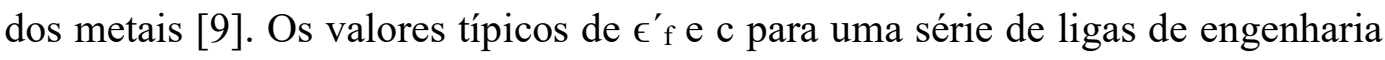
estão listados na figura 11. 


\begin{tabular}{|c|c|c|c|c|c|c|}
\hline Material & Condition & $\sigma_{\mathrm{y}}{ }^{\dagger}(\mathrm{MPa})$ & $\sigma_{\mathrm{f}}^{\prime}(\mathrm{MPa})$ & $\epsilon_{\mathrm{f}}^{\prime}$ & $b$ & $c$ \\
\hline \multicolumn{7}{|l|}{ Al alloys ${ }^{\dagger}$} \\
\hline 1100 & annealed & 97 & 193 & 1.80 & -0.106 & -0.69 \\
\hline 2014 & T6 & 462 & 848 & 0.42 & -0.106 & -0.65 \\
\hline 2024 & T351 & 379 & 1103 & 0.22 & -0.124 & -0.59 \\
\hline 5456 & H311 & 234 & 724 & 0.46 & -0.110 & -0.67 \\
\hline 7075 & T6 & 469 & 1317 & 0.19 & -0.126 & -052 \\
\hline \multicolumn{7}{|l|}{ Steels ${ }^{\dagger}$} \\
\hline 1015 & aircooled & 228 & 827 & 0.95 & -0.110 & -0.64 \\
\hline 4340 & tempered & 1172 & 1655 & 0.73 & -0.076 & -0.62 \\
\hline \multicolumn{7}{|l|}{ Ti alloys ${ }^{\dagger}$} \\
\hline $\mathrm{Ti}-6 \mathrm{Al}-4 \mathrm{~V}$ & solution-treated + aged & 1185 & 2030 & 0.841 & -0.104 & -0.69 \\
\hline \multicolumn{7}{|c|}{ Ni-base alloys ${ }^{\dagger}$} \\
\hline Inconel X & annealed & 700 & 2255 & 1.16 & -0.117 & -0.75 \\
\hline
\end{tabular}

${ }^{\dagger}$ Source: Osgood, 1982

${ }^{\ddagger}$ Refers to the monotonic yield strength

Figura 11: Parâmetros da equação de Coffin-Mason para algumas ligas [9].

Uma vez que a amplitude de tensão total em um teste de amplitude de tensão constante, $\Delta \epsilon / 2$, pode ser escrita como a soma da amplitude da deformação elástica, $\Delta \epsilon_{\mathrm{e}} / 2$ e amplitude da deformação plástica, $\Delta \epsilon_{\mathrm{p}} / 2$, temos:

$$
\frac{\Delta \epsilon}{2}=\frac{\Delta \epsilon_{\mathrm{e}}}{2}+\frac{\Delta \epsilon_{\mathrm{p}}}{2}
$$

A equação de Basquin relaciona a amplitude de tensão $(\sigma a=\Delta \sigma / 2)$, em um teste de fadiga de amplitude constante e totalmente reversa $(\mathrm{R}=-1$, ou seja, omáx $=-\sigma \min )$ com o número de inversões de carga para falha $\left(2 \mathrm{~N}_{\mathrm{f}}\right)$ da seguinte maneira:

$$
\frac{\Delta \sigma}{2}=\sigma_{a}=\frac{\left(\sigma_{\operatorname{máx}}-\sigma_{\min }\right)}{2}=\sigma_{f}^{\prime}\left(2 N_{f}\right)^{b}
$$

$\mathrm{Na}$ equação acima, $\sigma_{\mathrm{f}}^{\prime}$ é o coeficiente de resistência à fadiga e b é conhecido como expoente de Basquin que, para a maioria dos metais, está na faixa de - 0,05 a -0,12. Valores típicos de $\sigma_{\text {f }}^{\prime}$ foram listados na figura 11.

Sabendo que:

$$
\frac{\Delta \epsilon_{\mathrm{e}}}{2}=\frac{\Delta \sigma}{2 \mathrm{E}}=\frac{\sigma \mathrm{a}}{\mathrm{E}}
$$


Substituindo (9) em (10), temos:

$$
\frac{\Delta \epsilon_{\mathrm{e}}}{2}=\frac{\sigma_{f}^{\prime}}{\mathrm{E}}\left(2 N_{f}\right)^{\mathrm{b}}
$$

Substituindo (11) e (7) em (8), temos:

$$
\frac{\Delta \epsilon}{2}=\frac{\sigma_{f}^{\prime}}{\mathrm{E}}\left(2 N_{f}\right)^{\mathrm{b}}+\epsilon_{\mathrm{f}}^{\prime}\left(2 N_{f}\right)^{\mathrm{c}}
$$

A equação acima constitui a base para a abordagem da vida em fadiga controlada por deformação para o projeto de fadiga e encontrou aplicação generalizada na prática industrial.

\subsubsection{Fadiga de alto ciclo e altíssimo ciclo}

Duas curvas S-N descrevem o comportamento em fadiga de diferentes condições de materiais - uma para a resistência à fadiga superficial - região High Cycle Fatigue (HCF) e outra para a resistência à fadiga em volume - região VHCF (fig.9) [19].

Deslocando as duas curvas entre si de acordo com diferentes fatores, a curva S-N resultante pode descrever o comportamento em fadiga de diferentes materiais ou componentes mecânicos.

A resistência à fadiga diminui com o aumento do número de ciclos. Não existe um verdadeiro limite de fadiga, entretanto o limite de fadiga convencional ainda é uma boa estimativa.

No entanto, o limite de fadiga não pode ser uma propriedade geral do material, devendo assim o termo limite de fadiga ser substituído por resistência à fadiga para um determinado número de ciclos. 


\subsubsection{Curva de propagação de trincas por fadiga}

Os sítios de nucleação de trincas de fadiga incluem riscos superficiais, ângulos vivos, rasgos de chaveta, fios de roscas, mossas [22], ou seja, através de uma superfície muito rugosa (com mau acabamento superficial). Porém, caso a superfície seja bem acabada, a nucleação pode ocorrer através de um defeito metalúrgico (porosidade, precipitados, contorno de grão).

$\mathrm{Na}$ superfície é onde desenvolve o maior estado de tensão. Para deslocar para uma região subsuperficial tem que existir algum concentrador de tensão que faça a tensão local ser superior àquela encontrada na superfície, ou seja, ocorre uma intensificação de tensão. [23].

Conforme mostrado na figura 12 , três tipos de iniciação de trinca podem ser modelados em uma amostra cilíndrica com uma superfície polida, dependendo se é fadiga de baixo ciclo $\left(10^{4}\right.$ ciclos $)$, de alto ciclo $\left(10^{6}\right.$ ciclos $)$ ou altíssimo ciclo (10 $10^{9}$ ciclos).
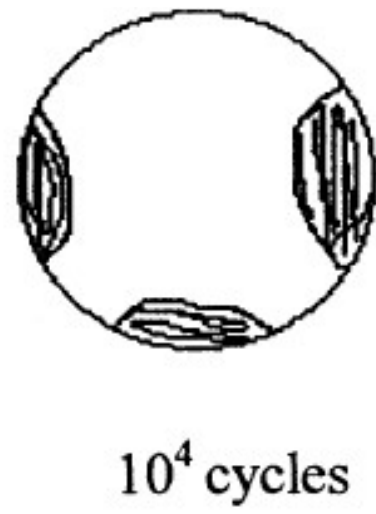

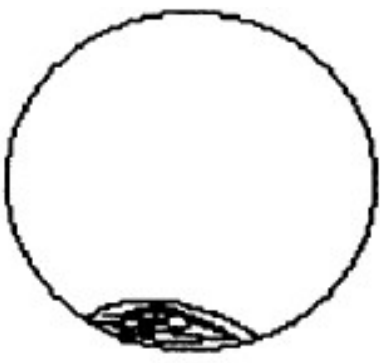

$10^{6}$ cycles

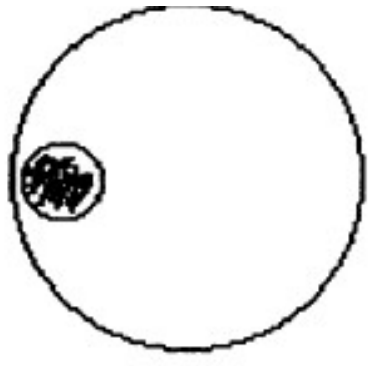

$10^{9}$ cycles

Figura 12: Tipos de Nucleação de trincas dependendo da região da curva S-N [24].

As Bandas de Deslizamento Persistentes (Persistent Slip Bands) representam a nucleação de trincas de fadiga sem a presença de um concentrador de tensão natural (Mecânico) na superfície, ou metalúrgico, e só ocorre em materiais dúcteis [25].

Na superfície do material vai existir a ação de uma tensão de cisalhamento, fazendo com que a superfície escorregue para fora. Se a tensão de cisalhamento for maior que o limite de escoamento do material, ocorre uma deformação plástica local, levando o material a encruar. Quando um novo ciclo de carregamento é 
feito a superfície que volta não é a original e sim uma paralela a ela em bandas de deslizamento persistentes [26].

Com isso, ocorre a movimentação de discordâncias, fazendo intrusões e extrusões, gerando uma "rugosidade" na superfície que muda o estado de tensões, agindo como um concentrador de tensões, propiciando a nucleação de trincas de fadiga [27].

Nas bandas de deslizamento persistentes a concentração de tensões é mais intensa, com isso quando o material não é mais capaz de acumular deformação plástica uma ou mais trincas são nucleadas.

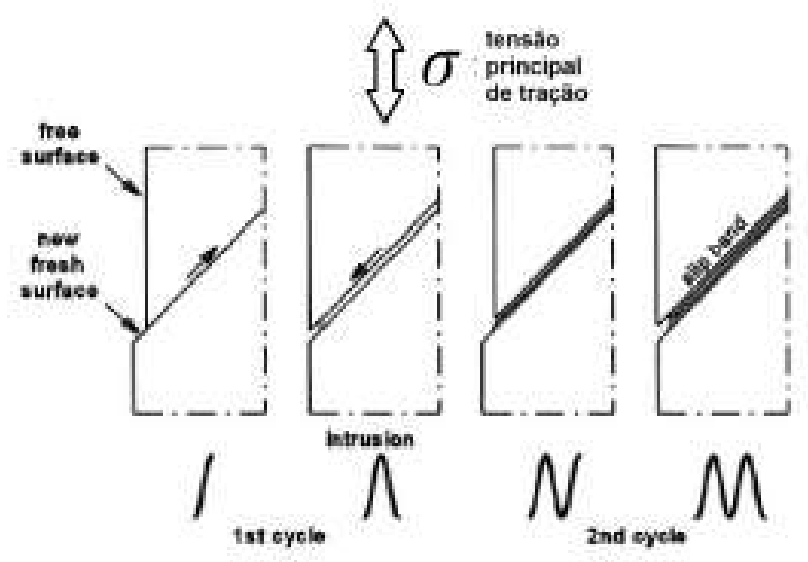

Figura 13: Formação de intrusões e extrusões devido ao carregamento cíclico em fadiga de baixo ciclo. Adaptado de [27,28].

Plano crítico e Plano de fratura não são sinônimos para materiais dúcteis. O primeiro é definido como aquele em que a amplitude de tensão cisalhante atinge o máximo valor, sendo responsável assim pela nucleação da trinca e dependente de propriedades dos materiais. Já o segundo é assumido como sendo o plano que experimenta a máxima amplitude de tensão normal (propagação da trinca) [29].

O processo de fadiga se divide em três fases: Iniciação (Nucleação), Propagação estável e Propagação Instável. A etapa de nucleação já foi explicada anteriormente, as demais etapas são observadas na figura 14: 


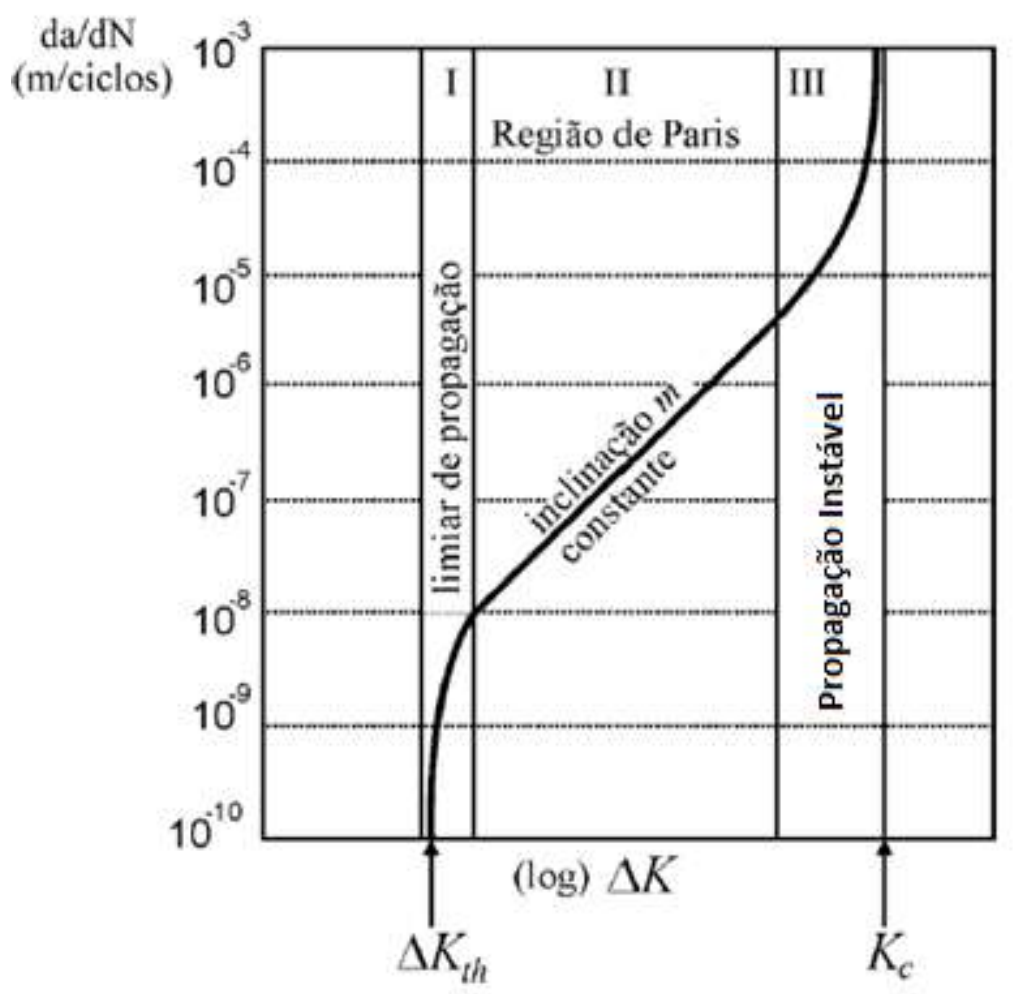

Figura 14: Curva da/dN versus $\Delta \mathrm{K}$, indicando o quanto a trinca cresce por ciclo. Curva de tolerância ao dano [28].

Os métodos práticos de ensaios não destrutivos são capazes de detectar trincas da ordem de $1 \mathrm{~mm}$, sendo assim é conveniente considerar que a fase de iniciação termina para esse tamanho de trinca [13].

Entretanto, o que se observa é que os métodos convencionais de ensaios não destrutivos só conseguem detectar as trincas na fase 2 , onde a trinca se propaga de maneira estável (fig.15).

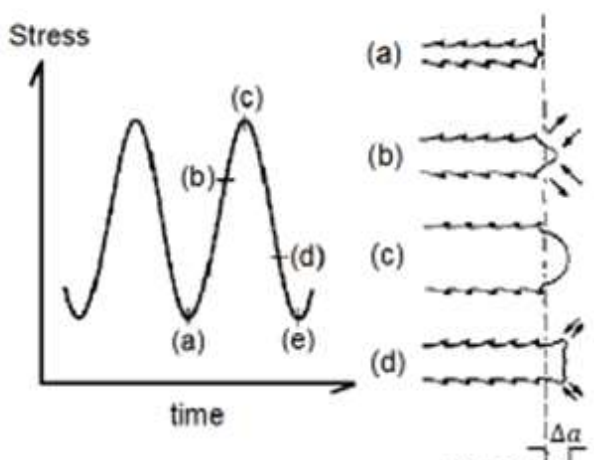

(e)

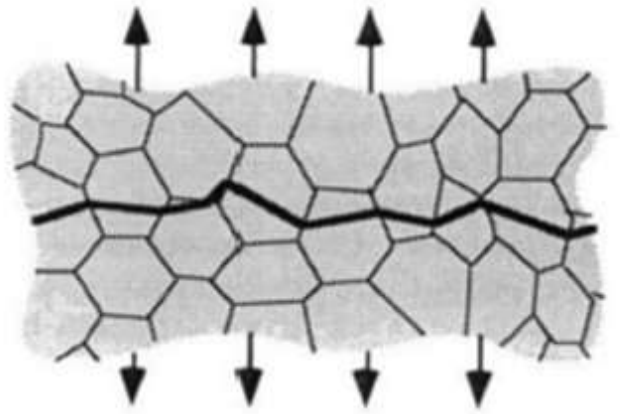

(b) Processo de propagação dentro dos gràos

(a) Avanço em cada ciclo

Figura 15: Propagação de uma trinca na fase 2 [27]. 
Na fase I (não é a fase de iniciação e sim de limiar de propagação), a velocidade de propagação é muito baixa, a zona plástica nessa região é muito pequena (da ordem de grandeza do tamanho de grão) e assim a microestrutura afeta de forma marcante a velocidade de propagação. Diversos pesquisadores [30 - 33] verificaram um aumento da resistência à propagação de trinca nas proximidades de $\Delta \mathrm{K}_{\text {th }}$ com o aumento do tamanho de grão.

Nessa região existe um nível mínimo de $\Delta \mathrm{K}$, denominado de $\Delta \mathrm{K}_{\mathrm{th}}$, para que a trinca passe a crescer sob a ação de cargas cíclicas [34 - 40]. A existência desse limiar de propagação pode levar à ocorrência de trincas estacionárias, ou seja, trincas que não se propagam mesmo com um carregamento cíclico, permanecendo do mesmo tamanho indefinidamente.

$\mathrm{Na}$ figura 16, se evidencia de forma esquemática as etapas de nucleação, propagação estável e propagação instável - que levarão a fratura do material.

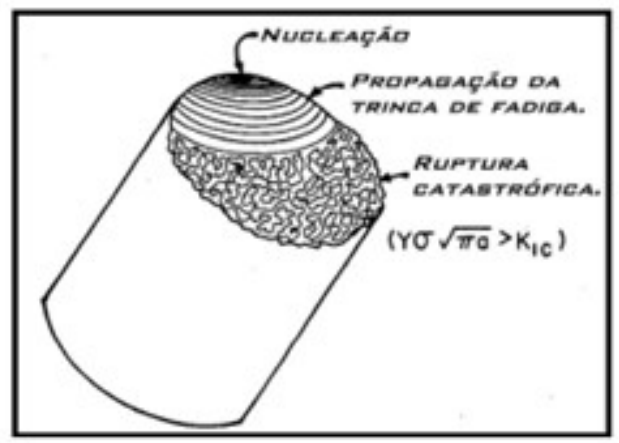

Figura 16: Superfícies características de uma fratura, evidenciando as etapas de nucleação, propagação e ruptura. [26].

Em componentes metálicos sujeitos a fadiga de alto ciclo, uma fração relativamente alta (cerca de $80 \%$ ) da vida total em fadiga é requerida para que uma trinca tenha um tamanho adequado $(1 \mathrm{~mm})$, que possa ser detectado por ensaios de inspeção [41,42].

Sendo assim, é muito importante ter um modelo de estimativa preciso para explicar o comportamento curto de propagação de trincas por fadiga (cerca de $20 \%$ ) e o número de ciclos que são necessários para criar essa trinca.

$\mathrm{Na}$ análise de trincas com mais de $1 \mathrm{~mm}$ (longas), várias modificações da lei de Paris foram propostas por diferentes pesquisadores para considerar o limiar de propagação de trincas longas, $\Delta \mathrm{K}_{\mathrm{thR}}$. Duas das expressões mais simples para taxas de propagação de trincas, $\mathrm{d} a / \mathrm{dN}$, são: 


$$
\begin{gathered}
\mathrm{da} / \mathrm{dN}=\mathrm{C}\left(\Delta \mathrm{K}-\Delta \mathrm{K}_{\mathrm{thR}}\right)^{\mathrm{m}} \\
\mathrm{da} / \mathrm{dN}=\mathrm{C}^{*}\left(\Delta \mathrm{K}^{\mathrm{m} *}-\Delta \mathrm{K}_{\mathrm{thR}}{ }^{\mathrm{m} *}\right)
\end{gathered}
$$

Nas equações (13) e (14), $\Delta \mathrm{K}$ é definido como sendo a variação do fator de intensidade de tensão aplicada e $\mathrm{C}, \mathrm{C} *$, $\mathrm{m}$ e $\mathrm{m}$ * são constantes que dependem do material, do ambiente e da relação de carga. A expressão (13) foi proposta por Zheng e Hirt [43], e a expressão (14) por Klesnil e Lukáš [44].

O limite de fadiga pode ser definido pela faixa de tensão aplicada nominal mínima para a qual o $\Delta \mathrm{K}$ aplicado é igual ou superior ao limiar de propagação de trincas por fadiga, $\Delta \mathrm{K}_{\mathrm{th}}$, para qualquer comprimento de trinca. Portanto, ambas as expressões dão o mesmo resultado quando o limite de fadiga ou a resistência de diferentes configurações é estimado.

No caso de trincas curtas (menores que $1 \mathrm{~mm}$ ), $\Delta \mathrm{K}_{\text {th }}$ é uma função do comprimento da trinca e aumenta a partir de um valor mínimo que está associado ao limite de fadiga do material até um valor máximo dado por $\Delta \mathrm{K}_{\mathrm{thR}}$ [45].

As análises comuns de fadiga geralmente contemplam o uso do conceito de curva de resistência, expressado pelas equações (13) ou (14). No entanto, se o comportamento anômalo de propagação de trincas geralmente observado em trincas curtas deve ser incluído, a estimativa de taxas de crescimento de trincas curtas de fadiga deve considerar um limite de propagação dependente do comprimento da trinca, $\Delta \mathrm{K}_{\mathrm{th}}$, da seguinte maneira:

$$
\begin{aligned}
& \mathrm{d} a / \mathrm{dN}=\mathrm{C}\left(\Delta \mathrm{K}-\Delta \mathrm{K}_{\mathrm{th}}\right)^{\mathrm{m}} \\
& \mathrm{d} a / \mathrm{dN}=\mathrm{C}^{*}\left(\Delta \mathrm{K}^{\mathrm{m} *}-\Delta \mathrm{K}_{\mathrm{th}}^{\mathrm{m} *}\right)
\end{aligned}
$$

A variação do fator de intensidade de tensão aplicada total, $\Delta K$, pode ser avaliada de forma adequada para qualquer configuração, e uma vez que as medidas experimentais de valores de limiar dependentes do comprimento de trinca são difíceis de obter, elas geralmente são estimadas usando modelos de previsão disponíveis. 
Três destes modelos são apresentados a seguir, plotados esquematicamente na figura 17, que mostra o limiar de propagação estimado em função do comprimento da trinca (diagrama de Kitagawa e Takahashi [50]).

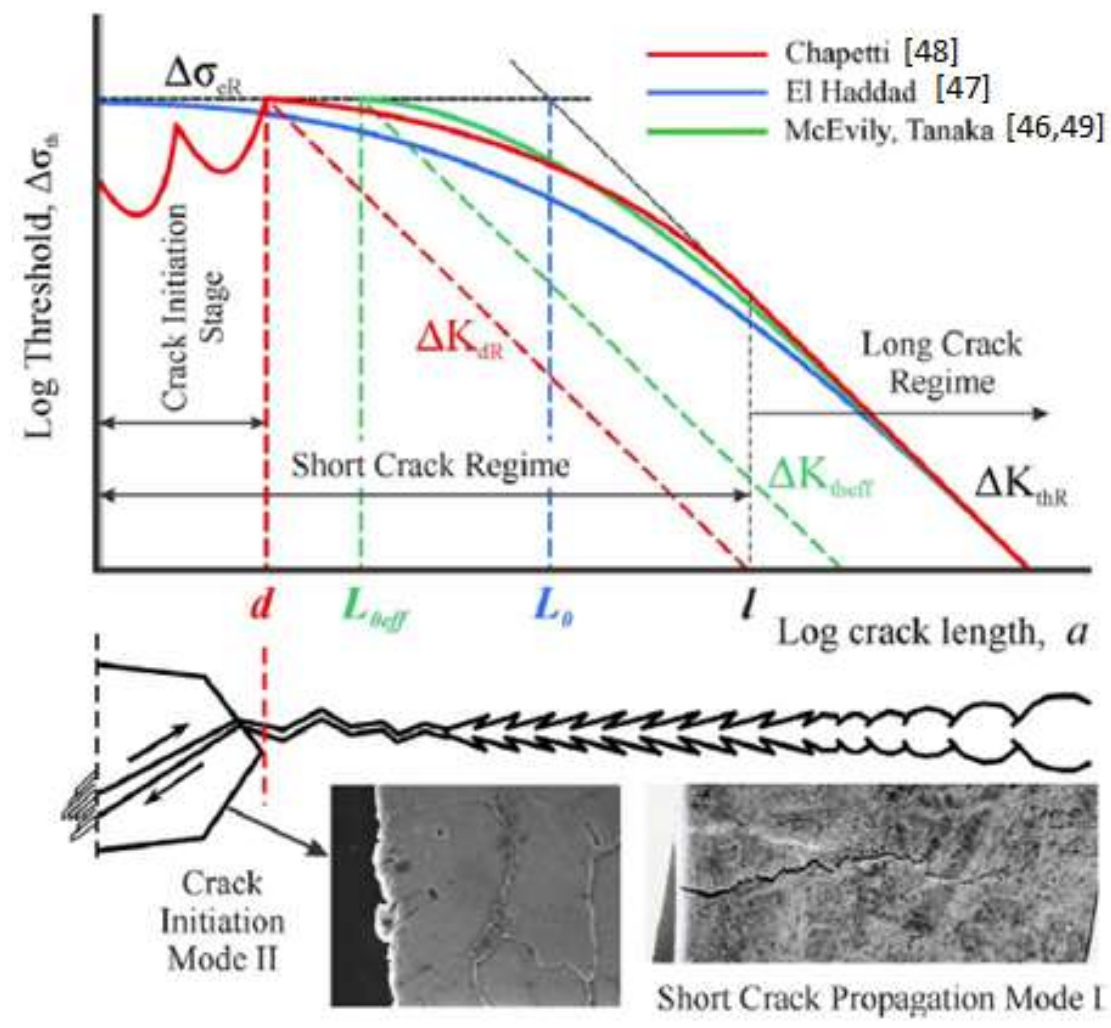

Figura 17: Representação esquemática dos modelos analisados em um diagrama de tipo KitagawaTakahashi [45].

Uma linha reta dada pela expressão (17) pode ser plotada para relacionar os conceitos básicos dos modelos:

$$
\Delta \mathrm{K}_{\mathrm{dR}}=\gamma \Delta \sigma_{\mathrm{eR}} \sqrt{\pi a}
$$

Pode-se ver pela figura 17, que o modelo de El Haddad não permite uma definição da transição entre os estágios de iniciação e propagação das trincas de fadiga.

No caso dos modelos que utilizam os conceitos de fechamento de trinca (Chapetti e McEvily, Tanaka), define-se um comprimento de trinca intrínseco ( $\left.\mathrm{L}_{0 \text { eff }}\right)$ associado ao limite de fadiga $\left(\Delta \sigma_{\mathrm{e} R}\right)$. A partir do modelo de McEvily, Tanaka, traça-se uma paralela (curva $\Delta \mathrm{K}_{\text {theff) }}$, de forma a distinguir os regimes de propagação para trincas curtas e longas. 
No modelo Chapetti, há uma definição clara do estágio de iniciação da trinca, pois aponta o número de ciclos necessários para iniciar a propagação de uma trinca com um comprimento igual ao tamanho de grão d.

A variação do fator de intensidade de tensões efetivo, $\Delta \mathrm{K}_{\mathrm{eff}}$, pode ser obtido através de dados de abertura da trinca definidos a partir de uma faixa de tensão efetiva como sendo:

$$
\Delta \sigma_{\text {eff }}=\sigma_{\text {máx }}-\sigma_{\text {op }}
$$

onde:

$\sigma_{\text {máx }}=$ máxima tensão aplicada;

$\sigma_{\mathrm{op}}=$ tensão de abertura da trinca.

Para o cálculo do $\Delta \mathrm{K}_{\mathrm{eff}}$, tem-se:

$$
\Delta K_{e f f}=\Delta \sigma_{e f f} \sqrt{\pi a} f\left(\frac{a}{w}\right)
$$

A figura 18 mostra como a variação do intensificador de tensões efetivo atua no processo de "fechamento" da trinca.

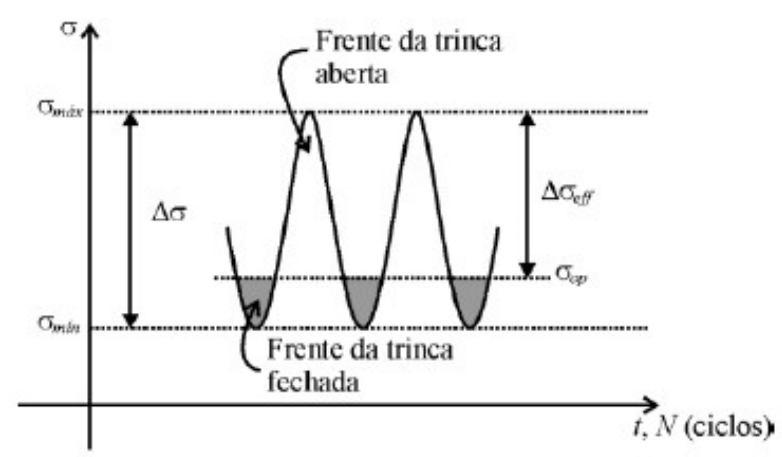

Figura 18: "Frente" da trinca com relação ao nível de carregamento [28]. 


\subsubsection{Características macroscópicas e microscópicas da superfície de fratura}

A superfície de fratura de um corpo de prova cilíndrico (fig,19) pode apresentar três regiões bastante distintas sendo elas: Zona Fibrosa - que indica uma propagação estável da trinca, Zona Radial - propagação instável e Zona Cisalhada - inclinada num ângulo de $45^{\circ}$ do eixo de tração, onde pode ocorrer deformação plástica, pois não existe triaxialidade de tensões.
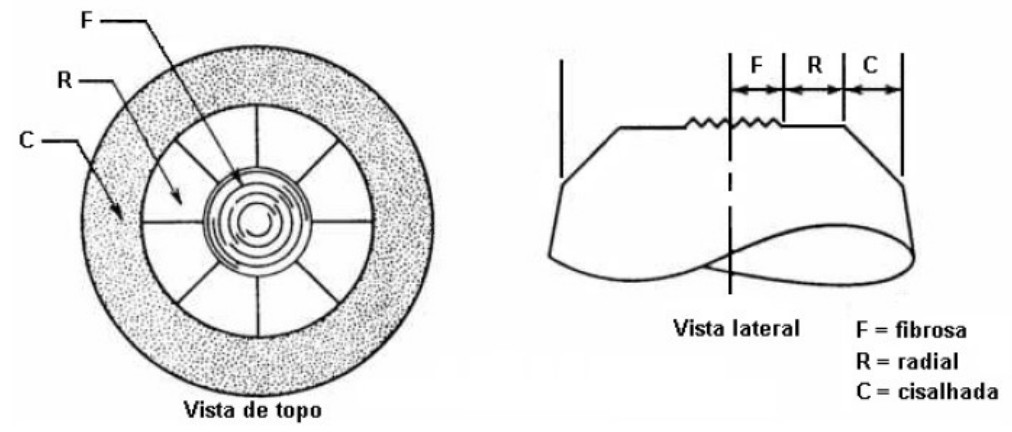

Figura 19: Representação das zonas cisalhadas, radial e fibrosa na fratura de um corpo cilíndrico liso - Adaptado de [51].

Para corpos retangulares (fig.20), à medida que aumenta a razão da largura pela espessura a zona fibrosa irá apresentar uma forma elíptica. A zona radial, se existir, passa a apresentar um aspecto diferente, e são normalmente chamadas marcas de sargento ou catraca, onde temos superposição de trincas, ou seja, onde se tem múltiplas posições de iniciação de trincas, apontando para o local de início da falha.

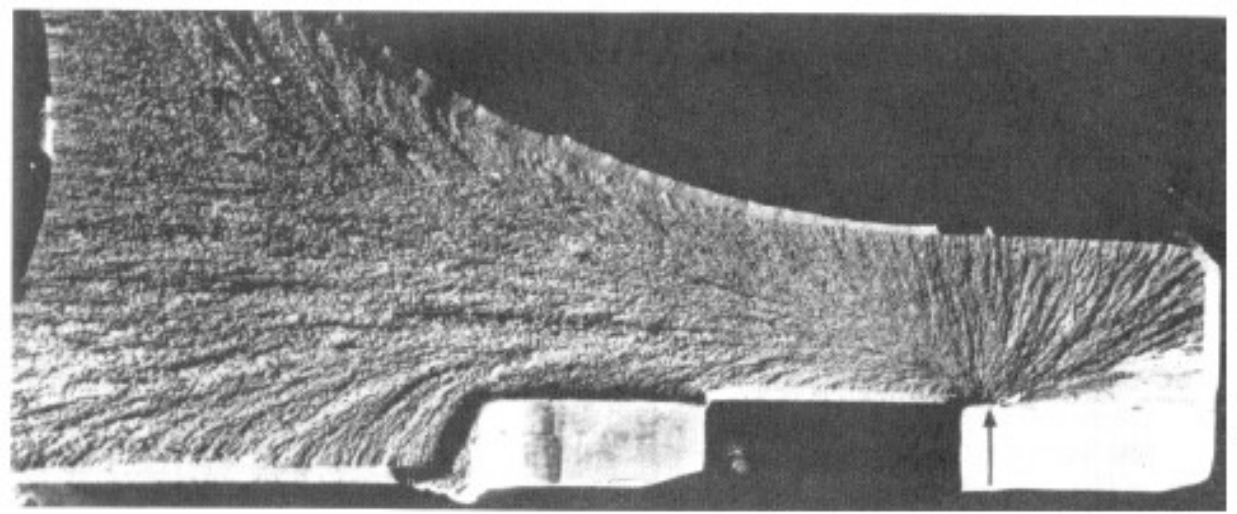

Figura 20: Local de iniciação da fratura marcada com uma flecha [52]. 
É importante frisar que existe uma diferença entre Fratura Frágil e Fratura Dúctil, tanto no aspecto macroscópico, quanto no aspecto microscópico. Macroscopicamente, o fator que as diferencia, como já citado nesse trabalho, é o tamanho da zona plástica (quantidade de plastificação) que o material apresenta no ligamento.

Entretanto, microscopicamente, Fratura Frágil e Dúctil se diferenciam de acordo com o tipo de propagação que a trinca experimenta, ou seja, se o rompimento da ligação atômica se deu de maneira distorcida, com deslizamento de planos, na presença de tensões de cisalhamento, a fratura é microscopicamente dúctil. Se o rompimento foi por tensão normal, a fratura é microscopicamente frágil, apresentando facetas de clivagem (fig. 21).

A grande maioria dos materiais de engenharia é formada por soluções sólidas (aços, ligas de alumínio, ligas de titânio,...), ou seja, são materiais dúcteis com sistemas de deslizamentos capazes de transformar um esforço normal em cisalhante e na presença de partículas de segunda fase, são capazes de experimentar uma grande deformação plástica antes de fraturarem (fig. 22).

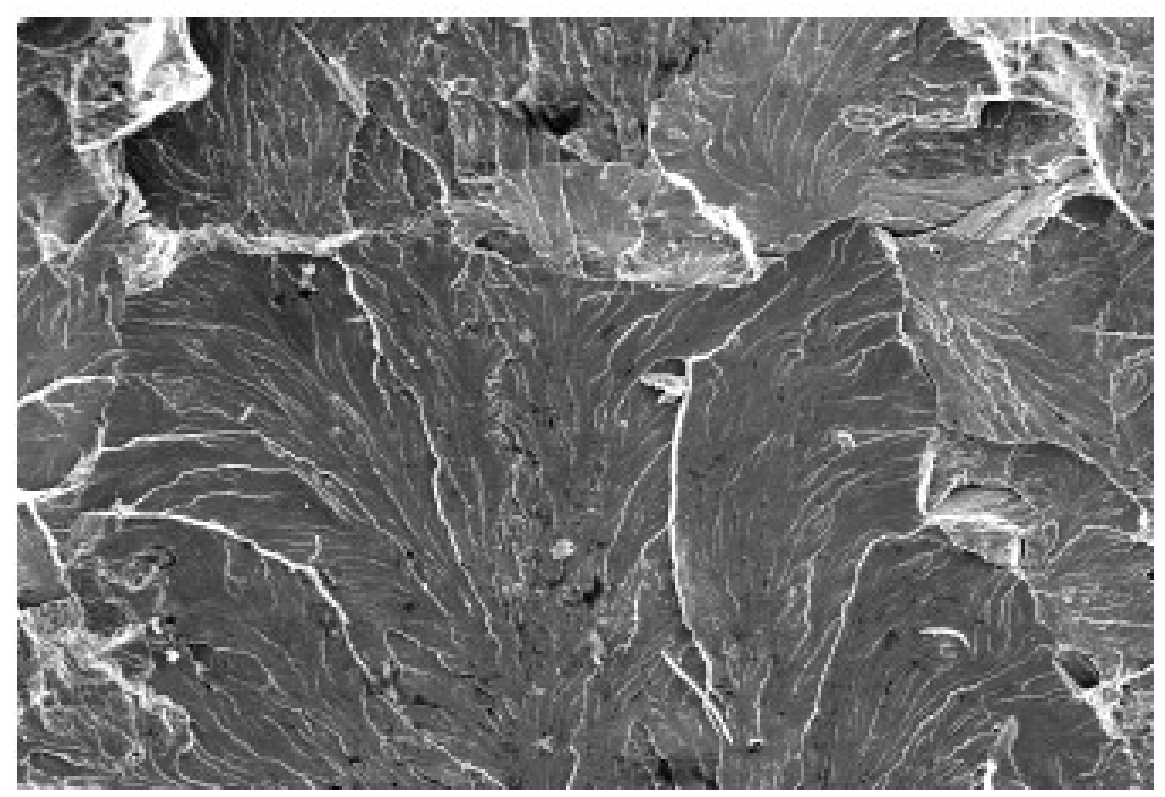

Figura 21: Aspecto das facetas de clivagem com "rios" característicos que indicam o sentido de propagação da fratura (ASME METALS HANDBOOK- FRACTOGRAPHY, 1987). 


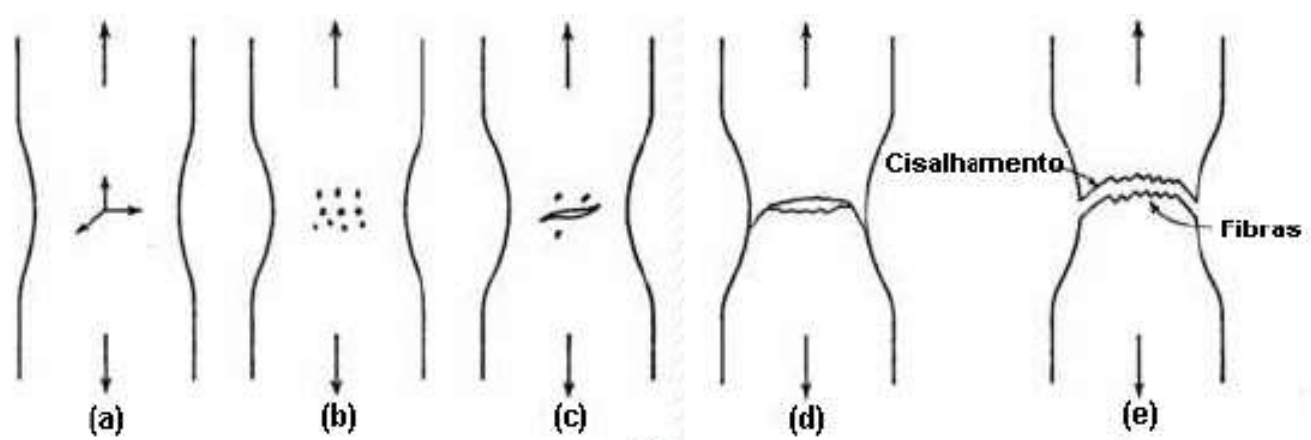

(a)

(b)

(a)

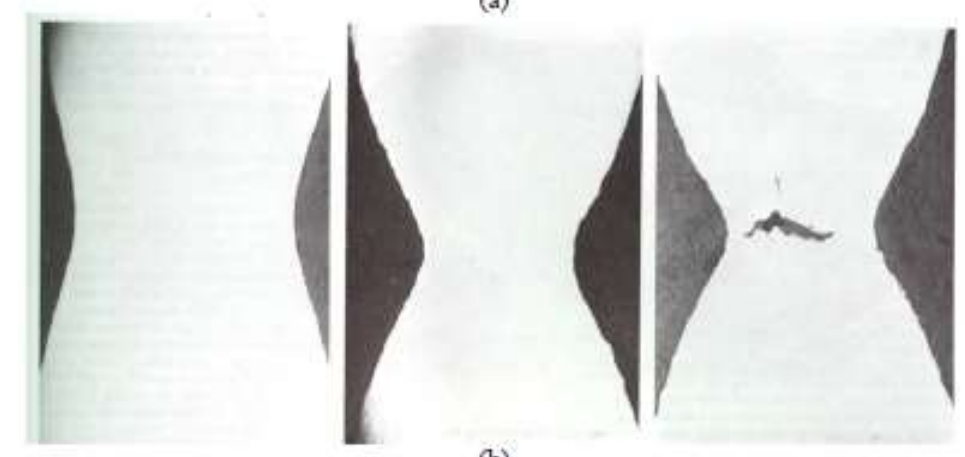

(b)

Figura 22: Estricção de um corpo de prova cilíndrico, coalescimento das cavindades vai diminuindo a seção resistente do corpo [52].

\section{Marcas de praia:}

São características macroscópicas que mostram o sentido de propagação da trinca estando associadas à mudança no regime de carregamento (por exemplo: paradas de equipamentos depois do uso ininterrupto ao longo de vários dias).

Quando há a parada em um equipamento, ocorre uma oxidação na ponta da trinca, que vai dificultar a propagação da mesma, pois a oxidação tem uma resistência mecânica maior, ou seja, serão necessários maiores níveis de tensão para que sua trinca vença essa barreira de oxidação [26].

As marcas de praia estão sempre presentes no estágio 2 de propagação, desde o início até o fim desse estágio, entretanto são mais visíveis no final [53].

\section{Estrias de fadiga:}

Cada estria de fadiga marca o incremento da trinca, o crescimento $\mathrm{d} a / \mathrm{dN}$, ou seja, o quanto a trinca propagou em cada ciclo de carregamento. São características microscópicas da superfície de fratura, sinais de deformação plástica na superfície do material. (fig. 15). 


\subsection{Aspectos Microestruturais}

A influência das inclusões sobre a resistência à fadiga dos aços depende principalmente do tamanho e forma, da resistência à deformação, da orientação da tensão e da resistência do aço.

Acredita-se que a redução da resistência à fadiga decorre da concentração de tensão introduzida pela inclusão ou pela cavidade que contém a inclusão. Inclusões ou cavidades alongadas têm pouco efeito se estiverem paralelas à direção da tensão, mas podem reduzir seriamente a resistência à fadiga se forem perpendiculares a ela [21].

A resistência à fadiga de alguns tipos de aço é pouco afetada pela presença de inclusões, onde adições de chumbo e enxofre, por exemplo, não a reduzem consideravelmente. Teed [54] apontou que o ferro forjado com até 2,5\% de Si possui resistência à fadiga transversal igual à resistência à fadiga longitudinal.

$\mathrm{Na}$ investigação de aços de uma liga que sofre laminação, Frith [55] descobriu que as inclusões presentes não pareciam ter efeito significativo sobre a resistência à fadiga dos aços tratados termicamente com $827,4 \mathrm{MPa}$ de resistência à tração.

Entretanto, quando tratada termicamente com uma resistência à tração de 1103,2 MPa, a resistência à fadiga transversal foi ligeiramente afetada, e no caso da resistência à tração de $1516,8 \mathrm{MPa}$, as resistências à fadiga longitudinal e transversal foram consideravelmente reduzidas.

Ransom e Mehl [56] mostraram que a presença de inclusões no aço SAE 4340 tem um efeito maior na resistência à fadiga transversal do que na resistência à fadiga longitudinal. Eles descobriram que a resistência a fadiga transversal estava relacionada à ductilidade.

Stewart e Williams [57] investigaram o efeito de inclusões por meio de testes de fadiga em flexão e torção. Em aços com cerca de 551,6 MPa de resistência à tração, os autores descobriram que a presença de inclusões longitudinais não influenciou a resistência à fadiga longitudinal em flexão, mas reduziu a resistência à fadiga longitudinal em torção em 20 a 25\%.

A importância do tamanho das inclusões foi demonstrada por Cummings, Stulen e Schulte [58] a partir dos resultados de muitos testes de fadiga nos aços de baixa liga SAE 4340 e 4350, tratados termicamente com resistência à tração entre 
827,4 e $1861,6 \mathrm{MPa}$. As inclusões foram esferoidais e variaram em tamanho até $76,2 \mu \mathrm{m}$ de diâmetro.

Em baixas faixas de tensão, em trincas de fadiga propagadas a partir de uma única inclusão com diâmetro superior a 25,4 $\mu \mathrm{m}$, o endurecimento em um determinado intervalo de tensão foi inversamente proporcional ao tamanho da inclusão. Nenhuma relação simples entre tamanho de inclusão e resistência a fadiga foi obtida em intervalos de tensão elevados porque as fraturas resultaram de mais de uma trinca.

A influência das inclusões sobre a resistência à fadiga de uma série de aços tratados termicamente com uma resistência à tração com cerca de $1723,7 \mathrm{MPa}$ foi investigada por Atkinson [59], onde o autor concluiu que o tamanho das inclusões por si só não oferece uma base para comparar os diversos tipos de inclusão que normalmente ocorrem nos aços, mas que o número e a forma das inclusões poderiam estar correlacionados com a resistência a fadiga, introduzindo uma "contagem de Inclusão de Fairey".

Epremian e Mehl [60] investigaram a relação entre os fatores metalúrgicos e a variação estatística das propriedades de fadiga. Os resultados dos testes em aço SAE 4340 indicaram que a dispersão na resistência à fadiga e no limite de fadiga era muito mais dependente do conteúdo de inclusão do que da composição ou do tratamento térmico.

Styri [61] atribuiu a dispersão às áreas fracas locais na estrutura e, além das inclusões, pode haver segregação local, ferrita livre, austenita retida e tensão interna.

A influência do processo de fabricação sobre a resistência à fadiga foi investigada também por Fisher e Sheehan [62] para a liga de aço SAE 4340, tratada termicamente com resistência à tração entre 1585,8 e 1930,5 MPa. Os resultados demonstraram claramente que a presença de grandes inclusões foi prejudicial, embora não tenha sido obtida uma estreita correlação entre o tamanho da inclusão e a resistência à fadiga.

O projeto de fadiga de peças metálicas fundidas está fortemente ligado ao processo de fundição. O projetista precisa alcançar um compromisso entre a resistência à fadiga do componente e o tamanho de defeito permitido devido ao processo. Para realizar esta combinação, é necessário um critério que leve em consideração a influência do defeito no limite de fadiga. 
Muitas abordagens foram propostas para avaliar a influência de um defeito na vida em fadiga. Uma visão geral desse problema pode ser encontrada no trabalho de Murakami [63].

$\mathrm{O}$ autor relaciona um defeito com a vida em fadiga usando quatro parâmetros: tipo de defeito (inclusão, poro, impureza, ...), morfologia do defeito (esférico, hemisférico, complexo, ...), posição do defeito (interna, subsuperficial ou superficial) e tamanho de defeito (relacionado ou não ao sentido de carregamento).

Nadot e Nadot-Martin [64] definiram um defeito como um poro hemisférico na superfície e o tamanho do defeito foi estudado com uma variável influência na resistência à fadiga.

De fato, para o caso de um defeito com diâmetro $\mathrm{D}=1000 \mu \mathrm{m}$, para tamanho de grão $\mathrm{Dg}=30 \mu \mathrm{m}$, houve uma redução de $32 \%$ no limite de fadiga; enquanto que para $\mathrm{Dg}=340 \mu \mathrm{m}$ foi de $11 \%$. Assim, quando o diâmetro do grão Dg cresceu, o limite de fadiga $\sigma_{D}$ tornou-se menos sensível ao defeito, ou seja, quanto mais fino o grão, maior foi a diminuição observada.

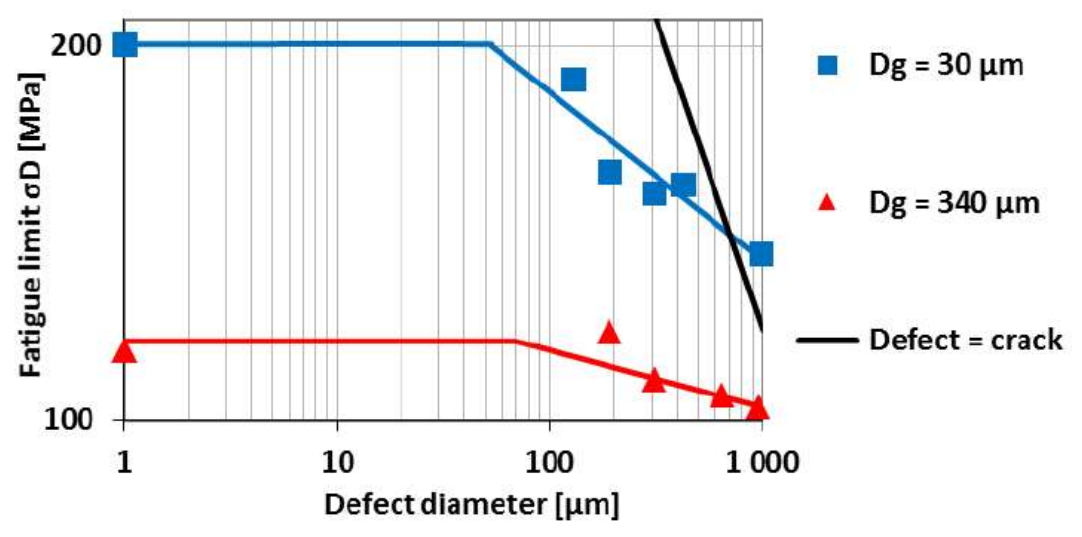

Figura 23: Diagramas de Kitagawa para ambas as microestruturas $($ defeito $=$ trinca calculada com $3 \mathrm{MPa} \mathrm{m}{ }^{1 / 2}$ threshold efetivo) [64].

Para D perto de zero, o intervalo $\sigma_{\mathrm{D}}$ entre duas microestruturas foi de 85 MPa e para $\mathrm{D}=1000 \mu \mathrm{m}$, o intervalo $\sigma_{\mathrm{D}}$ foi de $35 \mathrm{MPa}$. Assim, quando o diâmetro do defeito D cresce para $1000 \mu \mathrm{m}$, o intervalo limite de fadiga entre duas microestruturas é dividido por 2,4. 
O limiar de propagação $\Delta \mathrm{K}_{\text {th }}$ para trincas curtas e defeitos foi estimado por muitos pesquisadores usando o modelo de Murakami que usa o parâmetro $\sqrt{\text { area }}$ e a dureza Vickers (HV). Murakami e Endo [65] propuseram, com base em dados do limiar para crescimento de trincas em corpos de prova contendo defeitos que variavam de 40 a $500 \mu \mathrm{m}$, a seguinte expressão para estimar $\Delta \mathrm{K}_{\text {th }}$ para trincas superficiais e $\mathrm{R}=-1$ :

$$
\Delta \mathrm{K}_{\mathrm{th}}=3,3 \times 10^{-3}(\mathrm{HV}+120)(\sqrt{\text { area }})^{\frac{1}{3}}
$$

$\mathrm{Na}$ equação 20 , o parâmetro $\sqrt{\text { area }}$ está em $\mu \mathrm{m}$. Assumindo que a trinca superficial é semielíptica, tem-se:

$$
\sqrt{\text { area }}=\sqrt{\frac{\pi}{2}} a
$$

Com as expressões acima podemos estimar o valor de $\Delta \mathrm{K}_{\text {th }}$ como uma função do comprimento da trinca, a:

$$
\Delta \mathrm{K}_{\mathrm{th}}=3,56 \times 10^{-3}(\mathrm{HV}+120) a^{\frac{1}{3}}
$$

Dados relatados por Tokaji et al [66] para um aço S45C (SAE 1045) indicam: $\mathrm{HV}=241 \mathrm{~kg} / \mathrm{mm}^{2}, \sigma \mathrm{u}=621 \mathrm{MPa}$ (resistência à tração), $\mathrm{d}=14 \mu \mathrm{m} \mathrm{e}$ $\Delta \sigma_{\mathrm{eR}}=430 \mathrm{MPa}$ para $\mathrm{R}=-1$. Considerou-se também que $\Delta \mathrm{K}_{\mathrm{thR}}=10 \mathrm{MPa} \mathrm{m}{ }^{1 / 2}$, um valor conservador.

Segundo Chapetti [67], o limiar de propagação do material em função do comprimento da trinca é definido como:

$$
\Delta \mathrm{Kth}=\Delta \mathrm{KdR}+(\Delta \mathrm{KthR}-\Delta \mathrm{KdR})\left[1-\mathrm{e}^{-\mathrm{k}(a-\mathrm{d})}\right]
$$

onde:

$$
\Delta \mathrm{KdR}=\gamma \Delta \sigma \mathrm{eR} \sqrt{\pi \mathrm{d}}
$$


A expressão (24) estima um valor de $\Delta \mathrm{K}_{\mathrm{dR}}$ igual a $1,8 \mathrm{MPa} \mathrm{m}^{1 / 2}$. Por outro lado, a estimativa dada pelo modelo de Murakami, expressão (22), representa 3,1 MPa $\mathrm{m}^{1 / 2}$ para $a=\mathrm{d}$, em torno de $68 \%$ maior.

A Fig. 24 mostra as curvas de limiar dadas pelas expressões acima, onde podemos apreciar a vantagem de usar expressões (22) e (24) para estimar $\Delta \mathrm{K}_{\text {th. }}$.

Muitos pesquisadores aplicaram o modelo de Murakami sem cuidar da limitação da expressão (22) associada ao limiar de propagação para trincas longas $\Delta \mathrm{K}_{\text {thR }}$, que é uma constante do material, para uma determinada razão de tensão $\mathrm{R}$, independente do comprimento da trinca.

Se essa limitação não for considerada são obtidas importantes superestimações para valores de dureza relativamente altos e comprimentos de trinca relativamente longos.

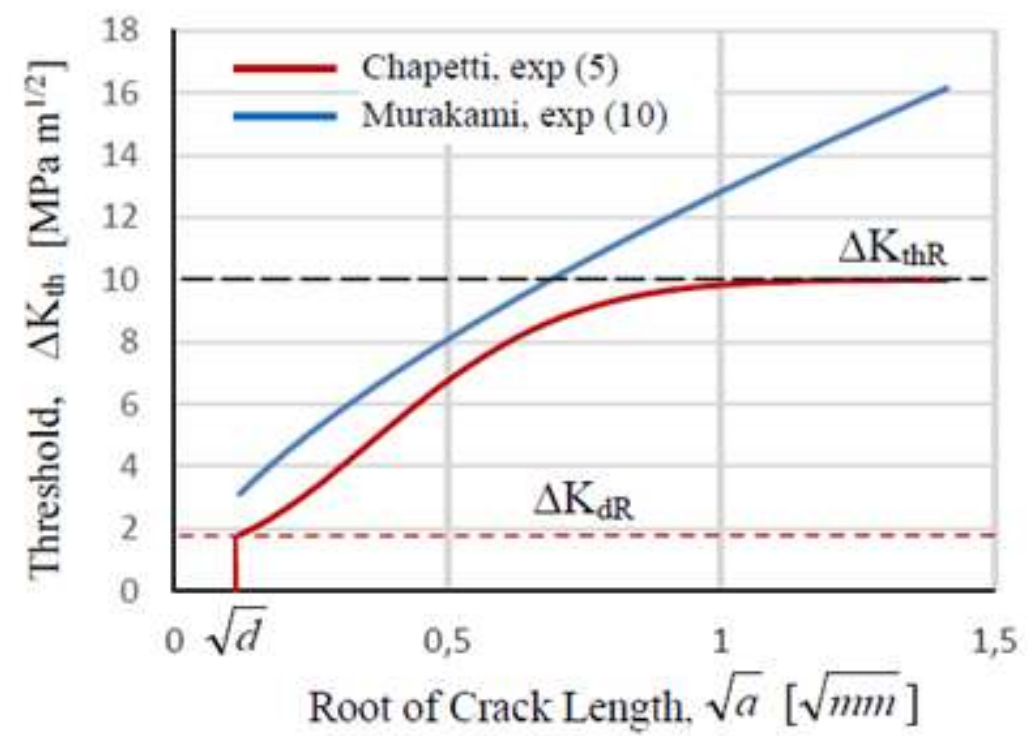

Figura 24: Curva de valor estimado para limiar de propagação para o aço S45C [66]

A razão entre as tensões mínimas e máximas de um carregamento em fadiga (R) exerce influência no limiar de propagação de trincas de fadiga $\left(\Delta K_{\text {th }}\right)$, onde uma redução de $\mathrm{R}$ acarreta em um aumento no valor de $\Delta \mathrm{K}_{\mathrm{th}}$, ou seja, fixando o incremento do tamanho de trinca em, por exemplo $10^{-7} \mathrm{~mm} /$ ciclo, uma redução em R (por exemplo de 0,93 para 0,1) leva a um aumento no valor do threshold de 3 para $9 \mathrm{MPa} \sqrt{m}$, como pode ser observado na figura 25 : 


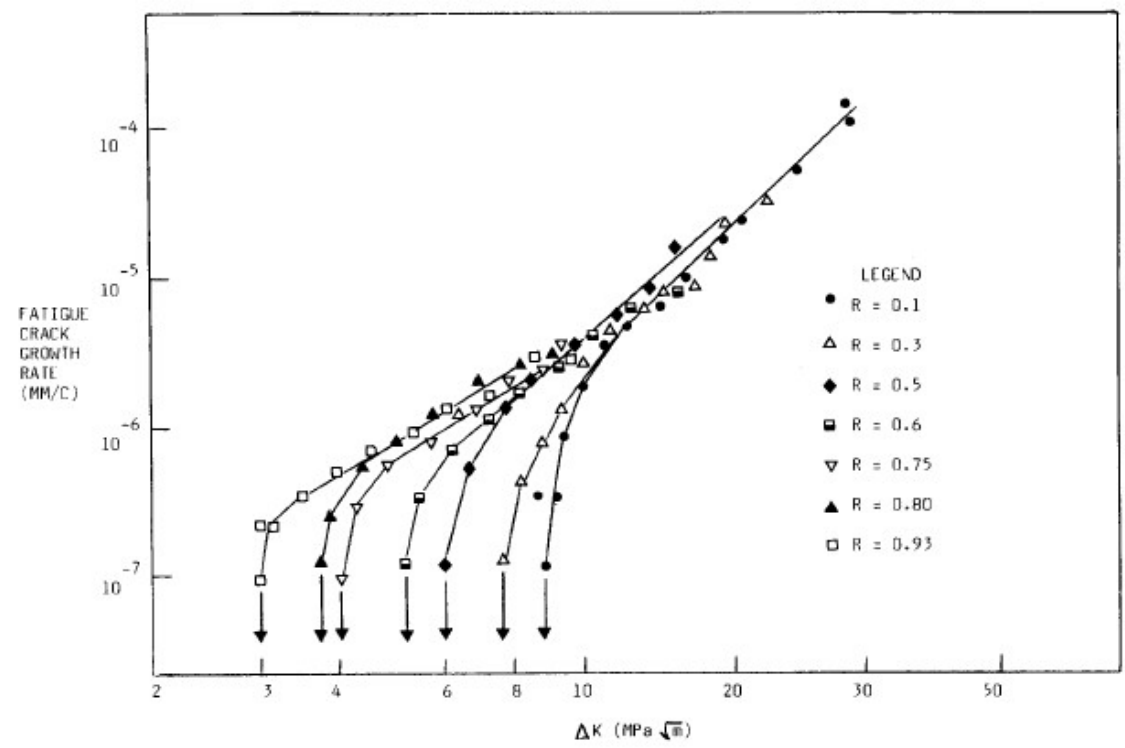

Figura 25: Efeito do R sobre o threshold de um aço com microestrutura austenítica [73].

Um outro fator que influencia o threshold é o tipo de microestrutura presente no material estudado. A figura 26 mostra a variação do valor de $\Delta \mathrm{K}_{\text {th }}$ de acordo com diferentes tipos de microestruturas.

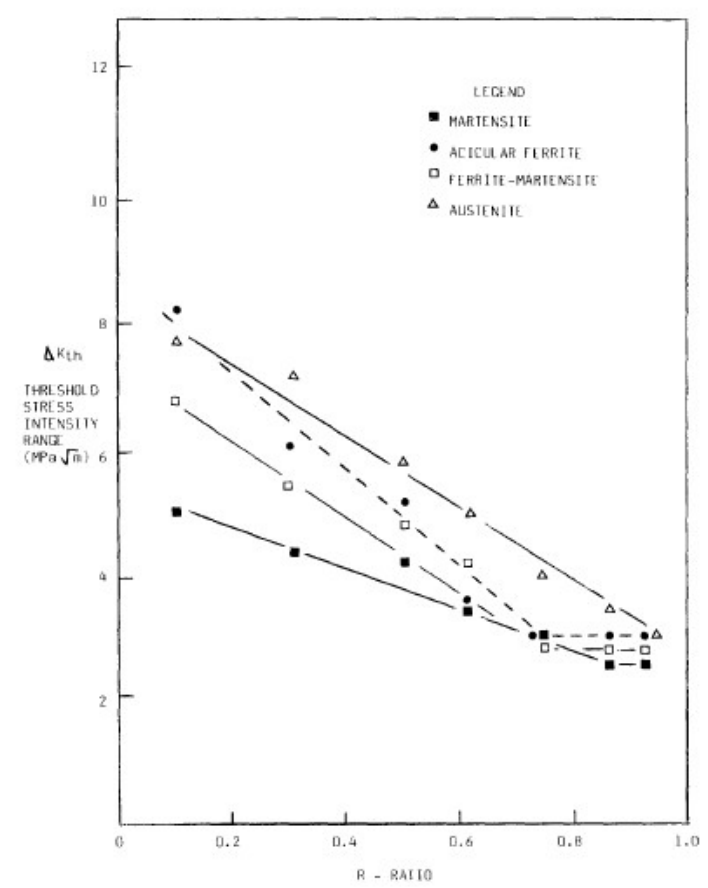

Figura 26: Efeito do R sobre o threshold para diferentes microestruturas [73]. 


\section{Materiais e Métodos}

No tópico a seguir são mostradas as etapas de Caracterização dos materiais (usinagem de corpos de prova do material do eixo que rompeu), com a determinação da Composição química, buscou-se aços similares que pudessem ser uma alternativa ao uso e o Tratamento térmico nas amostras (têmpera e revenimento - a fim de deixar todos os materiais com dureza similares). Em seguida descrevem-se Ensaios mecânicos de tração (Determinação das propriedades mecânicas) e o Ensaio de Propagação de trincas (Levantamento da curva $\mathrm{d} a / \mathrm{dN}$ versus $\Delta \mathrm{K}$ ). Por último, descrevem-se as análises microestruturais, por Microscopia Óptica e Microscopia Eletrônica de Varredura.

\subsection{Caracterização dos materiais}

Os materiais ensaiados são normatizados de acordo com o Deutsches Institut für Normun (DIN) e Society of Automotive Engineers (SAE) e tiveram corpos de prova do tipo $\mathrm{C}(\mathrm{T})$ - compacto de tração para ensaio de propagação de trincas - usinados no Laboratório de Estruturas e Materiais (Departamento de Engenharia Civil e Ambiental, Puc-Rj). No Laboratório de Ensaios Mecânicos da Puc-Rj foram realizados os ensaios de propagação das trincas por fadiga.

Os aços estruturais SAE 4140 e SAE 4340 foram comprados em barras redondas de $150 \mathrm{~mm}$ de comprimento e com diâmetros de 4 3/4 e 5 polegadas e a escolha desses aços foi visando à garantia de propriedades mecânicas semelhantes, uma vez que a literatura indica que as composições químicas desses aços são similares ao do material de referência (DIN 34CrNiMo6).

O aço DIN 34CrNiMo6 é um aço de baixa liga e de alta resistência mecânica e elevada tenacidade à fratura, similar ao SAE 4340. Seus principais elementos de liga são $\mathrm{Cr}$, Ni e Mo.

O principal efeito da adição de cromo ao aço é uma sensível melhora na resistência à oxidação (inclusive em temperaturas elevadas) e na resistência à 
corrosão, em geral. O cromo tem grande afinidade pelo oxigênio e oxida-se, preferencialmente, formando uma película forte e aderente de óxidos e hidróxidos, que protege o Ferro, retardando a oxidação do material [71].

O Molibdênio tem como principal finalidade melhorar a resistência à fluência do aço, contribuindo também para aumentar a resistência mecânica em temperaturas elevadas.

A adição tanto de $\mathrm{Cr}$, como de Mo e Ni nos aços, tem como consequência o retardamento da reação de decomposição da austenita no resfriamento, dando com isso mais tempo para a formação da martensita, levando-a a existir em maior quantidade, ou seja, aumenta a temperabilidade do aço.

O fato dessa classe de aços estruturais (DIN 34CrNiMo6, SAE 4340, DIN 42CrMo4 e SAE 4140) ter boa temperabilidade, implica que eles são capazes de endurecer mesmo com pequenas velocidades de resfriamento, sendo indicados em peças que exigem elevada dureza, resistência e tenacidade, como eixos virabrequins em usinas termoelétricas.

\subsubsection{Composição química}

A composição química das amostras dos aços SAE 4140 e SAE 4340 foi feita no laboratório Materials Test Center Ltda, sendo baseada na norma ASTM (American Society Testing and Materials) A751, 2014a [68].

O aço de referência (DIN 34CrNiMo6) teve a sua composição química fornecida pelo fabricante do eixo que rompeu e será apresentada e discutida no Capítulo 4, assim como a composição química do aço DIN 42CrMo4.

\subsubsection{Tratamento Térmico}

Os certificados da amostra SAE 4140 emitidos pela Gerdau indicou a dureza Brinell (Hardness Brinell - HB) de 185, já o da amostra SAE 4340, emitido pela Arcelormital, indicou dureza de 250 HB. O material de referência apresentou dureza média de $270 \mathrm{HB}$ (fornecida pelo fabricante).

O corpo de prova do material DIN 42CrMo4 foi ensaiado e apresentou dureza de 268 HB. Essa diferença na escala de dureza das amostras, principalmente com relação ao aço SAE 4140, indica a necessidade da realização 
de tratamentos térmicos, a fim de garantir que todas as amostras possuam durezas similares.

Tratamentos térmicos são operações de aquecimento e resfriamento controlados, que visam afetar as características de aços e ligas especiais. Enquanto alguns tipos aplicam-se em uma ampla gama de aços e ligas, outros têm sua aplicação restrita a determinadas famílias de aços ou ligas [69].

A têmpera consiste em resfriar o aço, após a austenitização, a uma velocidade suficientemente rápida a fim de obter a estrutura metaestável martensítica.

Para o controle da taxa de resfriamento, utilizam-se diversos meios de têmpera sendo os mais comuns a água (mais severa), óleo e ar (menos severo),

Entretanto, o aço martensítico obtido através da têmpera não apresenta muita aplicabilidade industrial, pois apesar de possuir uma elevada resistência mecânica, apresenta baixa ductilidade e tenacidade, sendo assim extremamente duro e frágil.

A fim de obter um material com ótimas combinações de resistência mecânica e tenacidade, deve-se logo após a têmpera realizar o tratamento de revenimento, formando assim a martensita revenida.

Esse tratamento consiste em aquecer o material uniformemente até uma temperatura abaixo daquela de austenitização, manter o mesmo nesta temperatura por tempo suficiente para equalização da temperatura e assim obter as propriedades mecânicas desejadas (fig. 27) [69].

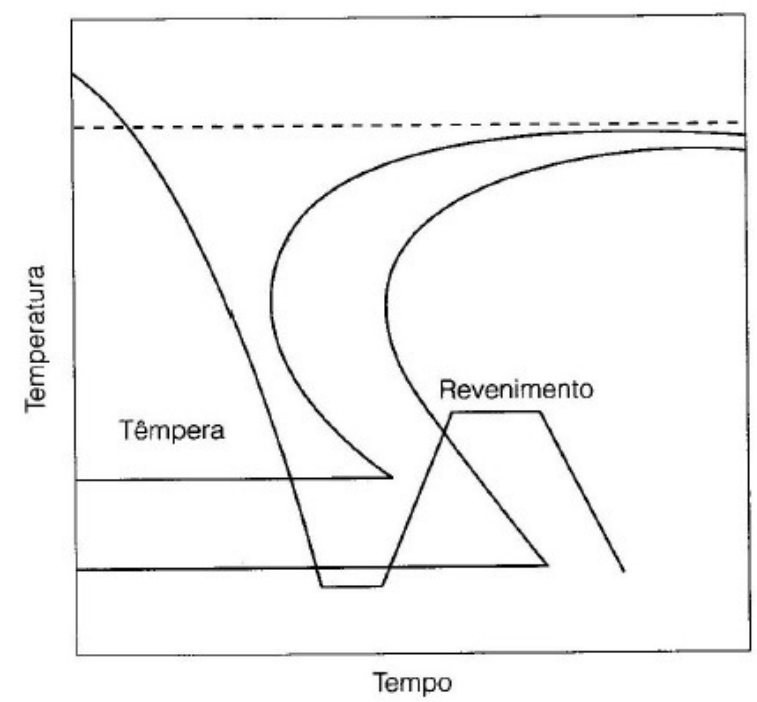

Figura 27: Ciclo de têmpera + revenimento [69] 
As amostras dos aços SAE 4140 e SAE 4340 foram temperadas a $870^{\circ} \mathrm{C}$ e resfriadas em óleo. A etapa seguinte foi o revenimento, a $650^{\circ} \mathrm{C}$. Esses procedimentos foram realizados pela TEMPERAÇO RIO que é um laboratório certificado pela norma ISO9001:2008.

\subsection{Ensaios Mecânicos}

\subsubsection{Ensaio de Tração}

Amostras dos aços SAE 4140, SAE 4340 e DIN 42CrMo4 tiveram corpos de prova usinados no Laboratório de Estruturas e Materiais - Puc-Rj com base na norma ASTM E8M “Test Methods for Tension Testing of Metallic Materials" (ASTM E8M, 2016), para a determinação de suas propriedades mecânicas através de ensaios de tração.

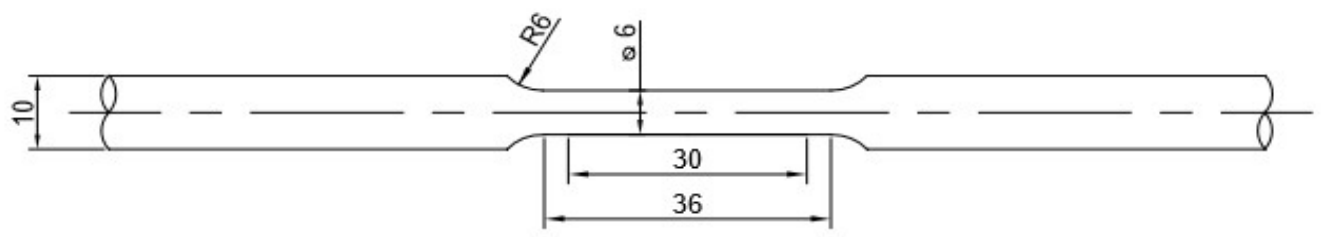

(a)

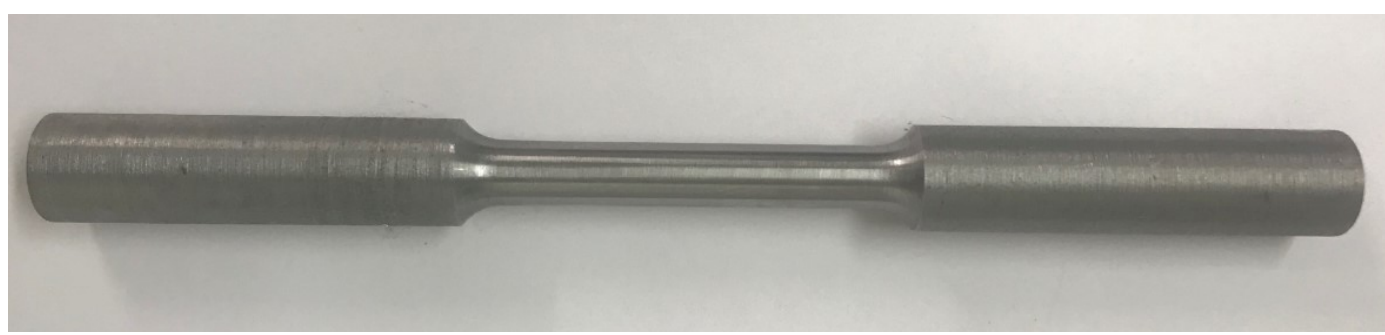

(b)

Figura 28 - Corpo de prova de tração: (a) Dimensões em mm, (b) Corpo de prova de tração usinado [70].

A máquina Instron (5500R, número de série 6233) com capacidade de 100 $\mathrm{kN}$ foi utilizada para a realização dos ensaios de tração. Nessa máquina, as extremidades dos corpos de prova são presas por garras e os mesmos são marcados em pontos equidistantes da região útil, na qual também foram acoplados um extensômetro (clip gage) com $25 \mathrm{~mm}$ de capacidade de abertura, posicionado na superfície do comprimento útil do corpo de prova. 
Os cálculos para o percentual de redução de área e para o alongamento foram feitos de acordo com as equações abaixo [22]:

$$
\frac{\mathrm{Ai}-\mathrm{Af}}{\mathrm{Ai}} \times 100 \%
$$

Onde:

$\mathrm{Ai}=$ Área da seção transversal útil inicial.

Af = Área da seção transversal útil final.

$$
\frac{\mathrm{Lf}-\mathrm{Li}}{\mathrm{Li}} \times 100 \%
$$

Onde:

$\mathrm{Li}=$ Comprimento longitudinal inicial.

$\mathrm{Lf}=$ Comprimento longitudinal final.

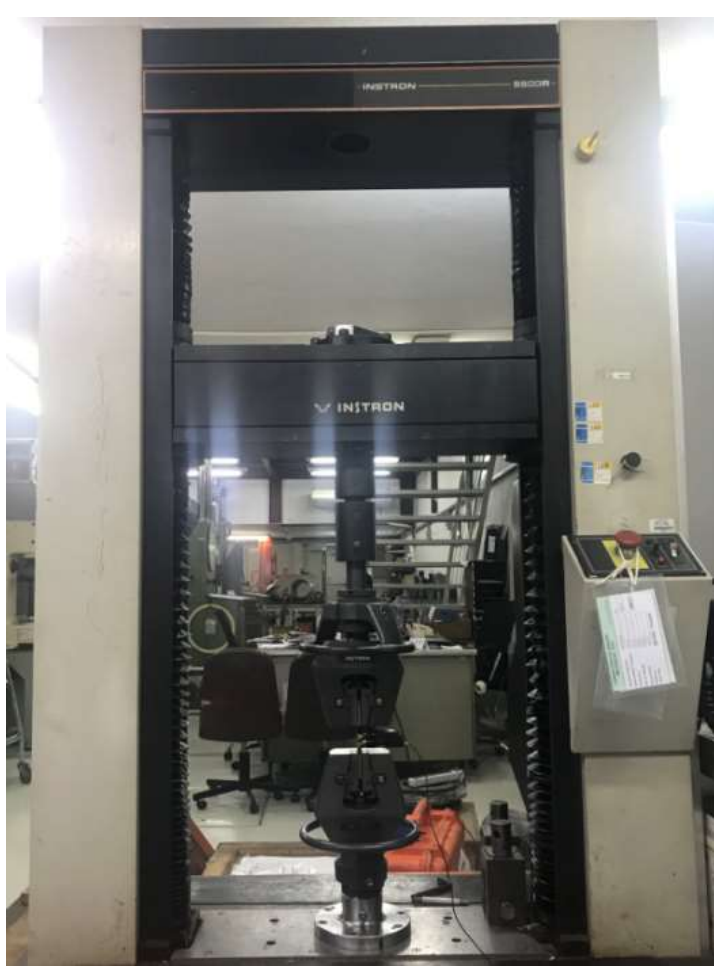

(a)

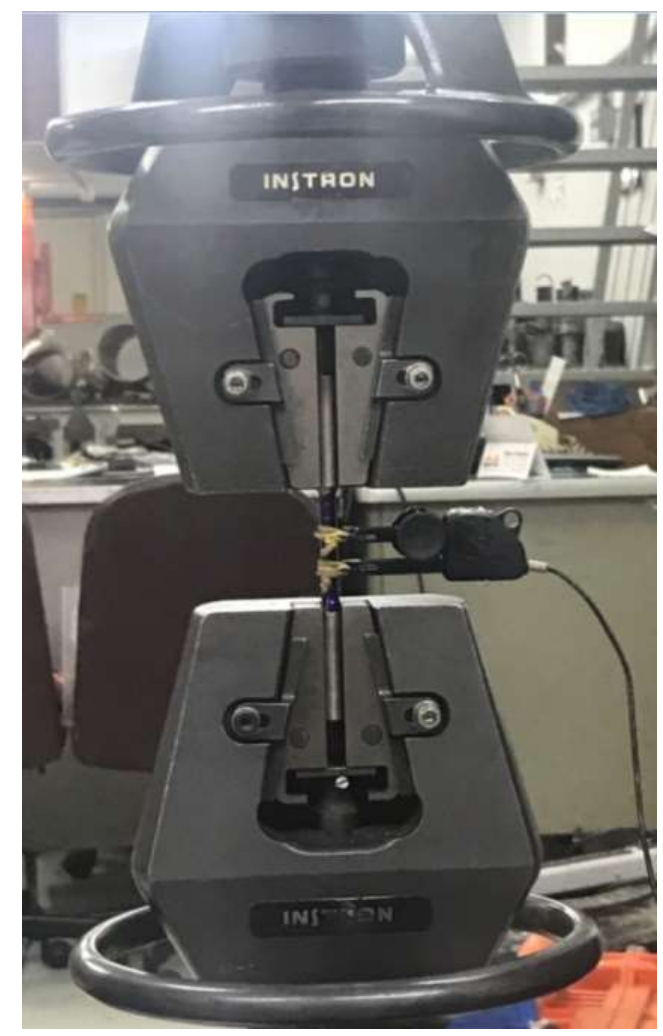

(b)

Figura 1 - Máquina Instron 5500R: (a) Visão geral da máquina; (b) Detalhe do corpo de prova e extensômetro fixados durante ensaio [70]. 


\subsubsection{Ensaio de Propagação da trinca por Fadiga}

Os cálculos para a determinação da pré trinca de fadiga nos corpos de prova do tipo C(T) foram feitos de acordo com as normas ASTM E1820 e ASTM E1290 e as dimensões dos cps respeitaram as limitações impostas pela norma ASTM E647 (fig.30).

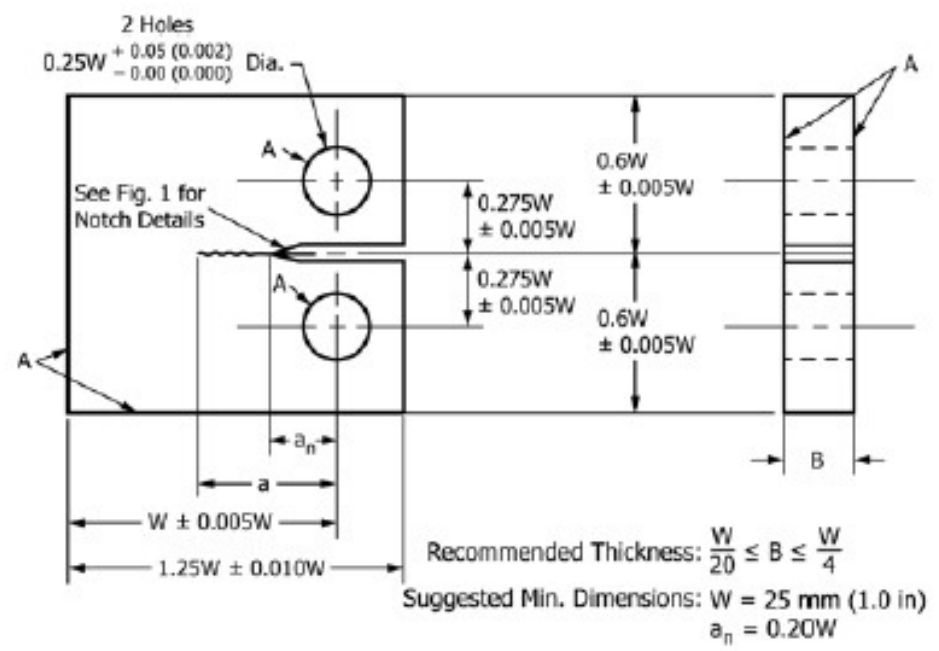

Figura 30: Dimensões do Corpo de Prova C(T) para Ensaio de Propagação de trincas por Fadiga.

De acordo com a norma ASTM E1820 todos os corpos de prova devem ter um valor de carga máxima para abertura da pré trinca de fadiga dado por:

$$
\mathrm{P}_{\text {máx }}=\frac{0,4 \mathrm{~B} b_{0}{ }^{2} \sigma_{\mathrm{y}}}{2 \mathrm{w}+a_{0}}
$$

Os valores de interesse para a equação 27 estão indicados na tabela 1:

Tabela 1: Valores de W e B utilizados.

\begin{tabular}{|c|c|c|c|c|}
\hline Material & $\mathbf{W}(\mathbf{m m})$ & $\mathbf{B}(\mathbf{m m})$ & $\boldsymbol{a}_{\mathbf{0}}(\mathbf{m m})$ & $\boldsymbol{b}_{\mathbf{0}}(\mathbf{m m})$ \\
\hline 42CrMo4 & 50,00 & 12,50 & 10,00 & 40,00 \\
\hline 34CrNiMo6 & 50,00 & 12,50 & 10,00 & 40,00 \\
\hline SAE 4140 & 40,00 & 10,00 & 8,00 & 32,00 \\
\hline SAE 4340 & 40,00 & 10,00 & 8,00 & 32,00 \\
\hline
\end{tabular}


Vale ressaltar que o valor de $\sigma y$ presente na equação 27 é uma média entre a tensão limite de escoamento e o limite de resistência mecânica. Esta norma ainda indica uma equação para o cálculo do parâmetro $\mathrm{K}$ (fator de Intensidade de tensões), dado por:

$$
\mathrm{K}(\mathrm{i})=\frac{P_{(i)}}{\left(B^{2} W\right)^{1 / 2}} f\left(\frac{a i}{w}\right)
$$

onde:

$$
f\left(\frac{a i}{W}\right)=\frac{\left\{\left(2+\frac{a i}{W}\right)\left[0,886+4,64\left(\frac{a i}{W}\right)-13,32\left(\frac{a i}{W}\right)^{2}+14,72\left(\frac{a i}{W}\right)^{3}-5,6\left(\frac{a i}{W}\right)^{4}\right]\right\}}{\left(1-\frac{a i}{W}\right)^{3 / 2}}
$$

A equação 28 possui duas incógnitas ( $\mathrm{K}$ e $\mathrm{P}$ ), impossibilitando assim a resolução. Mas, se utilizarmos como parâmetro K, o valor fornecido pela norma ASTM E1290 $(\mathrm{Kmáx}=25 \mathrm{MPa} \sqrt{\mathrm{m}})$ encontra-se um valor para carga máxima (Pmáx).

É importante frisar que se deve escolher o menor valor de carga máxima possível, pois um Pmáx alto leva a um Kmáx elevado o que torna grande a zona plástica na frente da trinca.

Com uma extensa zona plástica a frente da ponta da trinca, será mais difícil fazer com que ela se propague, e com isso, ao aumentar a carga visando a propagação da mesma, pode-se levar à fratura do material.

Visando o menor valor de carga necessária para a pré trinca de fadiga se propagar, mais duas condições serão analisadas: Pmáx $\rightarrow$ Valor mínimo $\{0,6$ Fy ou $\left.\mathrm{Kmáx}=1,5 \times 10^{-4} \sqrt{\mathrm{m}} \times \mathrm{E}\right\}$.

$$
\begin{aligned}
& \mathrm{Fy}=\frac{B(W-a)^{2}}{(2 W+q)} \sigma_{e} \\
& \mathrm{Kmáx}=\frac{P \text { máx }}{B \sqrt{W}} \mathrm{f}\left(\frac{a}{W}\right)
\end{aligned}
$$

Considerando o módulo de elasticidade como sendo de $210 \mathrm{GPa}$ (aços em geral), Kmáx assume o valor de 31,5 $\mathrm{MPa} \sqrt{ } \mathrm{m}$ ).

É importante informar que a norma ASTM E647 indica que o menor valor indicado para a pré trinca de fadiga corresponde ao maior valor dentre as seguintes condições: $10 \%$ do valor de B ou $1,0 \mathrm{~mm}$. 
Para a determinação da pré trinca de fadiga a máquina servo-hidráulica MTS 810 com capacidade de $250 \mathrm{kN}$ - foi utilizada (figs. 31 e 32 ).

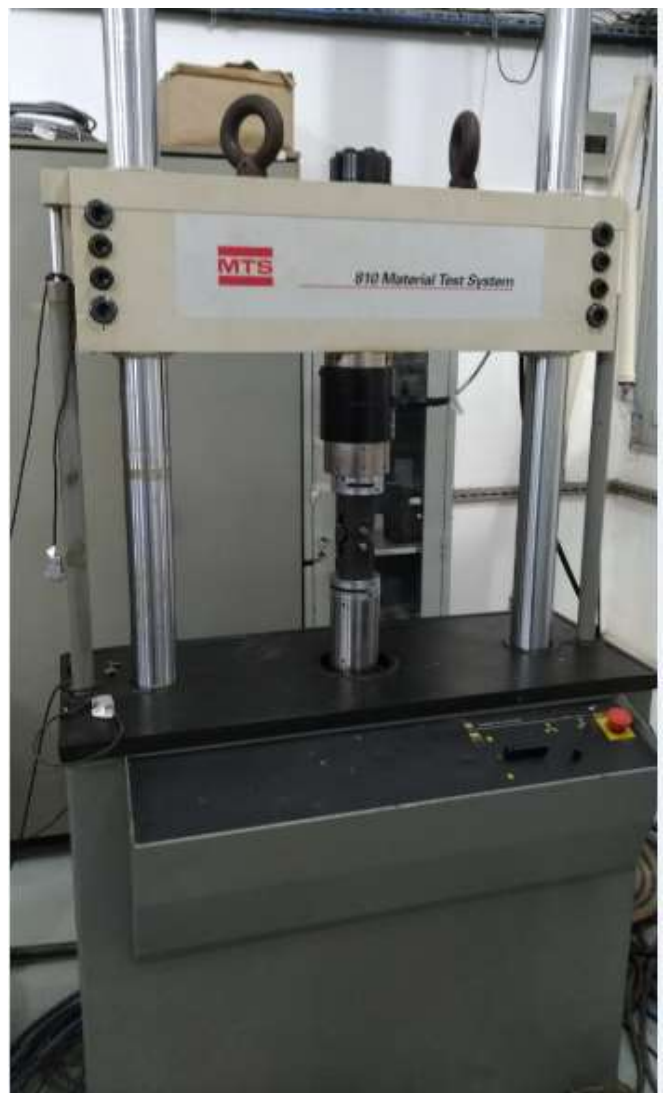

Figura 31: Máquina Servo-Hidráulica MTS 810-250kN.

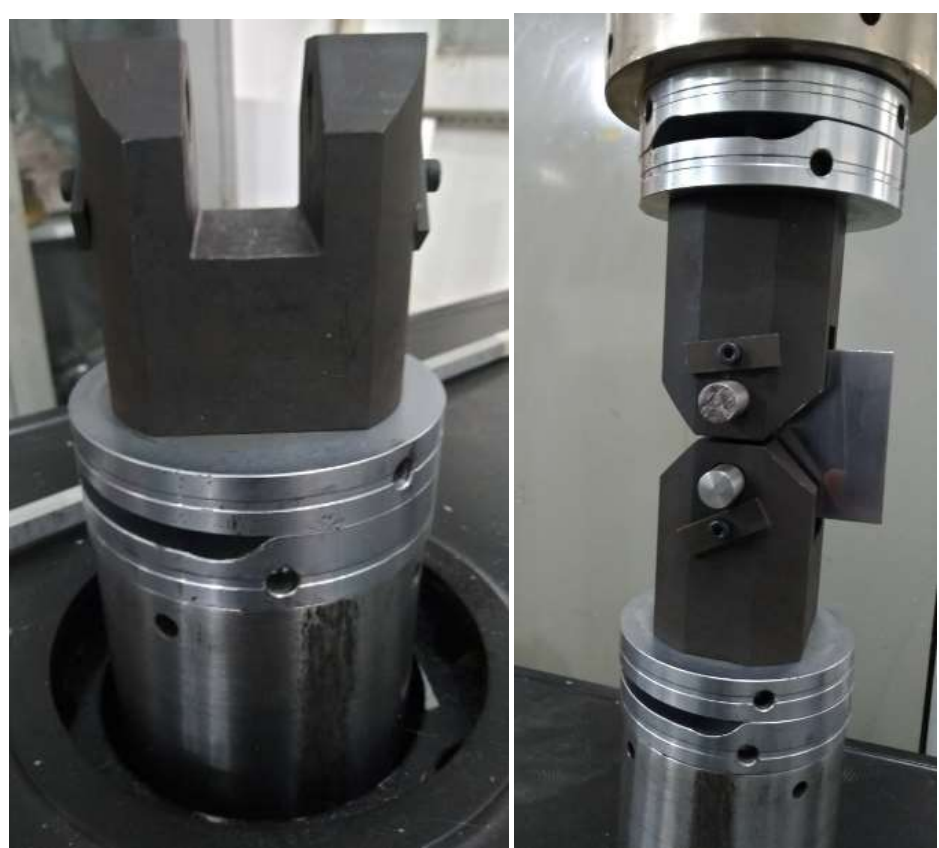

Figura 32: (a) “Garras” e Anéis de Pressão; (b) Fixação do corpo de prova C(T) na Máquina Servo-Hidráulica MTS 810-250kN. 
Os ensaios para a determinação da pré trinca de fadiga foram realizados no Laboratório de Estruturas e Materiais da Puc-Rj - Departamento de Engenharia Civil e Ambiental.

Vale ressaltar que antes da utilização dos cps na máquina MTS 810-250 kN, os mesmos tiveram que ser lixados e polidos, a fim de evitar que as marcas do processo de usinagem dificultassem o acompanhamento visual do crescimento da trinca.

Sendo assim, os corpos de prova foram lixados manualmente com lixas d'água (Norton) com granulometrias de 100, 220, 340, 600, 800 e 1200, e em seguida foram polidos nas politrizes metalográficas DPU 10 (Struers) e Aropol VV-PU (Arotec) com panos metalográficos de tecidos sintéticos utilizando pastas de diamante com granulometria de 6, 3 e $1 \mu \mathrm{m}$ (figs. 33 e 34 ).

A preparação das amostras foi realizada no Laboratório de Metalografia e Tratamentos Térmicos da Puc-Rj na temperatura ambiente.
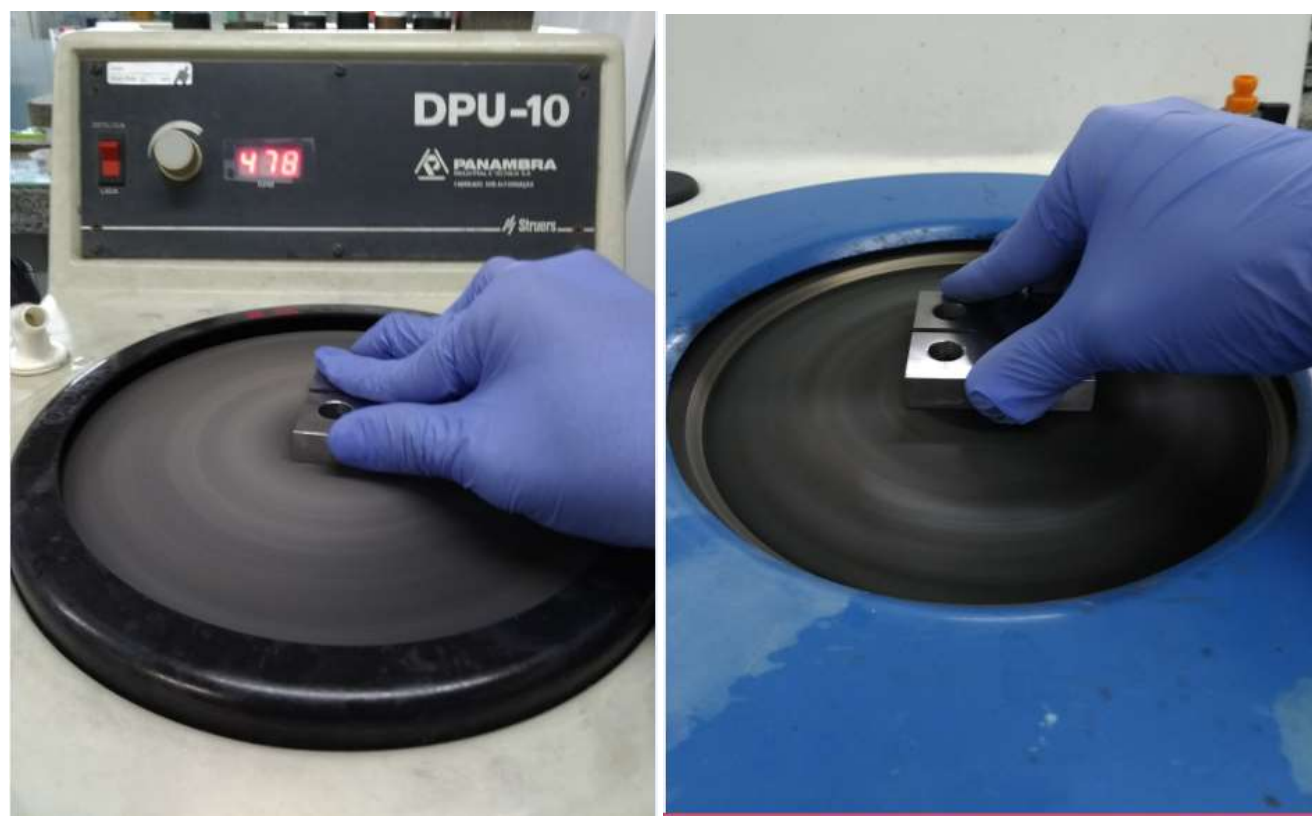

Figura 33: Polimento das amostras: a) Politriz DPU-10 com abrasivo de $6 \mu \mathrm{m}$; b) Politriz Aropol VV com abrasivo de $1 \mu \mathrm{m}$. 

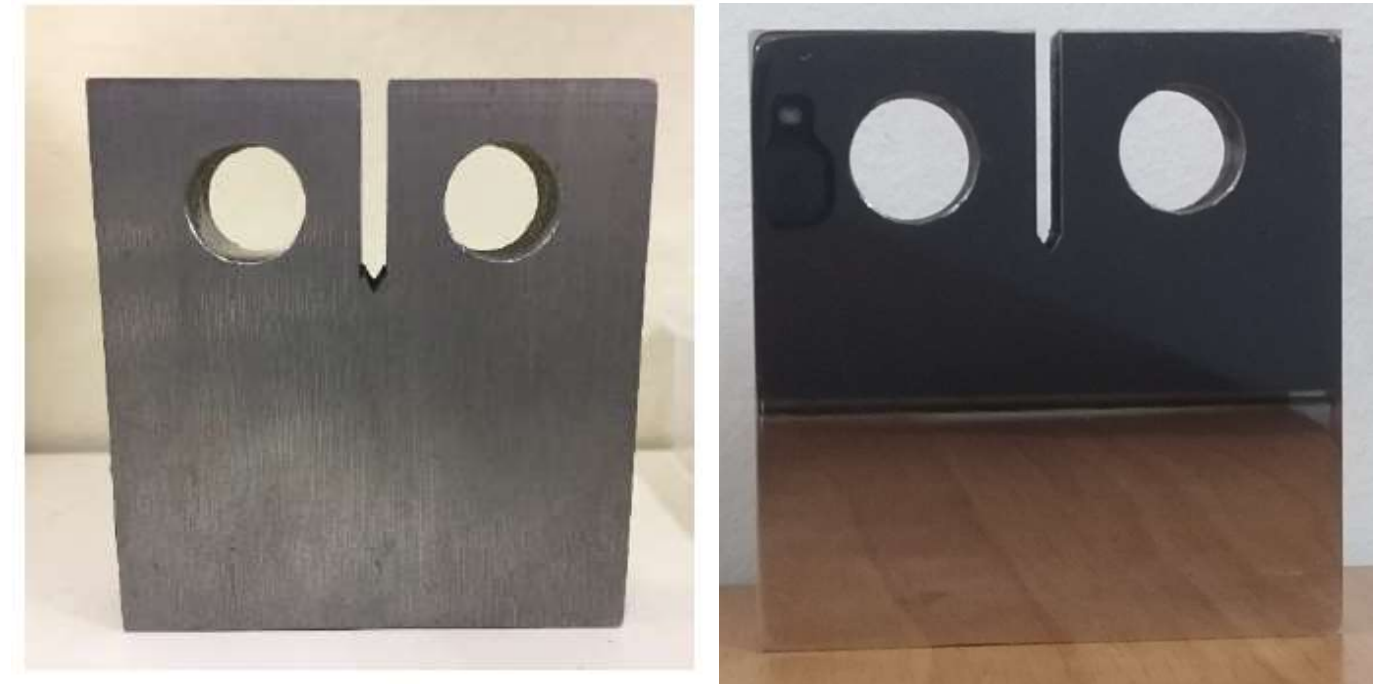

Figura 34: a) Corpo de prova do tipo $\mathrm{C}(\mathrm{T})$ com marcas típicas de usinagem; b) Corpo de prova após polimento

Os ensaios para a determinação da curva de propagação das trincas por fadiga foram realizados de acordo com a norma ASTM E647 em corpos de prova do tipo $\mathrm{C}(\mathrm{T})$, que foram testados numa máquina servo-hidráulica - Instron (modelo 8874 com capacidade de $25 \mathrm{kN}$ ) (fig.35).
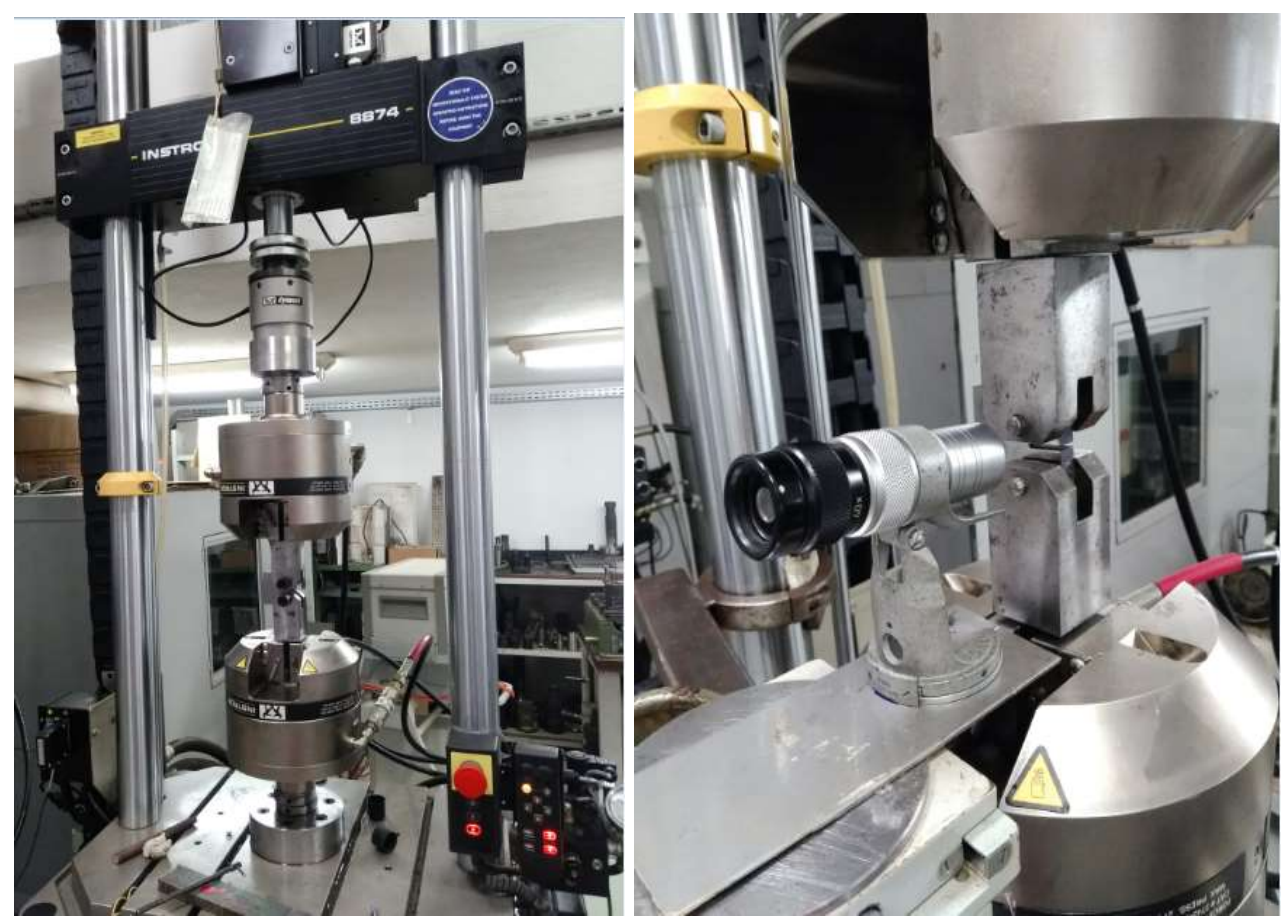

Figura 35: a) Máquina Servo-Hidráulica Instron $8874-25$ kN; b) Microscópio Óptico acoplado a máquina. 
Os ensaios mecânicos de tração e de propagação de trincas de fadiga foram realizados no Laboratório de Ensaios Mecânicos (LEM) da Puc-Rj na temperatura ambiente.

A equação para o cálculo da variação do fator de intensidade de tensões $(\Delta \mathrm{K})$ é dada pela norma ASTM E647, indicando que:

$$
\Delta K=\frac{\Delta P}{B \sqrt{ } W} \frac{(2+\alpha)}{(1-\alpha)^{3 / 2}}\left(0,886+4,64 \alpha-13,32 \alpha^{2}+14,72 \alpha^{3}-5,6 \alpha^{4}\right)
$$

onde:

$\Delta \mathrm{P}=$ Diferença entre a carga máxima e mínima aplicadas;

$\mathrm{B} \sqrt{ } \mathrm{W}=$ informações geométricas do $\mathrm{cp}$;

$\alpha=a / \mathrm{W}$

$a=$ tamanho da trinca.

A primeira carga máxima utilizada corresponde aquela calculada através da equação 32 , usando um $\Delta \mathrm{K}_{\text {médio }}$ de $28,25 \mathrm{MPa} \vee \mathrm{m}$ (valor entre $25 \mathrm{MPa} \vee \mathrm{m}$ e 31,5 $\mathrm{MPa} \vee \mathrm{m})$.

Com esse valor de $\Delta \mathrm{K}$, o corpo de provas foi submetido a ciclos de 5000 a 10000 vezes e, com o auxílio de um microscópio óptico com aumento de 50x (colocado próximo a bancada de testes), o tamanho da trinca foi medido.

Após essa etapa, a carga máxima foi reduzida em cerca de $10 \%$ e repetiu-se toda a etapa descrita no parágrafo anterior, até o ponto em que, após $10^{5}$ ciclos (ASTM A647) a trinca não apresentasse um incremento de tamanho $(\mathrm{d} a / \mathrm{dN}=0)$. Para essa condição, calculou-se o $\Delta \mathrm{K}$ novamente através da equação 32 e esse valor será o limiar de propagação da trinca $\left(\Delta \mathrm{K}_{\mathrm{th}}\right)$. 


\subsection{Microscopia}

\subsubsection{Microscopia Óptica}

Com o intuito de verificar se as inclusões estariam no caminho preferencial das trincas de fadiga dos aços estruturais estudados nesse trabalho, um microscópio óptico do tipo Stereo Zeiss Discovery V8, com lentes de diferentes magnificações foi utilizado (fig.36).
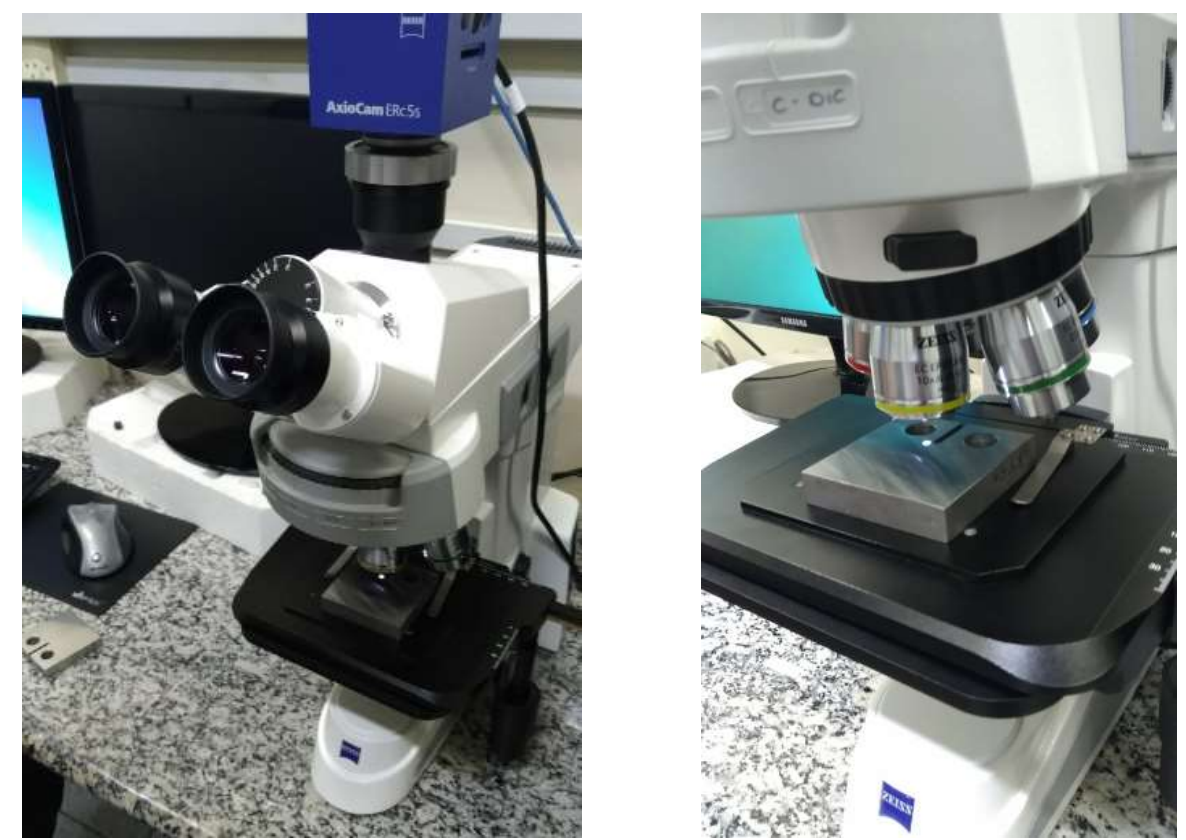

Figura 36: a) Microscópio Óptico Stereo Zeiss Discovery V8. b) Lentes de magnificação do microscópio.

Nas figuras 37 a 40 observa-se que aspectos microestruturais estão no caminho preferencial de propagação das trincas nos corpos de prova (cp) para os aços SAE 4340, DIN 34CrNiMo6 (material de referência) e DIN 42CrMo4. No caso da amostra do SAE 4140, o polimento foi responsável por induzir tensões residuais que foram capazes de "fechar" a trinca de fadiga. 


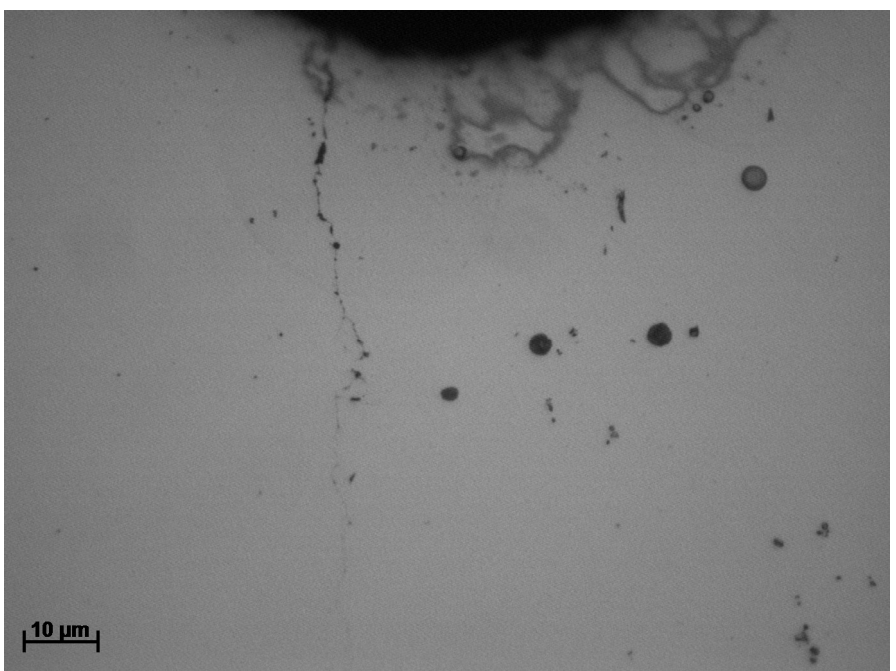

Figura 37: Microscopia Óptica no cp do SAE 4340 - Aumento de 500x.

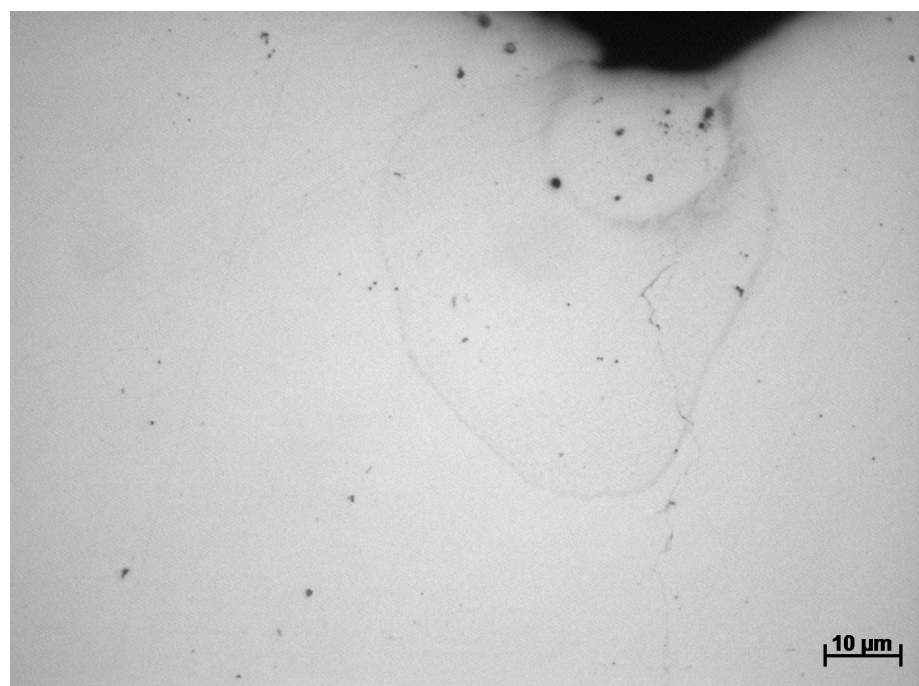

Figura 38: Microscopia Óptica no cp do DIN 42CrMo - Aumento de 500x.

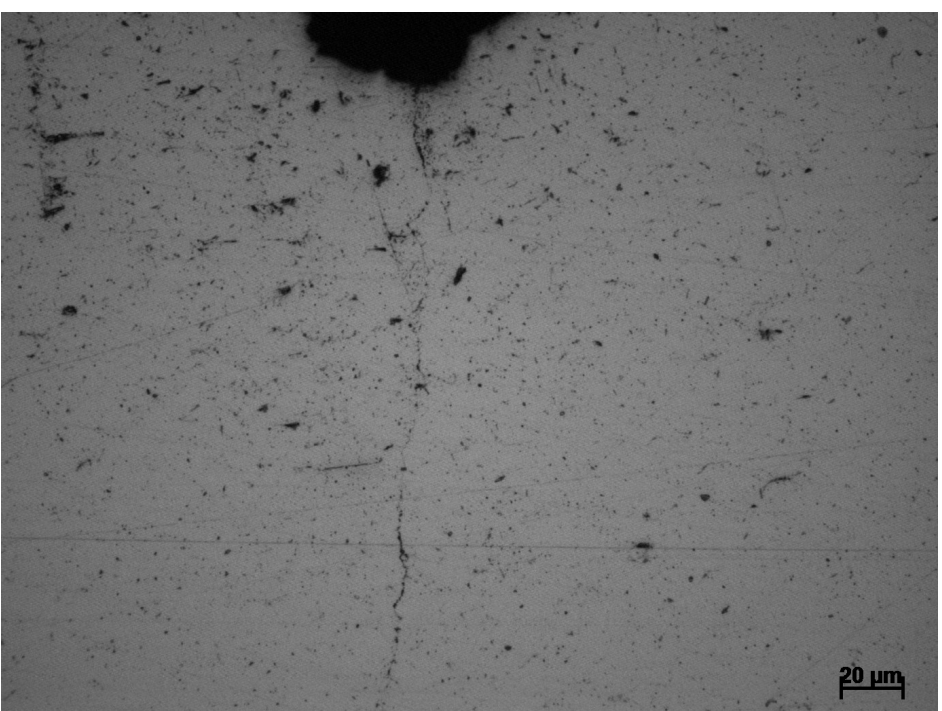

Figura 39: Microscopia Óptica no cp do DIN 34CrNiMo ${ }_{6}$ - Aumento de 200x. 


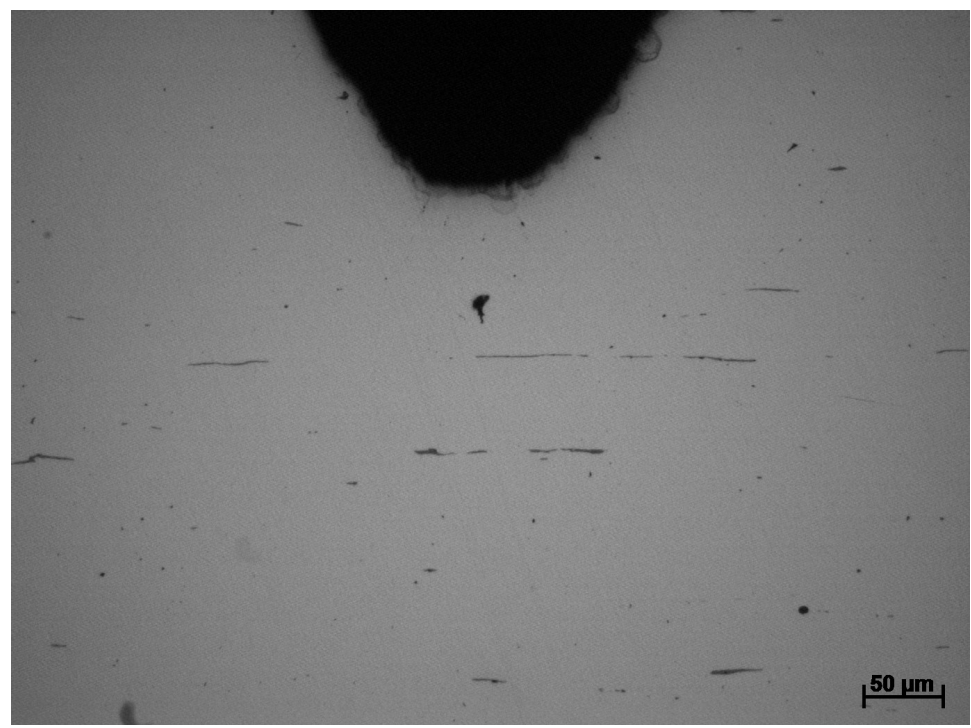

Figura 40: Microscopia Óptica no cp do SAE 4140 - Aumento de 100x.

O lixamento / polimento mecânico retira material do corpo de prova, causando deformações plásticas que podem induzir tensões residuais que vão fechar a trinca. Toda vez que houver uma heterogeneidade de deformação plástica, aparecerão tensões elásticas para equilibrar o sistema. Se o campo de tensões criado após o polimento mecânico for de tensões compressivas, a trinca "fechará".

Com isso, o corpo de prova desse material deve voltar a ser ensaiado em fadiga, visando eliminar os campos de tensão residual gerados pelo polimento. Entretanto, é inerente ao ensaio de fadiga a criação de novos campos de tensão residual que também tendem a "fechar" a ponta da trinca.

Como o ensaio de fadiga é cíclico, onde a carga oscila entre um valor máximo e um mínimo, a trinca só "avança” (aumenta de tamanho) após criar uma zona plástica à sua frente.

A carga máxima leva a criação de uma zona plástica máxima, assim como de zona elástica, enquanto na carga mínima as zonas plástica e elástica são mínimas. Com isso, para a zona elástica passar de um valor máximo para o mínimo, tem que ocorrer a redução da área da zona plástica, que, como é irreversível, leva a tensão a "grampear" (comprimir) a zona plástica para equilibrar o sistema, fechando assim a ponta da trinca. 


\subsubsection{Microscopia Eletrônica de Varredura}

Um Microscópio Eletrônico de Varredura (MEV) utiliza um feixe de elétrons no lugar dos fótons utilizados em um microscópio óptico convencional, sendo um equipamento que fornece rapidamente informações sobre a morfologia e identificação de elementos químicos de uma amostra sólida (fig. 41).

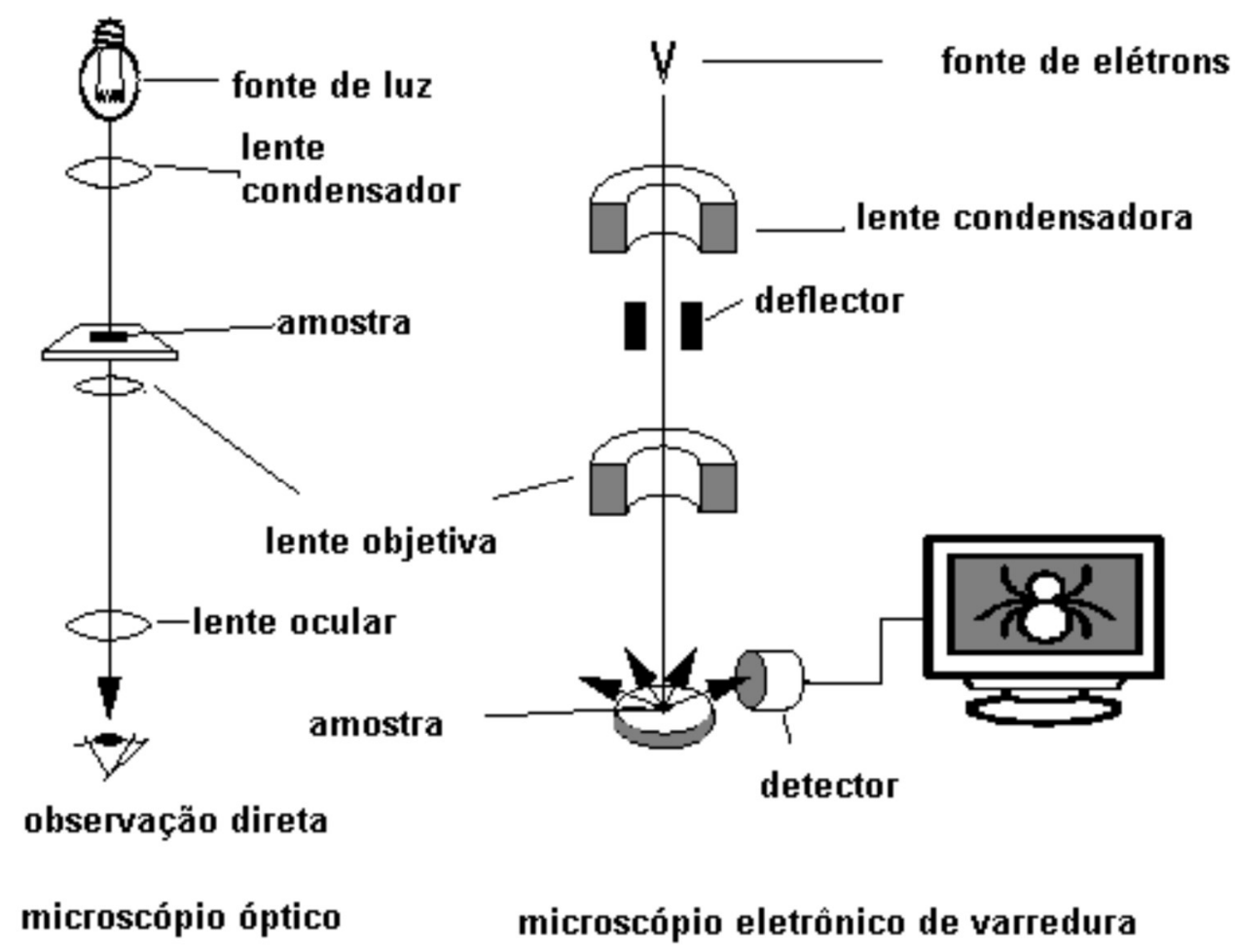

Figura 41: Desenho esquemático para comparação entre microscópio óptico e microscópio eletrônico de varredura [72].

De Bloglie, em 1925, mostrou o dualismo onda-partícula e, por conseguinte, que o comprimento de onda de um elétron é função de sua energia que pode ser comunicada a uma nova partícula carregada por meio de um campo elétrico acelerador.

Assim, sob uma voltagem suficientemente alta, por exemplo, $50 \mathrm{kV}$, elétrons de comprimento de onda extremamente curto $(\lambda=0,005 \AA)$ e, portanto, de poder de resolução potencialmente alto, como uma fonte de iluminação, podem ser produzidos. 
Além disto, devido às suas cargas, os elétrons podem ser focalizados por campos eletrostáticos ou eletromagnéticos e, então, são capazes de formar imagens. Eles possuem, portanto, as características essenciais necessárias a um microscópio de alta resolução [72].

No Microscópio Óptico (MO) a resolução, ou seja, a capacidade de distinguir dois objetos próximos, é função da lente e de sua abertura numérica, e da difração que pode estar presente no processo. O MEV possui maior resolução, dada pelo fino diâmetro do feixe de elétrons que varre a amostra (quanto menor o feixe, maior a resolução e magnificação possível).

Nesse trabalho foi utilizado um Microscópio Eletrônico de Varredura (MEV), modelo JSM-6510LV localizado no Laboratório de Microscopia Eletrônica da Puc-Rj (fig. 42), com magnificação de 300.000 vezes e $20 \mathrm{kV}$ de tensão do filamento utilizada nas análises.
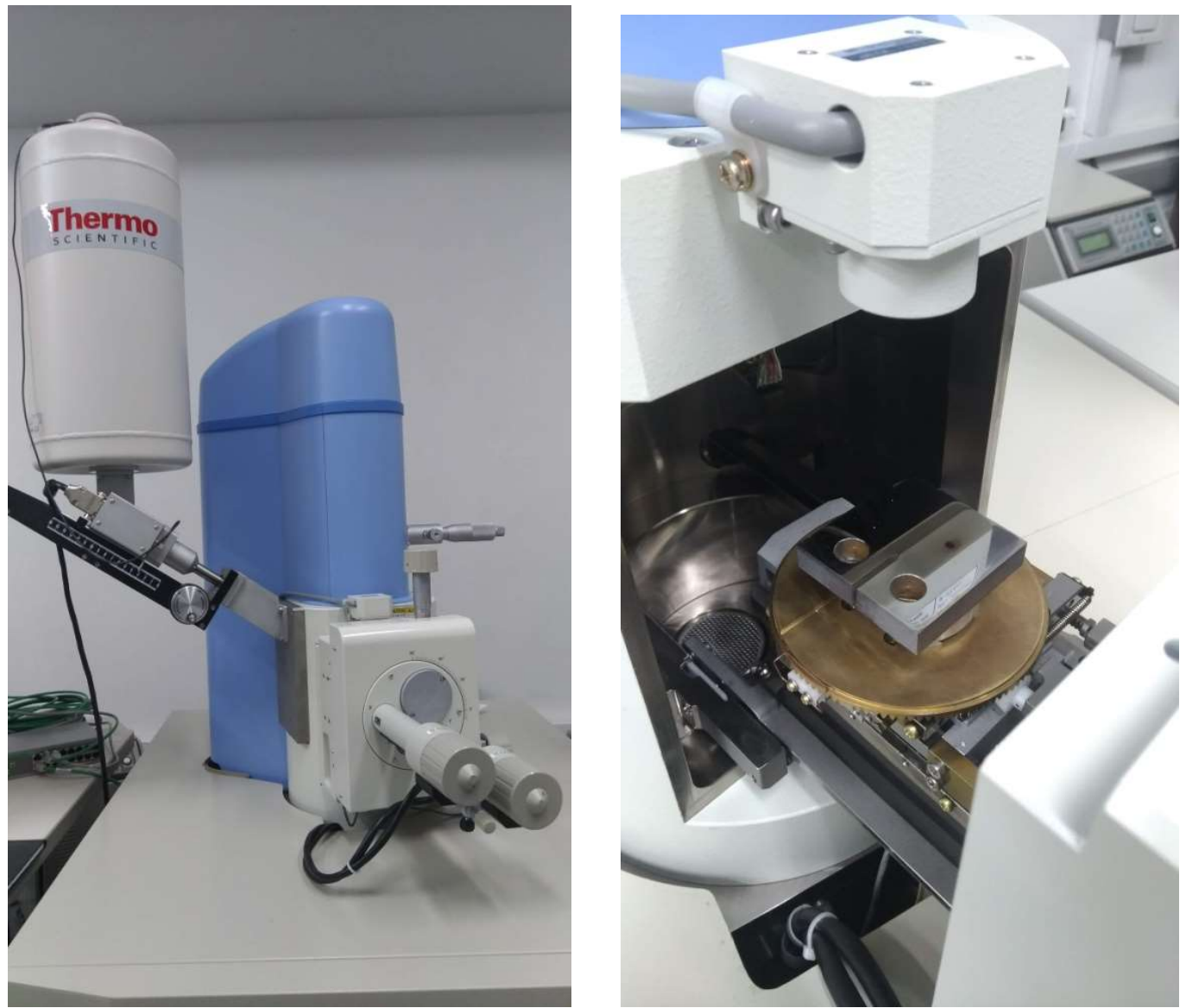

Figura 42: a) MEV utilizado no ensaio; b) Cp no porta amostras do MEV. 
Os elétrons acelerados do feixe podem interagir de forma elástica ou inelástica com os átomos de uma amostra. $\mathrm{Na}$ interação elástica, os elétrons do feixe incidem na amostra, interagindo com os núcleos dos átomos. Suas trajetórias são alteradas (semelhante a um satélite em órbita ao redor de um planeta) e eles emergem da amostra, porém não perdem energia nesse processo.

Esta interação gera os elétrons retro espalhados que são dependentes do número atômico da amostra, e atingem grandes profundidades do material. Ao emergir eles são detectados por um detector que gera um sinal elétrico proporcional a quantidade de elétrons recebidos (detectores de estado sólido). Quanto maior o número atômico do elemento presente na amostra, maior o brilho na imagem, pois o elétron irá ricochetear mais, gerando contraste na imagem.

$\mathrm{Na}$ interação inelástica, os elétrons perdem energia ao interagir com a amostra. Esta energia é utilizada para a geração de dois outros processos: os elétrons secundários e a geração de raios $\mathrm{X}$ (entre outros).

$\mathrm{Na}$ geração de radiação raios $\mathrm{X}$, o feixe interage com os elétrons mais internos dos átomos, arrancando-os e deixando o átomo instável. Um elétron de uma camada mais externa decai para o vazio deixado, e nesse processo "devolve" energia na forma de um fóton de radiação.

Esse fóton é bem definido para os níveis de energia discretos do átomo, e cada elemento têm seus níveis de energia específicos. Assim, essa radiação pode ser utilizada para identificar os elementos químicos de acordo com a radiação emitida, embora não identifique os compostos formados por eles.

Nas figuras a seguir observa-se uma melhor resolução nas amostras dos diferentes aços estruturais estudados nesse trabalho, proporcionada pelo uso do MEV com detectores de elétrons secundários. Esse tipo de ensaio permitiu uma melhor visualização do caminho percorrido pela trinca e sua interação com os aspectos microestruturais das amostras. 


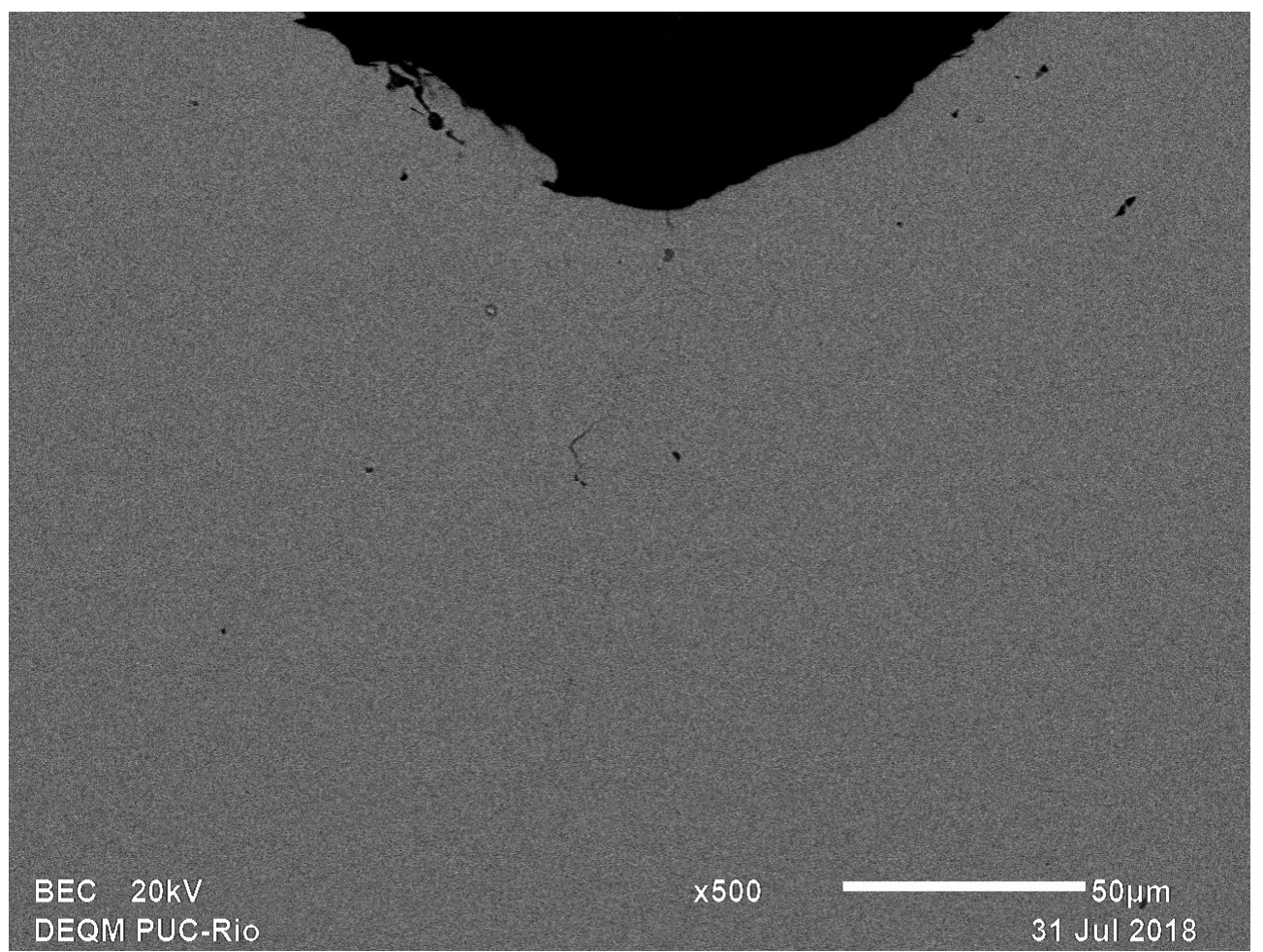

Figura 43: MEV na amostra de DIN 42CrMo - Aumento de 500x.

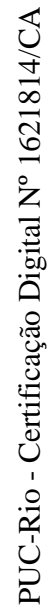

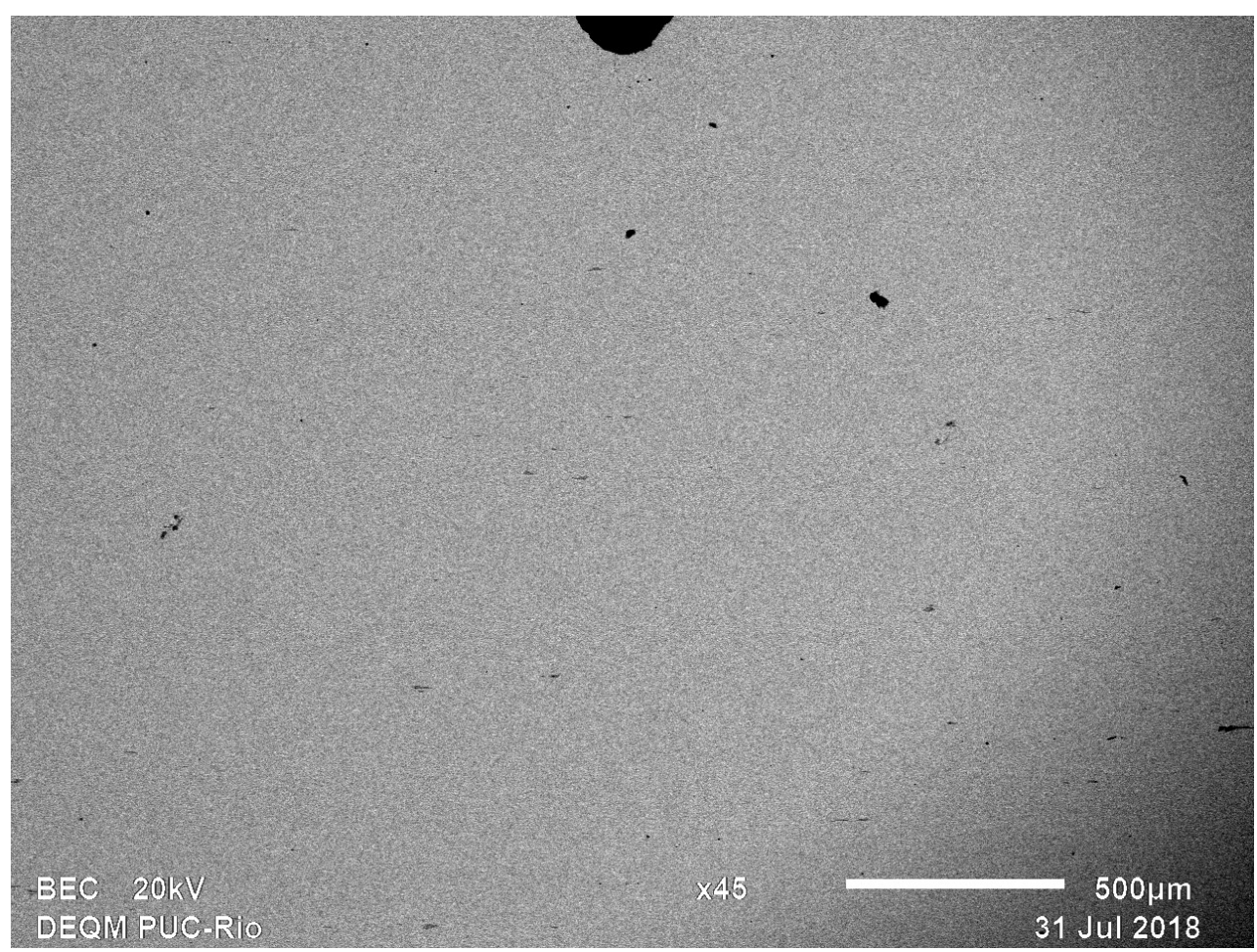

Figura 44: MEV na amostra de SAE 4340 - Aumento de 500x. 


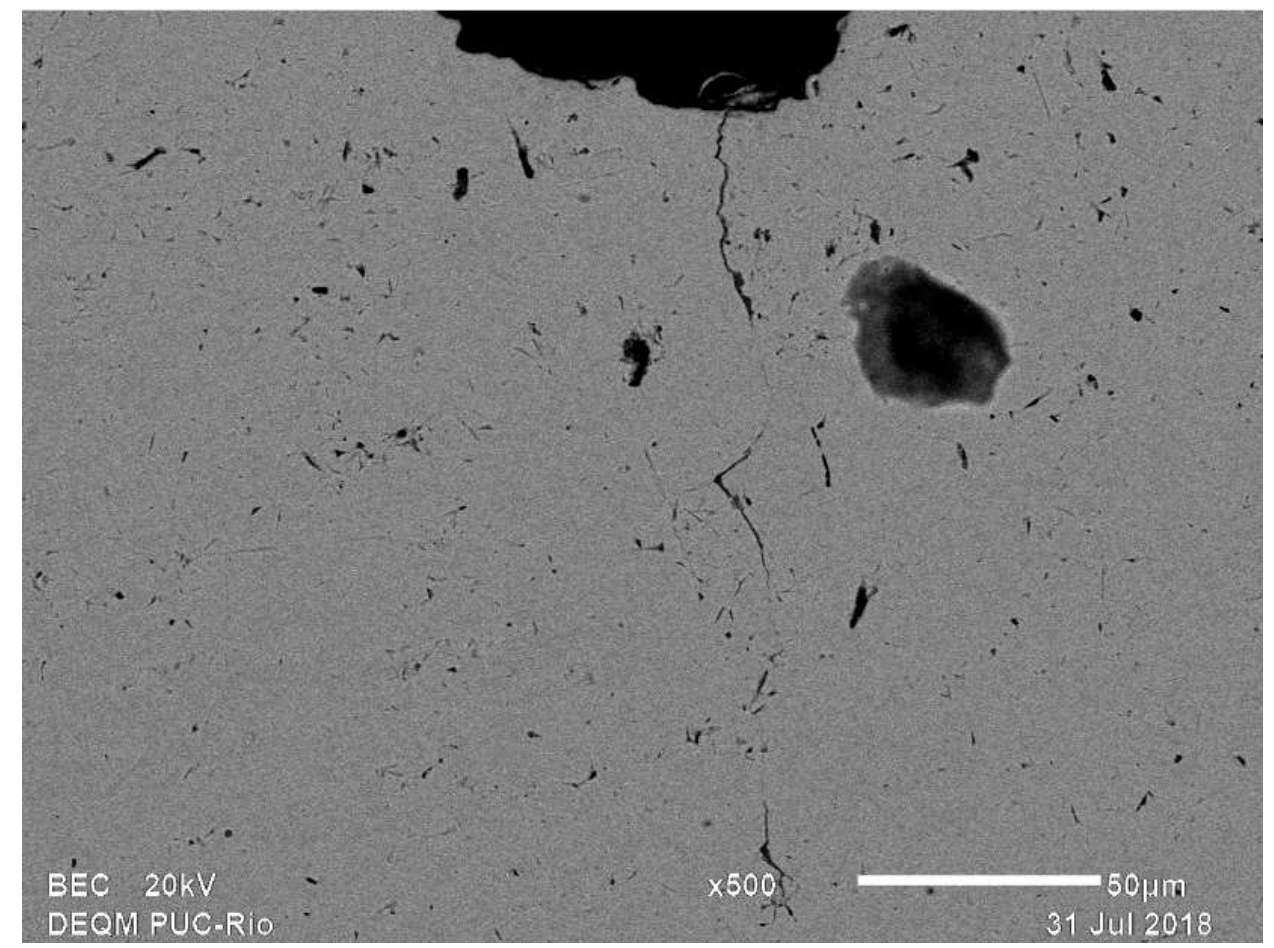

Figura 45: MEV na amostra de DIN 34CrNiMo - Aumento de 500x.

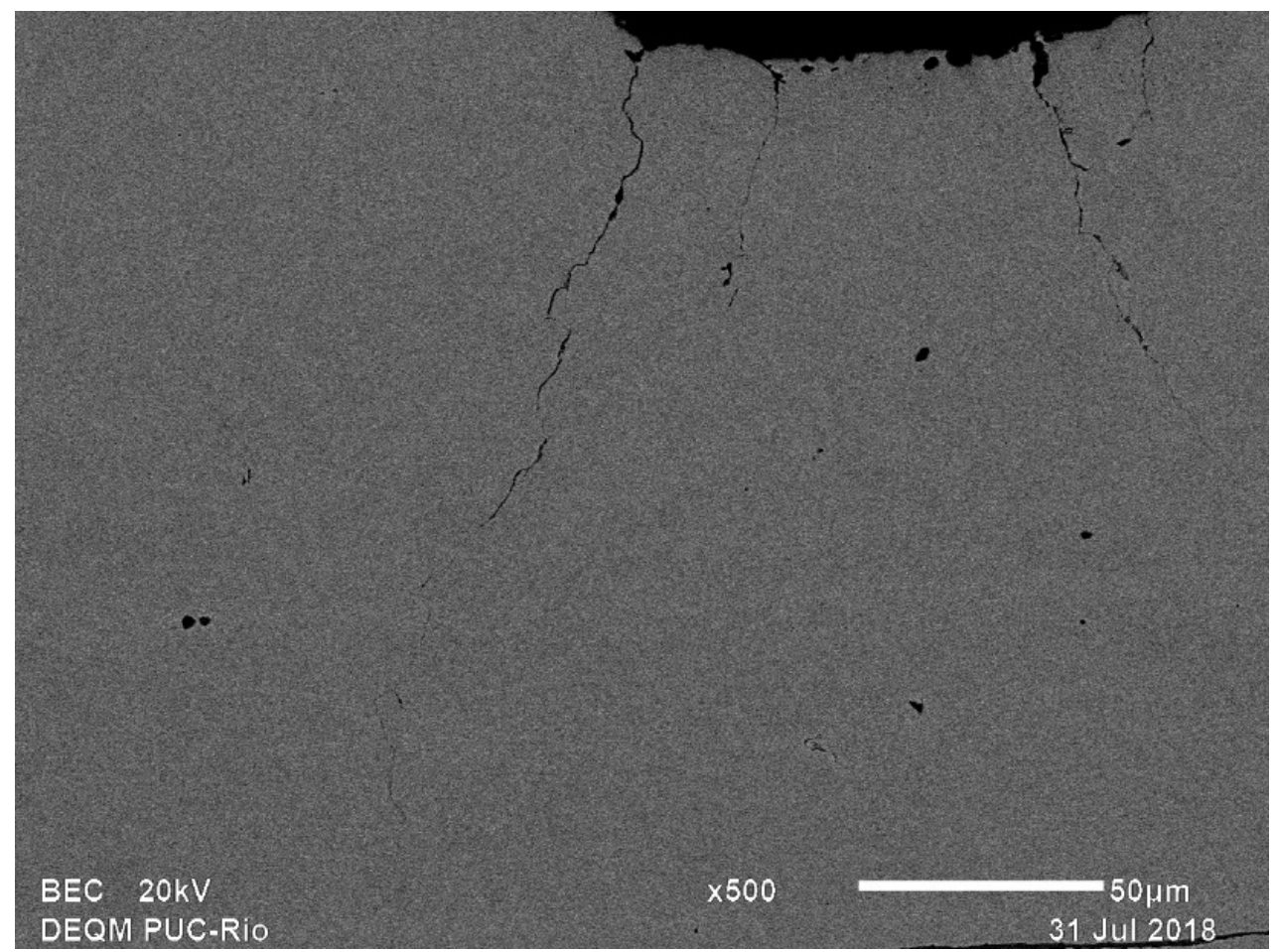

Figura 46: MEV na amostra de SAE 4140 - Aumento de 500x. 


\section{Resultados e Discussão}

\subsection{Composição química}

Tabela 2: Composição química das amostras dos aços estudados [68,71].

\begin{tabular}{|c|c|c|c|c|c|c|c|c|c|}
\cline { 2 - 11 } \multicolumn{1}{c|}{} & \multicolumn{10}{c|}{ \% na amostra (wt) } \\
\cline { 2 - 11 } \multicolumn{1}{c|}{} & C & Mn & Si & Cu & Cr & V & Mo & Ni & Fe \\
\hline DIN 42CrMo4 & 0,38 & 0,85 & 0,27 & 0,18 & 0,97 & 0,01 & 0,20 & - & 96,9 \\
\hline DIN 34CrNiMo6 & 0,38 & 0,77 & 0,09 & 0,12 & 1,07 & 0,13 & 0,29 & 0,72 & 96,4 \\
\hline SAE 4140 & 0,42 & 0,86 & 0,26 & 0,01 & 1,06 & 0,0047 & 0,17 & 0,043 & 97,1 \\
\hline SAE 4340 & 0,42 & 0,64 & 0,23 & 0,16 & 0,75 & 0,024 & 0,21 & 1,26 & 96,2 \\
\hline
\end{tabular}

\subsection{Tratamento térmico}

Após os tratamentos térmicos citados no capítulo anterior, os aços SAE 4140 e SAE 4340 apresentaram dureza média de 262 HB e 277 HB, respectivamente.

Sabendo-se que a dureza média do material de referência é de $270 \mathrm{HB}$, os aços acima citados apresentaram dureza similar, tornando-os adequados, pelo menos em termos de dureza, para a substituição do material do eixo que rompeu.

\subsection{Ensaios mecânicos}

Após as realizações dos tratamentos térmicos de têmpera e revenimento, os materiais foram caracterizados mecanicamente através dos ensaios de tração e propagação de trincas. Os resultados destes ensaios são mostrados a seguir. 


\subsubsection{Ensaios de tração}

Tabela 3: Valores de tensões obtidas através do ensaio de tração [68,71].

\begin{tabular}{|c|c|c|c|c|c|c|c|c|}
\hline & \multicolumn{2}{|c|}{ 34CrNiMo6 } & \multicolumn{2}{c|}{ SAE 4140 } & \multicolumn{2}{c|}{ SAE 4340 } & \multicolumn{2}{c|}{ 42CrNiMo6 } \\
\hline \multirow{3}{*}{$\sigma \mathbf{y}(\mathbf{M P a})$} & A1 & 740,0 & B1 & 591,0 & C1 & 707,0 & D1 & 704,0 \\
\cline { 2 - 9 } & A2 & 720,0 & B2 & 602,0 & C2 & 655,0 & D2 & 686,0 \\
\cline { 2 - 9 } & A3 & 724,0 & B3 & 570,0 & C3 & 663,0 & D3 & 677,0 \\
\hline Média (MPa) & & $\mathbf{7 2 8 , 0}$ & & $\mathbf{5 8 7 , 7}$ & & $\mathbf{6 7 5 , 0}$ & & $\mathbf{6 8 9 , 0}$ \\
\hline DP (MPa) & & $\mathbf{1 0 , 6}$ & & $\mathbf{1 6 , 3}$ & & $\mathbf{2 8 , 0}$ & & $\mathbf{1 3 , 7}$ \\
\hline \multirow{3}{*}{ LRM (MPa) } & A1 & 915 & B1 & 808 & C1 & 846 & D1 & 880 \\
\cline { 2 - 9 } & A2 & 900 & B2 & 806 & C2 & 848 & D2 & 855 \\
\cline { 2 - 9 } & A3 & 875 & B3 & 792 & C3 & 843 & D3 & 850 \\
\hline Média (MPa) & & $\mathbf{8 9 6 , 7}$ & & $\mathbf{8 0 2 , 0}$ & & $\mathbf{8 4 5 , 7}$ & & $\mathbf{8 6 1 , 7}$ \\
\hline DP $(\mathrm{MPa})$ & & $\mathbf{2 0 , 2}$ & & $\mathbf{8 , 7}$ & & $\mathbf{2 , 5}$ & & $\mathbf{1 6 , 1}$ \\
\hline
\end{tabular}

Tabela 4: Parâmetros de ductilidade obtidos no ensaio de tração [68,71].

\begin{tabular}{|c|c|c|}
\cline { 2 - 3 } \multicolumn{1}{c|}{} & Alongamento (\%) & Redução de área (\%) \\
\cline { 2 - 3 } \multirow{2}{*}{ 34CrNiMo6 } & 15,20 & 45,00 \\
\cline { 2 - 3 } & 15,20 & 34,70 \\
\hline \multirow{2}{*}{ Média } & 12,00 & 42,50 \\
\hline Desvio Padrão & $\mathbf{1 4 , 1 3}$ & $\mathbf{4 0 , 7 3}$ \\
\hline \multirow{3}{*}{ SAE 4140 } & $\mathbf{1 , 8 5}$ & $\mathbf{5 , 3 7}$ \\
\cline { 2 - 3 } & 13,70 & 26,50 \\
\hline \multirow{2}{*}{ Média } & 14,50 & 30,80 \\
\hline Desvio Padrão & 12,30 & 22,00 \\
\hline \multirow{3}{*}{ SAE 4340 } & $\mathbf{1 3 , 5 0}$ & $\mathbf{2 6 , 4 3}$ \\
\cline { 2 - 3 } & $\mathbf{1 , 1 1}$ & $\mathbf{4 , 4 0}$ \\
\cline { 2 - 3 } & 15,20 & 45,00 \\
\hline Média & 15,20 & 34,70 \\
\hline Desvio Padrão & 12,00 & 42,50 \\
\hline \multirow{3}{*}{ 42CrMo4 } & $\mathbf{1 4 , 1 3}$ & $\mathbf{4 0 , 7 3}$ \\
\cline { 2 - 3 } & $\mathbf{1 , 8 5}$ & $\mathbf{5 , 3 7}$ \\
\cline { 2 - 3 } & 16,33 & 47,84 \\
\hline Média & 15,00 & 42,25 \\
\hline Desvio Padrão & 14,67 & 51,36 \\
\hline
\end{tabular}




\subsubsection{Ensaios de propagação das trincas de fadiga}

Uma das equações utilizadas para estimar o valor da carga máxima de abertura da pré-trinca de fadiga depende da média dos valores obtidos no ensaio de tração para a tensão de limite de escoamento (tabela 3). Entretanto, esses valores devem ser considerados como valores críticos, uma que leva à fratura do material com baixo ciclo de carregamento.

Tabela 5: Valores de Pmáx críticos calculados para a pré trinca de fadiga

\begin{tabular}{|c|c|}
\hline & Carga Máxima (kN) \\
\hline Material & Pmáx $=\left(0.4 \mathrm{~B} \mathrm{bo}^{2} \sigma \mathrm{y}\right) / 2 \mathrm{~W}+a_{0}$ \\
\hline 42CrMo4 & 50,11 \\
\hline SAE 4140 & 27,32 \\
\hline SAE 4340 & 31,42 \\
\hline 34CrNiMo6 & 52,95 \\
\hline
\end{tabular}

Tabela 6: Valores de Pmáx estimados para o cálculo da pré trinca de fadiga

\begin{tabular}{|c|c|c|}
\hline \multirow{3}{*}{ Material } & \multicolumn{2}{|c|}{ Carga Máxima (kN) } \\
\hline & \multicolumn{2}{|c|}{$25=\left[\operatorname{Pmáx} /\left(\mathrm{B}^{2} \times \mathrm{W}\right)^{1 / 2}\right] \times \mathrm{f}\left(a_{\mathrm{i}} / \mathrm{W}\right)$} \\
\hline & $\left(a_{0}=10,0 \mathrm{~mm}\right)$ & $\left(a_{1}=11,5 \mathrm{~mm}\right)$ \\
\hline 42CrMo4 & 16,35 & 14,95 \\
\hline SAE 4140 & 11,7 & 10,7 \\
\hline SAE 4340 & 11,7 & 10,7 \\
\hline 34CrNiMo6 & 16,35 & 14,95 \\
\hline
\end{tabular}

Uma outra forma de estimar os valores de carga para abertura da pré trinca de fadiga é usando como valor para Kmáx $=31,5 \mathrm{MPa} V_{\mathrm{m}}$ (equação 31 utilizando $\mathrm{E}=210 \mathrm{GPa})$, obtendo assim os seguintes valores de Pmáx: a) Pmáx ( $a_{0}=10,0$ $\mathrm{mm}) \rightarrow 20,6 \mathrm{kN}$; b) Pmáx $\left(a_{1}=11,5 \mathrm{~mm}\right) \rightarrow 18,9 \mathrm{kN}$, onde $a_{0}$ equivale a $0,20 \mathrm{~W}$ e $\boldsymbol{a}_{1}$ engloba o valor de $a_{0}$ mais a estimativa do valor da pré trinca $(1,5 \mathrm{~mm})$.

Com esses valores calculados, a carga selecionada para os corpos de prova dos materiais dos eixos rotores (DIN 34CrNiMo 6 e DIN 42CrMo4) foi de 15,0 kN 
e de $11,0 \mathrm{kN}$ para os corpos de prova dos aços 4140 e 4340, para que a pré trinca de fadiga atinja o valor de 1,5 mm, utilizando o menor valor de Pmáx, evitando assim que a magnitude da zona plástica formada a frente da ponta da trinca impedisse a propagação da mesma.

Para levantamento das curvas $\mathrm{d} a / \mathrm{dN}$ versus $\Delta \mathrm{K}$ dos aços estudados,

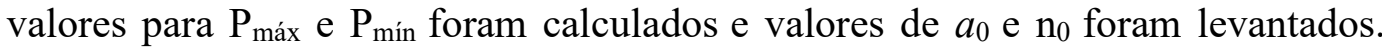
Após entre 5000 ciclos e 10000 ciclos com o auxílio do microscópio óptico observou-se quanto valeu $a_{\mathrm{f}}$ (fig. e com esse valor verificou-se também $\mathrm{n}_{\mathrm{f}}$ (fig.47).

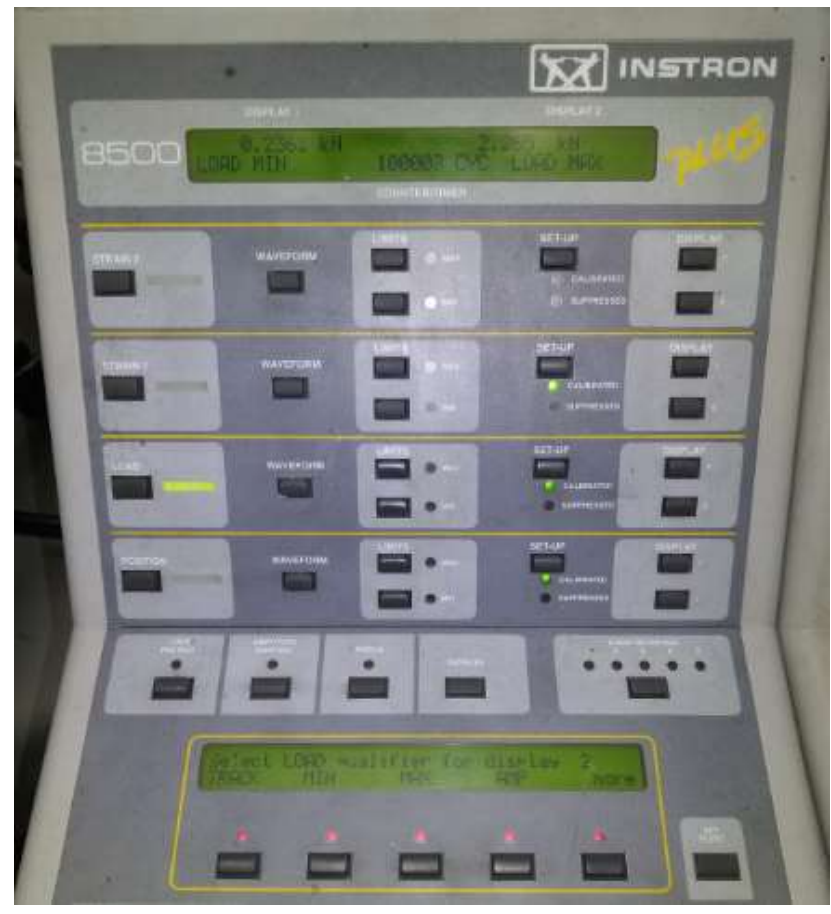

Figura 47: Display da Máquina Servo-Hidráulica da Instron indicando a carga máxima, carga mínima e número de ciclos realizados.

Esse procedimento deve ser repetido até a situação em que $\mathrm{d} a / \mathrm{dN}=0$ e com isso o valor de $\Delta \mathrm{K}$ foi calculado. A norma (ASTM A647) indica que $10^{5}$ ciclos na amostra devem ser feitos e caso não haja incremento no valor da trinca, este $\Delta \mathrm{K}$ calculado vem a ser o $\Delta \mathrm{K}_{\text {th }}$.

Caso a trinca aumente de tamanho nesse intervalo, a carga deve ser diminuída e observa-se se nessa nova situação não houve incremento no tamanho da mesma. As tabelas de 7 a 10 indicam o procedimento adotado para os diferentes aços estudados e as figuras 48 a 51 mostram as curvas $\mathrm{d} a / \mathrm{dN}$ versus $\Delta \mathrm{K}$ desses materiais. 
Tabela 7: Valores obtidos para levantamento da curva $\mathrm{d} a / \mathrm{dN}$ versus $\Delta \mathrm{K}$ para o aço SAE 4340

\begin{tabular}{|c|c|c|c|c|c|c|c|c|c|c|}
\hline & $P_{\text {máx }}(N)$ & $P_{\min }(\mathbf{N})$ & $\mathbf{N}_{\mathrm{i}}$ & $N_{f}$ & $a_{0}(\mathrm{~mm})$ & $a_{f}(m m)$ & $\Delta \mathrm{K}(\mathrm{MPa} \mathrm{Vm})$ & delta $\mathrm{N}$ & delta a & da / dn \\
\hline \multirow{19}{*}{ SAE 4340} & 13530 & 1480 & 0 & 8600 & 1,60 & 2,35 & 28,8695273 & 8600 & 0,75 & $8,72 \mathrm{E}-05$ \\
\hline & 12140 & 1190 & 23960 & 33063 & 2,35 & 3,4 & 27,60775953 & 9103 & 1,05 & 0,000115 \\
\hline & 10980 & 1160 & 33300 & 38367 & 3,40 & 4 & 26,54198374 & 5067 & 0,6 & 0,000118 \\
\hline & 9800 & 950 & 38630 & 43450 & 4,00 & 4,5 & 24,872455 & 4820 & 0,5 & 0,000104 \\
\hline & 8290 & 760 & 0 & 6850 & 4,5 & 5,1 & 21,85681791 & 6850 & 0,6 & $8,76 \mathrm{E}-05$ \\
\hline & 7160 & 720 & 0 & 6000 & 5,2 & 5,3 & 19,5525157 & 6000 & 0,1 & $1,67 \mathrm{E}-05$ \\
\hline & 6252 & 610 & 6400 & 12500 & 5,3 & 5,45 & 17,23989204 & 6100 & 0,15 & $2,46 \mathrm{E}-05$ \\
\hline & 5617 & 554 & 12920 & 17560 & 5,45 & 5,65 & 15,62017449 & 4640 & 0,2 & $4,31 \mathrm{E}-05$ \\
\hline & 5015 & 525 & 17800 & 25000 & 5,65 & 5,8 & 14,03115321 & 7200 & 0,15 & $2,08 \mathrm{E}-05$ \\
\hline & 4493 & 465 & 25740 & 35730 & 5,8 & 6 & 12,70909917 & 9990 & 0,2 & $2 \mathrm{E}-05$ \\
\hline & 4015 & 392 & 36100 & 45000 & 6 & 6,1 & 11,57892791 & 8900 & 0,1 & $1,12 \mathrm{E}-05$ \\
\hline & 3562 & 360 & 45190 & 55145 & 6,1 & 6,2 & 10,29937479 & 9955 & 0,1 & $1 \mathrm{E}-05$ \\
\hline & 3225 & 338 & 0 & 6482 & 6,2 & 6,3 & 9,346039884 & 6482 & 0,1 & $1,54 \mathrm{E}-05$ \\
\hline & 3065 & 298 & 6655 & 13721 & 6,3 & 6,4 & 9,015366157 & 7066 & 0,1 & $1,42 \mathrm{E}-05$ \\
\hline & 2580 & 246 & 14050 & 21405 & 6,4 & 6,45 & 7,653687775 & 7355 & 0,05 & $6,8 \mathrm{E}-06$ \\
\hline & 2530 & 251 & 0 & 9800 & 6,5 & 6,5 & 7,521638685 & 9800 & 0 & 0 \\
\hline & 2483 & 252 & 0 & 45494 & 6,5 & 6,8 & 7,363218915 & 45494 & 0,3 & $6,59 \mathrm{E}-06$ \\
\hline & 2272 & 228 & 0 & 100007 & 6,8 & 6,8 & 6,877994427 & 100007 & 0 & 0 \\
\hline & 2385 & 240 & 0 & 100000 & 6,8 & 6,8 & 7,217856187 & 100000 & 0 & 0 \\
\hline
\end{tabular}

Ao relacionar a coluna $\Delta \mathrm{K}$ desta tabela com a $\mathrm{d} a / \mathrm{dN}$, a curva de propagação de trincas de fadiga do material é levantada, conforme observado na figura 48:

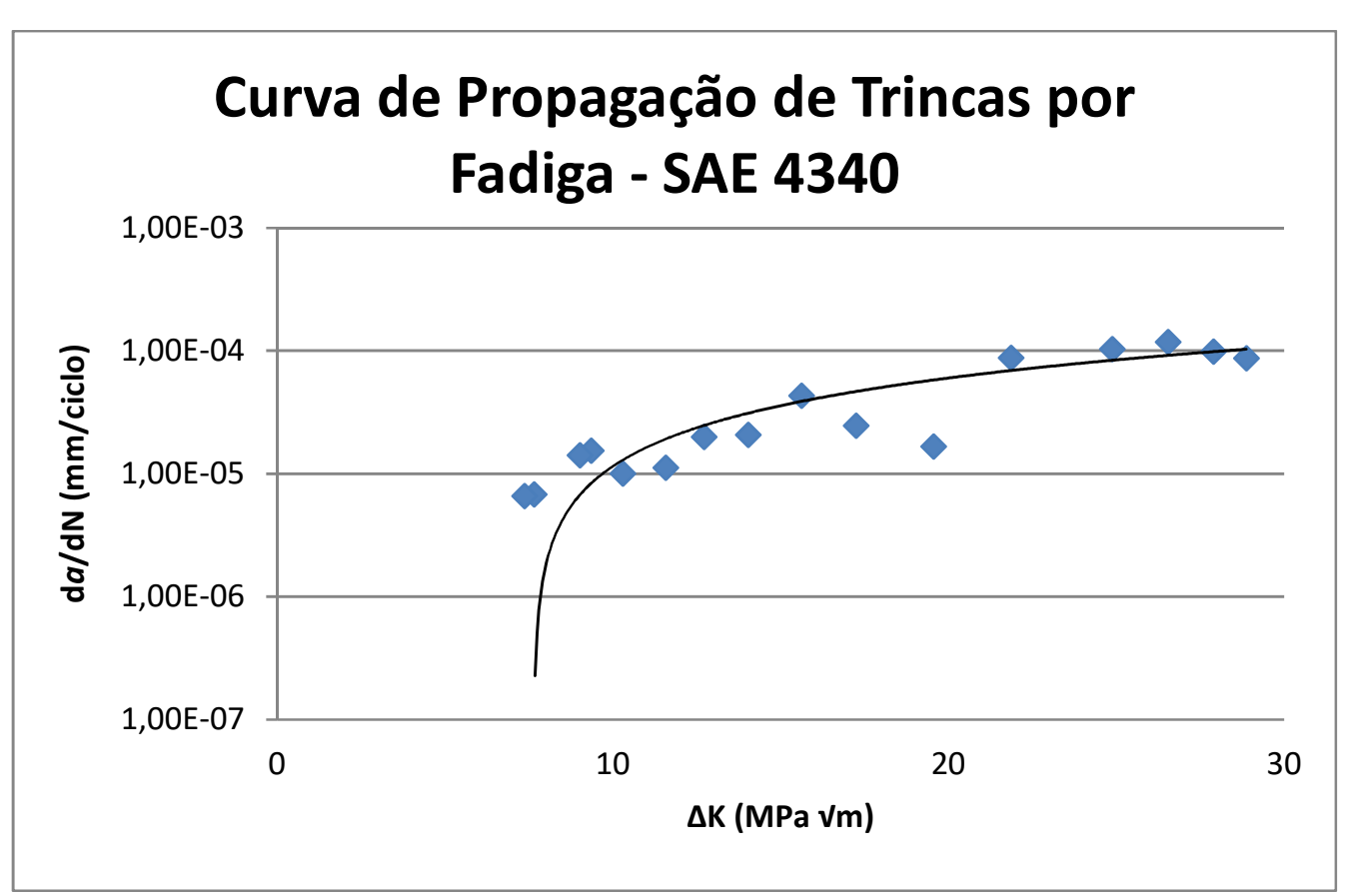

Figura 48: Curva da/dN versus $\Delta \mathrm{K}$ do $\mathrm{SAE} 4340$. 
Tabela 8: Valores obtidos para levantamento da curva $\mathrm{d} a / \mathrm{dN}$ versus $\Delta \mathrm{K}$ para o aço SAE 4140

\begin{tabular}{|c|c|c|c|c|c|c|c|c|c|c|}
\hline & $P_{\text {máx }}(\mathrm{N})$ & $P_{\min }(\mathrm{N})$ & $\overline{N_{i}}$ & $N_{f}$ & $a_{0}(m m)$ & $a_{f}(m m)$ & $\Delta \mathrm{K}(\mathrm{MPa} \mathrm{Vm})$ & delta $\mathbf{N}$ & delta a & $\mathrm{da} / \mathrm{dn}$ \\
\hline \multirow{13}{*}{ SAE 4140} & 13650 & 1353 & 19000 & 26340 & 1,3 & 2 & 28,85432967 & 7340 & 0,7 & $9,54 \mathrm{E}-05$ \\
\hline & 12210 & 1224 & 27730 & 33820 & 2 & 2,5 & 27,05112145 & 6090 & 0,5 & $8,21 \mathrm{E}-05$ \\
\hline & 10980 & 1098 & 34460 & 40050 & 2,5 & 2,8 & 25,16686725 & 5590 & 0,3 & $5,37 \mathrm{E}-05$ \\
\hline & 9830 & 988 & 41030 & 49520 & 2,8 & 3,15 & 22,97273746 & 8490 & 0,35 & $4,12 \mathrm{E}-05$ \\
\hline & 8975 & 872 & 50140 & 58132 & 3,15 & 3,5 & 21,54500975 & 7992 & 0,35 & $4,38 \mathrm{E}-05$ \\
\hline & 8084 & 810 & 59977 & 70015 & 3,5 & 4 & 19,78943188 & 10038 & 0,5 & $4,98 \mathrm{E}-05$ \\
\hline & 7275 & 723 & 70450 & 77405 & 4 & 4,15 & 18,41404804 & 6955 & 0,15 & $2,16 \mathrm{E}-05$ \\
\hline & 6565 & 659 & 78130 & 85702 & 4,15 & 4,25 & 16,7603286 & 7572 & 0,1 & $1,32 \mathrm{E}-05$ \\
\hline & 5843 & 591 & 86110 & 92860 & 4,25 & 4,3 & 15,00094038 & 6750 & 0,05 & $7,41 \mathrm{E}-06$ \\
\hline & 5350 & 534 & 93245 & 98950 & 4,3 & 4,35 & 13,80007216 & 5705 & 0,05 & $8,76 \mathrm{E}-06$ \\
\hline & 4832 & 484 & 0 & 31375 & 4,4 & 4,5 & 12,53961945 & 31375 & 0,1 & $3,19 E-06$ \\
\hline & 4350 & 440 & 32075 & 132080 & 4,5 & 4,5 & 11,34929057 & 100005 & 0 & 0 \\
\hline & 4735 & 470 & 132400 & 232500 & 4,5 & 4,5 & 12,37972488 & 100100 & 0 & 0 \\
\hline
\end{tabular}

\section{Curva de Propagação de Trincas por Fadiga - SAE 4140}

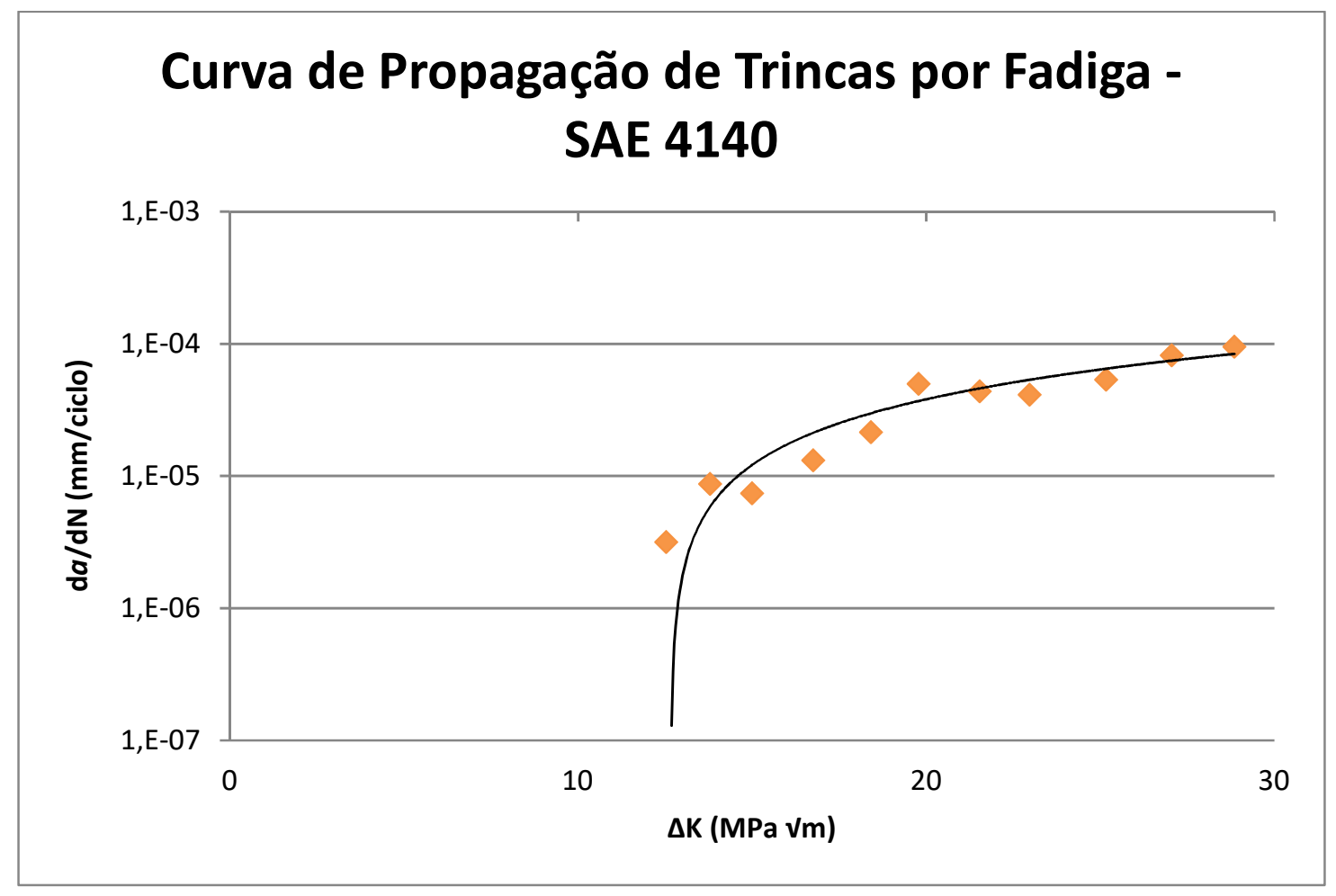

Figura 49: Curva $\mathrm{d} a / \mathrm{dN}$ versus $\Delta \mathrm{K}$ do $\mathrm{SAE} 4140$.

Tabela 9: Valores obtidos para levantamento da curva $\mathrm{d} a / \mathrm{dN}$ versus $\Delta \mathrm{K}$ para o aço DIN $42 \mathrm{CrMo} 4$.

\begin{tabular}{|c|c|c|c|c|c|c|c|c|c|c|}
\hline & $P_{\text {máx }}(N)$ & $P_{\min }(N)$ & $\mathrm{N}_{\mathrm{i}}$ & $N_{f}$ & $a_{0}(\mathrm{~mm})$ & $a_{f}(\mathrm{~mm})$ & $\Delta \mathrm{K}(\mathrm{MPa} \mathrm{V} \mathrm{m})$ & delta $\mathbf{N}$ & delta a & $\mathrm{da} / \mathrm{dn}$ \\
\hline \multirow{14}{*}{ DIN 42CRMO4 } & 19200 & 1890 & 5600 & 12290 & 1,3 & 1,75 & 28,53750718 & 6690 & 0,45 & $6,73 \mathrm{E}-05$ \\
\hline & 17300 & 1795 & 12500 & 19015 & 1,75 & 2 & 26,85590998 & 6515 & 0,25 & $3,84 \mathrm{E}-05$ \\
\hline & 15730 & 1563 & 20080 & 26990 & 2 & 2,25 & 24,96080307 & 6910 & 0,25 & $3,62 \mathrm{E}-05$ \\
\hline & 13900 & 1374 & 28130 & 34560 & 2,25 & 2,4 & 22,4461411 & 6430 & 0,15 & $2,33 \mathrm{E}-05$ \\
\hline & 12580 & 1247 & 35550 & 42012 & 2,4 & 2,6 & 20,51421363 & 6462 & 0,2 & $3,1 \mathrm{E}-05$ \\
\hline & 11210 & 1213 & 0 & 6380 & 2,6 & 2,75 & 18,3395949 & 6380 & 0,15 & $2,35 \mathrm{E}-05$ \\
\hline & 10080 & 1012 & 6788 & 14026 & 2,75 & 2,95 & 16,80224757 & 7238 & 0,2 & $2,76 \mathrm{E}-05$ \\
\hline & 9094 & 908 & 14780 & 19220 & 2,95 & 3,1 & 15,37028087 & 4440 & 0,15 & $3,38 \mathrm{E}-05$ \\
\hline & 8280 & 810 & 19880 & 26950 & 3,1 & 3,3 & 14,16535695 & 7070 & 0,2 & $2,83 \mathrm{E}-05$ \\
\hline & 7434 & 743 & 27450 & 34290 & 3,3 & 3,5 & 12,8559461 & 6840 & 0,2 & $2,92 \mathrm{E}-05$ \\
\hline & 7000 & 710 & 0 & 6100 & 3,5 & 3,6 & 12,2446297 & 6100 & 0,1 & $1,64 \mathrm{E}-05$ \\
\hline & 6570 & 650 & 6700 & 54200 & 3,7 & 4 & 11,67554165 & 47500 & 0,3 & $6,32 \mathrm{E}-06$ \\
\hline & 5806 & 584 & 0 & 100000 & 4 & 4 & 10,50140072 & 100000 & 0 & 0 \\
\hline & 6000 & 598 & 0 & 100000 & 4 & 4 & 10,8633793 & 100000 & 0 & 0 \\
\hline
\end{tabular}




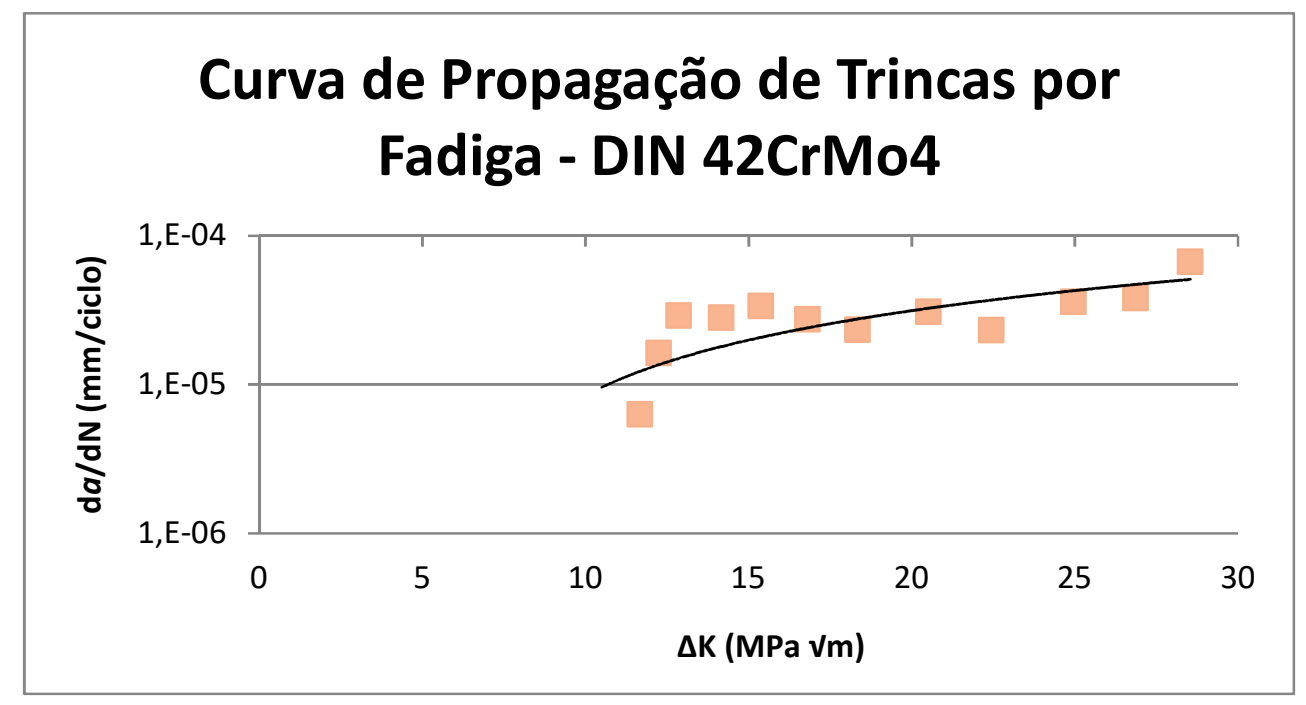

Figura 50: Curva da/dN versus $\Delta \mathrm{K}$ do DIN $42 \mathrm{CrMo} 4$.

Tabela 10: Valores obtidos para levantamento da curva $\mathrm{d} a / \mathrm{dN}$ versus $\Delta \mathrm{K}$ para o aço DIN 34CrNiMo6

\begin{tabular}{|c|c|c|c|c|c|c|c|c|c|c|}
\hline & $P_{\text {máx }}(\mathrm{N})$ & $P_{\min }(\mathrm{N})$ & $\overline{N_{i}}$ & $\mathbf{N}_{\mathrm{f}}$ & $a_{0}(\mathrm{~mm})$ & $a_{f}(m m)$ & $\Delta \mathrm{K}(\mathrm{MPa} \mathrm{Vm})$ & delta N & $\overline{\text { delta a }}$ & da / dn \\
\hline \multirow{20}{*}{ DIN 34CrNiMo6 } & 20120 & 1998 & 0 & 9000 & 1,6 & 2,5 & 31,0666005 & 9000 & 0,9 & 0,0001 \\
\hline & 18450 & 1890 & 0 & 6250 & 2,6 & 3,3 & \begin{tabular}{|l|}
29,33588874 \\
\end{tabular} & 6250 & 0,7 & 0,000112 \\
\hline & 16790 & 1653 & 7160 & 14380 & 3,3 & 3,95 & 27,84311621 & 7220 & 0,65 & $9 \mathrm{E}-05$ \\
\hline & 15200 & 1517 & 14980 & 20056 & 3,95 & 4,55 & \begin{tabular}{|l|}
26,04970148 \\
\end{tabular} & 5076 & 0,6 & 0,000118 \\
\hline & 13290 & 1355 & 20280 & 26090 & 4,55 & 5,1 & 23,44670351 & 5810 & 0,55 & $9,47 \mathrm{E}-05$ \\
\hline & 11790 & 1147 & 26580 & 33160 & 5,1 & 5,55 & \begin{tabular}{|l|}
21,51407991 \\
\end{tabular} & 6580 & 0,45 & $6,84 \mathrm{E}-05$ \\
\hline & 10550 & 1047 & 33540 & 39190 & 5,55 & 6 & \begin{tabular}{|l|}
19,66118576 \\
\end{tabular} & 5650 & 0,45 & $7,96 \mathrm{E}-05$ \\
\hline & 9441 & 945 & 39480 & 46070 & 6 & 6,45 & \begin{tabular}{|l|}
17,98948878 \\
\end{tabular} & 6590 & 0,45 & $6,83 \mathrm{E}-05$ \\
\hline & 8345 & 830 & 0 & 9300 & 6,45 & 6,8 & 16,28421079 & 9300 & 0,35 & $3,76 \mathrm{E}-05$ \\
\hline & 7500 & 743 & 9500 & 16000 & 6,8 & 7,1 & 14,9069373 & 6500 & 0,3 & $4,62 \mathrm{E}-05$ \\
\hline & 6750 & 685 & 16600 & 23780 & 7,1 & 7,45 & \begin{tabular}{|l|}
13,58777447 \\
\end{tabular} & 7180 & 0,35 & $4,87 \mathrm{E}-05$ \\
\hline & 6095 & 609 & 24060 & 30070 & 7,45 & 7,75 & \begin{tabular}{|l|}
12,51340311 \\
\end{tabular} & 6010 & 0,3 & $4,99 \mathrm{E}-05$ \\
\hline & 5475 & 558 & 30560 & 36000 & 7,75 & 8,05 & \begin{tabular}{|l|}
11,38979834 \\
\end{tabular} & 5440 & 0,3 & $5,51 \mathrm{E}-05$ \\
\hline & 4937 & 496 & 36340 & 42000 & 8,05 & 8,3 & \begin{tabular}{|l|}
10,44731336 \\
\end{tabular} & 5660 & 0,25 & $4,42 \mathrm{E}-05$ \\
\hline & 4499 & 444 & 42250 & 48733 & 8,3 & 8,55 & \begin{tabular}{|l|}
9,663097275 \\
\end{tabular} & 6483 & 0,25 & $3,86 \mathrm{E}-05$ \\
\hline & 3954 & 393 & 49150 & 56000 & 8,55 & 8,7 & \begin{tabular}{|l|}
8,596306414 \\
\end{tabular} & 6850 & 0,15 & $2,19 \mathrm{E}-05$ \\
\hline & 3614 & 363 & 0 & 7085 & 8,7 & 8,75 & \begin{tabular}{|c|}
7,909199404 \\
\end{tabular} & 7085 & 0,05 & $7,06 \mathrm{E}-06$ \\
\hline & 3245 & 325 & 7690 & 15000 & 8,75 & 8,8 & \begin{tabular}{|l|l|}
722375791 \\
\end{tabular} & 7310 & 0,05 & $6,84 \mathrm{E}-06$ \\
\hline & 2920 & 302 & 16000 & 116010 & 8,8 & 8,8 & 6,402341141 & 100010 & 0 & 0 \\
\hline & 3002 & 301 & 0 & 100000 & 8,8 & 8,8 & 6,605318343 & 100000 & 0 & 0 \\
\hline
\end{tabular}

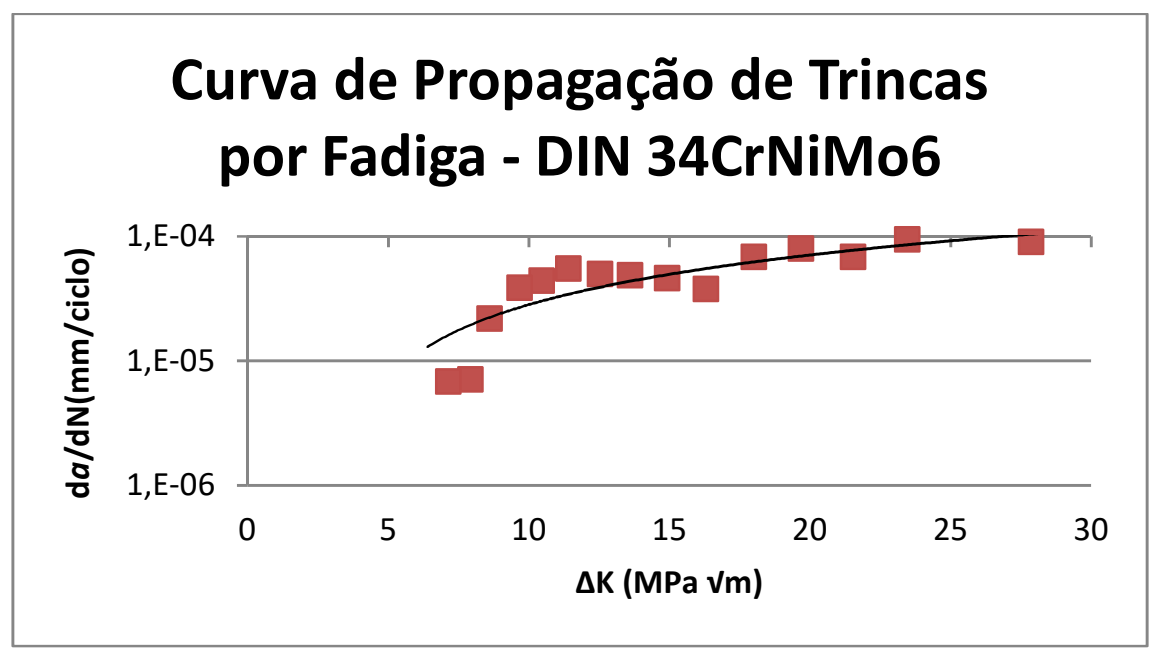

Figura 51: Curva $\mathrm{d} a / \mathrm{dN}$ versus $\Delta \mathrm{K}$ do DIN 34CrNiMo6. 
É importante frisar que as curvas levantadas para os aços estruturais (figs. 48 a 51) englobam as fases 1 e 2 da curva de propagação de trincas por fadiga, onde $\Delta \mathrm{K}_{\text {th }}$ é a fronteira entre as fases (fig.52).

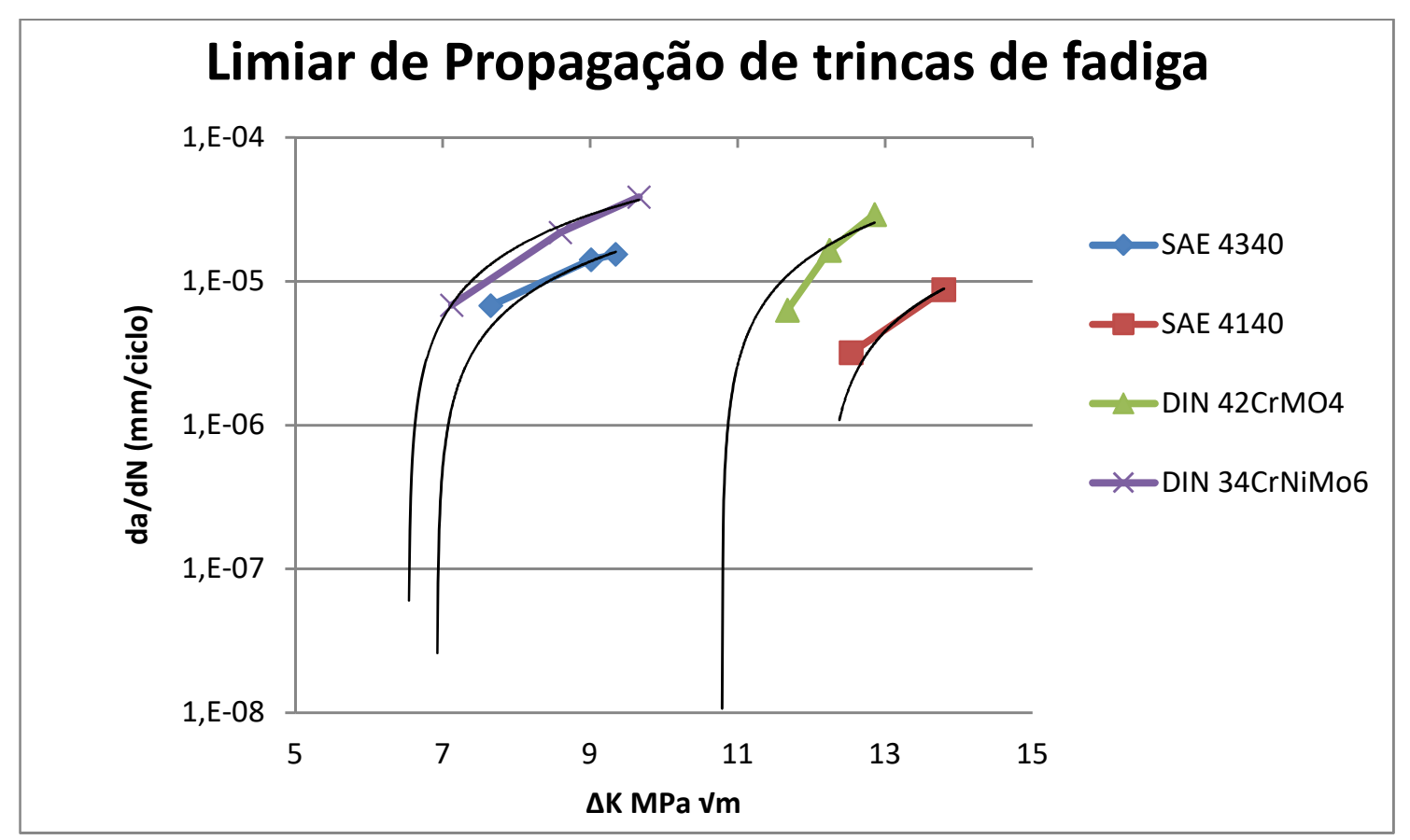

Figura 52: Limiar de propagação de trincas de fadiga dos quatro aços estruturais estudados.

A fim de obter um valor mais "acurado" para o threshold dos prováveis aços estruturais que possam vir a substituir o DIN 34CrNiMo6, mais ensaios de propagação de trincas por fadiga foram realizados, com os resultados mostrados nas tabelas de 11 a 13 . Já as curvas $\mathrm{d} a / \mathrm{dN}$ versus $\Delta \mathrm{K}$ desses materiais encontramse nas figuras 53 a 55 .

Vale ressaltar que nesses novos ensaios, a cada novo ciclo a carga máxima foi reduzida em cerca de 5\%. A redução ocorreu até o ponto em que não houve incremento no tamanho da trinca, quando $10^{5}$ ciclos foram realizados. Atingindo esse valor as cargas máximas e mínimas foram fixadas e a cada 10000 ciclos observou-se o quanto a trinca aumentou de tamanho. 
Tabela 11: Novos valores obtidos para levantamento da curva $\mathrm{d} a / \mathrm{dN}$ versus $\Delta \mathrm{K}$ para o aço SAE 4140

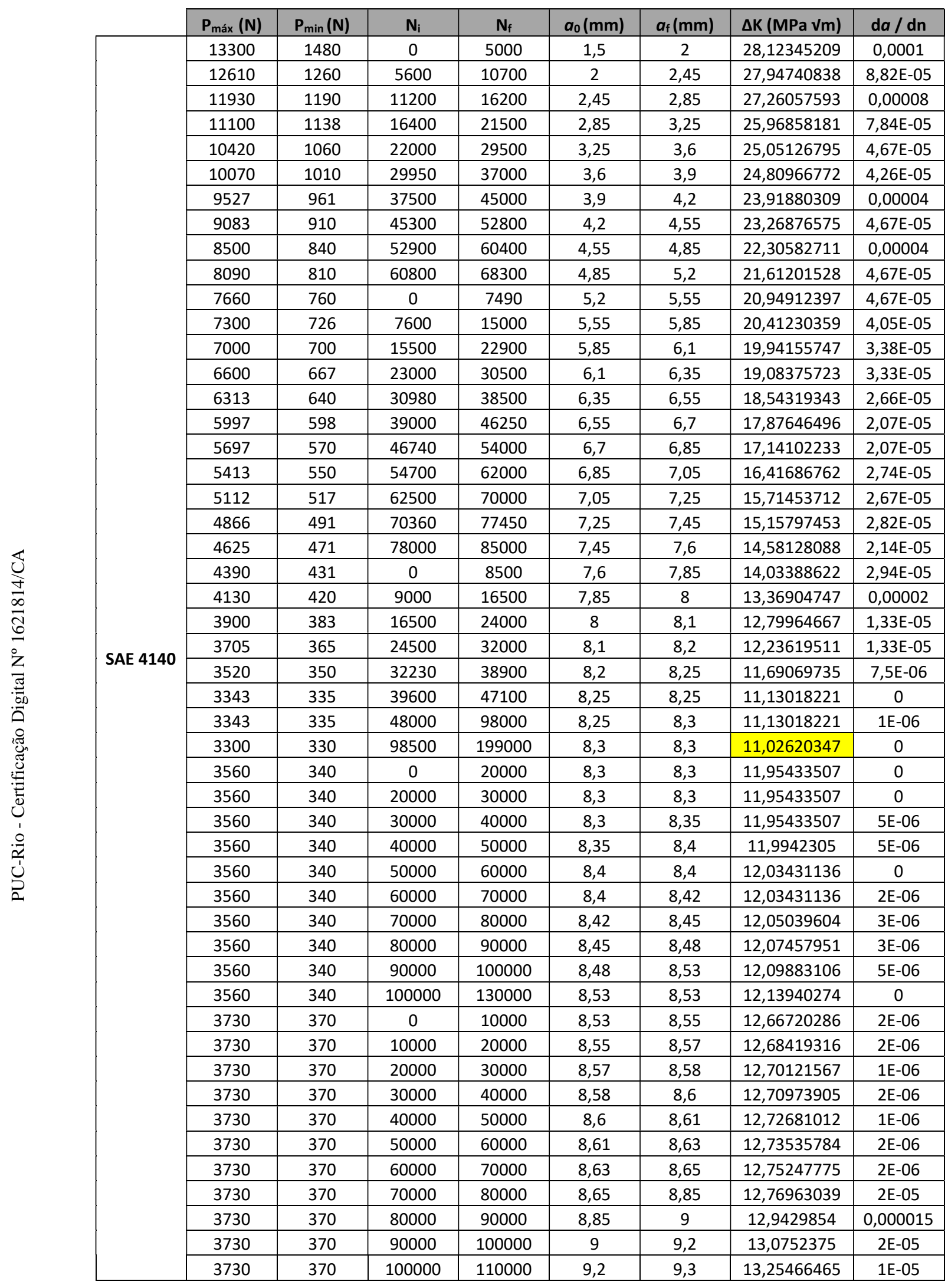




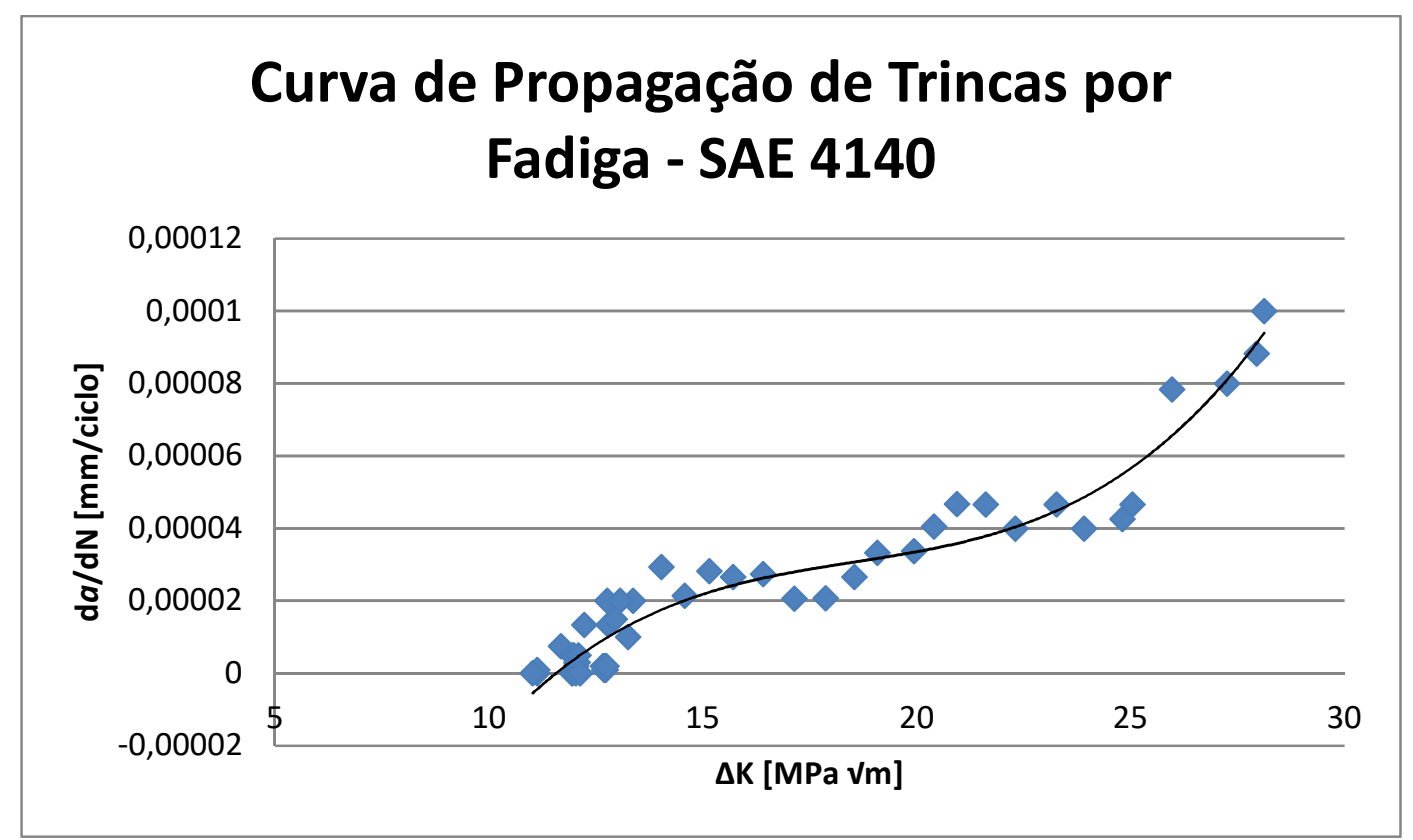

Figura 53: Nova curva da/dN versus $\Delta \mathrm{K}$ SAE 4140.

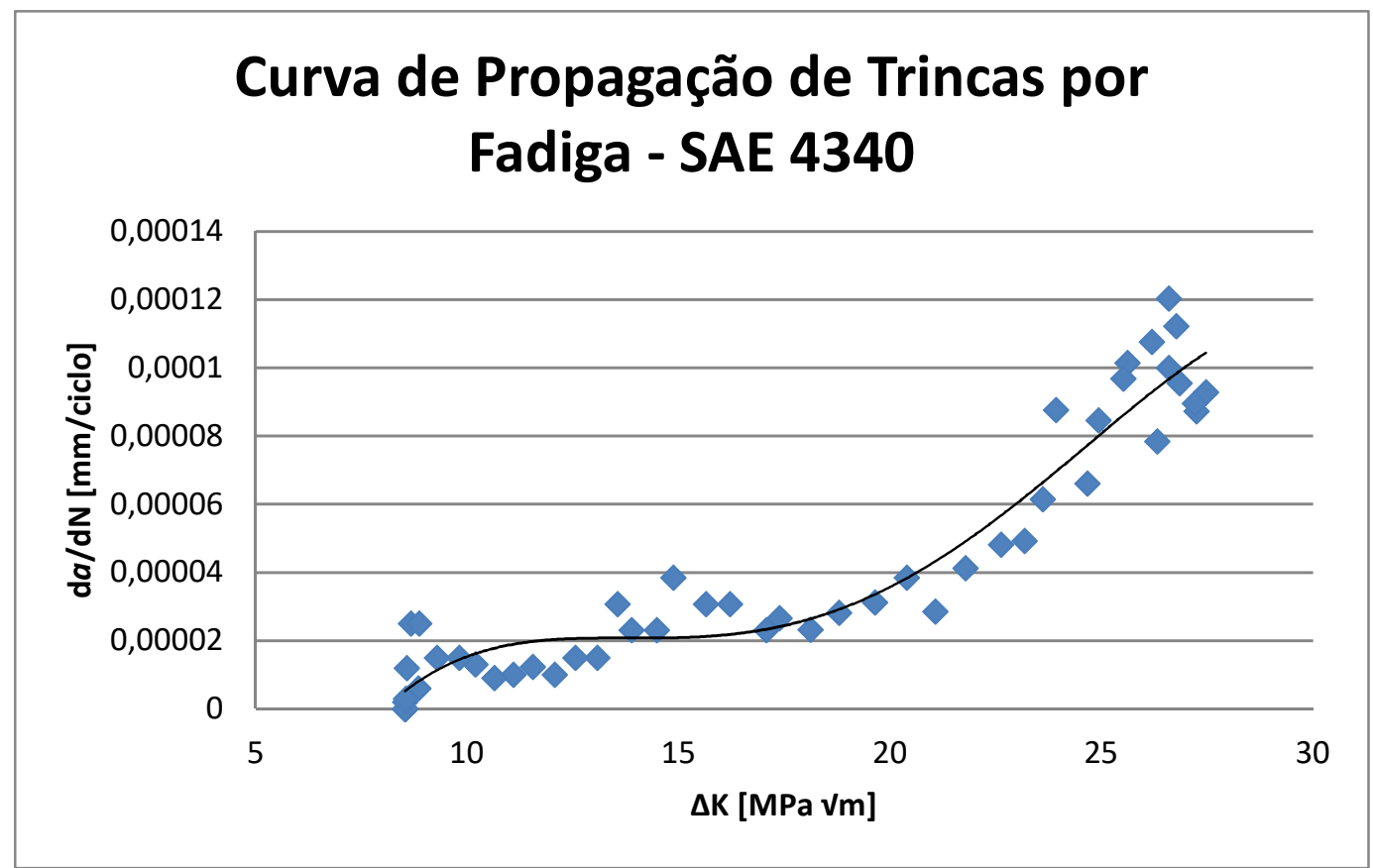

Figura 54: Nova curva da/dN versus $\Delta \mathrm{K}$ SAE 4340. 
Tabela 12: Novos valores obtidos para levantamento da curva $\mathrm{d} a / \mathrm{dN}$ versus $\Delta \mathrm{K}$ para o aço SAE 4340

\begin{tabular}{|c|c|c|c|c|c|c|c|c|}
\hline & $P_{\text {máx }}(\mathrm{N})$ & $P_{\min }(\mathrm{N})$ & $N_{i}$ & $\mathbf{N}_{\mathrm{f}}$ & $a_{0}(\mathrm{~mm})$ & $a_{\mathrm{f}}(\mathrm{mm})$ & $\Delta K(\mathrm{MPa} V \mathrm{~m})$ & $\mathrm{da} / \mathrm{dn}$ \\
\hline \multirow{50}{*}{ SAE 4340} & 13100 & 1410 & 0 & 5723 & 1,20 & 1,7 & 27,23878453 & 8,73668E-05 \\
\hline & 12630 & 1246 & 6000 & 13000 & 1,70 & 2,35 & 27,46232772 & 9,28571E-05 \\
\hline & 12000 & 1210 & 13500 & 20200 & 2,35 & 2,95 & 27,20435848 & $8,95522 \mathrm{E}-05$ \\
\hline & 11400 & 1170 & 20600 & 27400 & 2,95 & 3,6 & 26,84421551 & 9,55882E-05 \\
\hline & 10790 & 1080 & 27600 & 33000 & 3,60 & 4,25 & 26,58961077 & 0,00012037 \\
\hline & 10400 & 1030 & 33000 & 39500 & 4,25 & 4,98 & 26,76291153 & 0,000112308 \\
\hline & 9850 & 970 & 40000 & 46500 & 4,98 & 5,63 & 26,58281375 & $1 \mathrm{E}-04$ \\
\hline & 9330 & 940 & 46500 & 53000 & 5,63 & 6,33 & 26,18496546 & 0,000107692 \\
\hline & 8900 & 840 & 53000 & 59500 & 6,33 & 6,84 & 26,31162687 & 7,84615E-05 \\
\hline & 8420 & 830 & 60000 & 66500 & 6,84 & 7,5 & 25,60629292 & 0,000101538 \\
\hline & 8050 & 805 & 67000 & 73500 & 7,50 & 8,13 & 25,51451415 & 9,69231E-05 \\
\hline & 7550 & 760 & 74100 & 80600 & 8,13 & 8,68 & 24,92489467 & 8,46154E-05 \\
\hline & 7190 & 715 & 80700 & 87200 & 8,68 & 9,11 & 24,65784253 & $6,61538 \mathrm{E}-05$ \\
\hline & 6770 & 670 & 88000 & 94500 & 9,11 & 9,68 & 23,91613522 & 8,76923E-05 \\
\hline & 6440 & 650 & 94800 & 101300 & 9,68 & 10,08 & 23,60892416 & $6,15385 \mathrm{E}-05$ \\
\hline & 6155 & 628 & 0 & 6500 & 10,08 & 10,4 & 23,17670074 & $4,92308 \mathrm{E}-05$ \\
\hline & 5852 & 580 & 6780 & 13000 & 10,40 & 10,7 & 22,61548993 & $4,82315 \mathrm{E}-05$ \\
\hline & 5521 & 553 & 13350 & 19400 & 10,70 & 10,95 & 21,77621879 & 4,13223E-05 \\
\hline & 5242 & 522 & 19500 & 26500 & 10,95 & 11,15 & 21,06901871 & $2,85714 \mathrm{E}-05$ \\
\hline & 4987 & 485 & 27000 & 33500 & 11,15 & 11,4 & 20,39354175 & $3,84615 \mathrm{E}-05$ \\
\hline & 4735 & 480 & 34500 & 42500 & 11,40 & 11,65 & 19,63590365 & 0,00003125 \\
\hline & 4461 & 465 & 42900 & 50000 & 11,65 & 11,85 & 18,79044895 & $2,8169 \mathrm{E}-05$ \\
\hline & 4213 & 418 & 50400 & 56870 & 11,85 & 12 & 18,11856473 & 2,31839E-05 \\
\hline & 4000 & 400 & 57000 & 64500 & 12,00 & 12,2 & 17,38634154 & 2,66667E-05 \\
\hline & 3860 & 380 & \begin{tabular}{|l|}
64700 \\
\end{tabular} & 71200 & 12,20 & 12,35 & 17,06879534 & $2,30769 \mathrm{E}-05$ \\
\hline & 3630 & 363 & \begin{tabular}{|l|}
71700 \\
\end{tabular} & 78200 & 12,35 & 12,55 & 16,21276706 & $3,07692 \mathrm{E}-05$ \\
\hline & 3450 & 347 & \begin{tabular}{|l|}
78600 \\
\end{tabular} & 85100 & 12,55 & 12,75 & 15,64342976 & $3,07692 \mathrm{E}-05$ \\
\hline & 3230 & 327 & 85600 & 92100 & 12,75 & 13 & 14,87008606 & $3,84615 \mathrm{E}-05$ \\
\hline & 3070 & 300 & 93000 & 99500 & 13,00 & 13,15 & 14,47768322 & 2,30769E-05 \\
\hline & 2920 & 295 & 99900 & 106400 & 13,15 & 13,3 & 13,88862901 & $2,30769 \mathrm{E}-05$ \\
\hline & 2800 & 270 & \begin{tabular}{|l|}
107000 \\
\end{tabular} & 113500 & 13,30 & 13,5 & 13,55210726 & $3,07692 \mathrm{E}-05$ \\
\hline & 2660 & 260 & 0 & 10000 & 13,50 & 13,65 & 13,07108442 & 0,000015 \\
\hline & 2527 & 250 & 10000 & 20000 & 13,65 & 13,8 & 12,55826225 & 0,000015 \\
\hline & 2400 & 240 & 20000 & 30000 & 13,80 & 13,9 & 12,06521762 & $1 \mathrm{E}-05$ \\
\hline & 2280 & 230 & 30000 & 40500 & 13,90 & 14,03 & 11,54886869 & $1,2381 \mathrm{E}-05$ \\
\hline & 2166 & 220 & 40500 & 50500 & 14,03 & 14,13 & 11,08606444 & $1 \mathrm{E}-05$ \\
\hline & 2058 & 206 & 50500 & 60500 & 14,13 & 14,22 & 10,64220752 & $9 \mathrm{E}-06$ \\
\hline & 1955 & 195 & 60500 & 70500 & 14,22 & 14,35 & 10,19303985 & $1,3 \mathrm{E}-05$ \\
\hline & 1860 & 185 & 70800 & 80800 & 14,35 & 14,5 & 9,81185078 & 0,000015 \\
\hline & 1730 & 167 & 81500 & 91500 & 14,50 & 14,65 & 9,277927148 & 0,000015 \\
\hline & 1630 & 160 & 92800 & 122800 & 14,65 & 14,83 & 8,843410036 & $6 \mathrm{E}-06$ \\
\hline & 1550 & 155 & 123000 & 223000 & 14,83 & 14,83 & 8,529483628 & 0 \\
\hline & 1550 & 155 & 0 & 10000 & 14,83 & 14,83 & 8,529483628 & 0 \\
\hline & 1550 & 155 & 10000 & 20000 & 14,83 & 14,83 & 8,529483628 & 0 \\
\hline & 1550 & 155 & 20000 & 30000 & 14,83 & 14,83 & 8,529483628 & 0 \\
\hline & 1550 & 155 & 30000 & 40000 & 14,83 & 14,85 & 8,529483628 & $2 \mathrm{E}-06$ \\
\hline & 1550 & 155 & 40000 & 50000 & 14,85 & 14,88 & 8,544972501 & $3 \mathrm{E}-06$ \\
\hline & 1550 & 155 & 50000 & 60000 & 14,88 & 15 & 8,568296136 & $1,2 \mathrm{E}-05$ \\
\hline & 1550 & 155 & 60000 & 70000 & 15,00 & 15,25 & 8,662688192 & 0,000025 \\
\hline & 1550 & 155 & 70000 & 80000 & 15,25 & 15,5 & 8,865147254 & 0,000025 \\
\hline
\end{tabular}


Tabela 13: Novos valores obtidos para levantamento da curva $\mathrm{d} a / \mathrm{dN}$ versus $\Delta \mathrm{K}$ para o aço DIN $42 \mathrm{CrMo} 4$

\begin{tabular}{|c|c|c|c|c|c|c|c|c|}
\hline & $P_{\text {máx }}(\mathrm{N})$ & $P_{\min }(\mathrm{N})$ & $N_{i}$ & $N_{f}$ & $a_{0}(\mathrm{~mm})$ & $a_{\mathrm{f}}(\mathrm{mm})$ & $\Delta \mathrm{K}(\mathrm{MPa} \mathrm{Vm})$ & $\mathrm{da} / \mathrm{dn}$ \\
\hline \multirow{50}{*}{ DIN 42CrMo4 } & 18500 & 1850 & 0 & 7500 & 1,45 & 2,15 & 27,68237426 & $9,33 \mathrm{E}-05$ \\
\hline & 17575 & 1757,5 & 7550 & 15050 & 2,15 & 2,7 & 27,34084187 & 7,33E-05 \\
\hline & 16696,25 & 1669,625 & 16000 & 23500 & 2,7 & 3,2 & 26,76407593 & $6,67 \mathrm{E}-05$ \\
\hline & 15861,44 & 1586,144 & 23600 & 31100 & 3,2 & 3,7 & 26,11835389 & $6,67 \mathrm{E}-05$ \\
\hline & 15068,37 & 1506,837 & 31200 & 38700 & 3,7 & 4,15 & 25,4803662 & 0,00006 \\
\hline & 14314,95 & 1431,495 & 38800 & 46300 & 4,15 & 4,6 & 24,7864609 & $6 \mathrm{E}-05$ \\
\hline & 13599,2 & 1359,92 & 46400 & 53900 & 4,6 & 5,1 & 24,1071614 & $6,67 \mathrm{E}-05$ \\
\hline & 12919,24 & 1291,924 & 54000 & 61500 & 5,1 & 5,55 & 23,5038058 & 0,00006 \\
\hline & 12273,28 & 1227,328 & 61600 & 69100 & 5,55 & 6 & 22,85346506 & 0,00006 \\
\hline & 11659,61 & 1165,961 & 69200 & 76700 & 6 & 6,4 & 22,21933227 & $5,33 \mathrm{E}-05$ \\
\hline & 11076,63 & 1107,663 & 76800 & 84300 & 6,4 & 6,85 & 21,54635852 & $6 \mathrm{E}-05$ \\
\hline & 10522,8 & 1052,28 & 84400 & 91900 & 6,85 & 7,3 & 20,94701385 & 0,00006 \\
\hline & 9996,662 & 999,6662 & 92000 & 99500 & 7,3 & 7,75 & 20,36443388 & 0,00006 \\
\hline & 9496,829 & 949,6829 & 99600 & 107100 & 7,75 & 8,15 & 19,79871177 & $5,33 \mathrm{E}-05$ \\
\hline & 9021,987 & 902,1987 & 107200 & 114700 & 8,15 & 8,55 & 19,20029126 & $5,33 \mathrm{E}-05$ \\
\hline & 8570,888 & 857,0888 & 114800 & 122300 & 8,55 & 8,95 & 18,62122428 & $5,33 \mathrm{E}-05$ \\
\hline & 8142,343 & 814,2343 & 122400 & 129900 & 8,95 & 9,35 & 18,06120069 & 5,33E-05 \\
\hline & 7735,226 & 773,5226 & 130000 & 137500 & 9,35 & 9,8 & 17,51988978 & $6 \mathrm{E}-05$ \\
\hline & \begin{tabular}{|l|}
7348,465 \\
\end{tabular} & 734,8465 & 137600 & 145100 & 9,8 & 10,2 & 17,0417652 & $5,33 \mathrm{E}-05$ \\
\hline & 6981,042 & 698,1042 & 145200 & 152700 & 10,2 & 10,6 & 16,5358124 & $5,33 \mathrm{E}-05$ \\
\hline & 6631,99 & 663,199 & 152800 & 160300 & 10,6 & 11 & 16,04755471 & $5,33 \mathrm{E}-05$ \\
\hline & 6300,39 & 630,039 & 160400 & 167900 & 11 & 11,4 & 15,57660668 & $5,33 \mathrm{E}-05$ \\
\hline & 5985,371 & 598,5371 & 168000 & 175500 & 11,4 & 11,75 & 15,12257669 & 4,67E-05 \\
\hline & 5686,102 & 568,6102 & 175600 & 183100 & 11,75 & 12,1 & 14,64466926 & 4,67E-05 \\
\hline & 5401,797 & 540,1797 & 183200 & 190700 & 12,1 & 12,4 & 14,18447867 & $4 \mathrm{E}-05$ \\
\hline & 5131,707 & 513,1707 & 190800 & 198300 & 12,4 & 12,7 & 13,70293744 & $4 \mathrm{E}-05$ \\
\hline & 4875,122 & 487,5122 & 198400 & 205900 & 12,7 & 12,95 & 13,23976935 & $3,33 \mathrm{E}-05$ \\
\hline & 4631,366 & 463,1366 & 206000 & 213500 & 12,95 & 13,15 & 12,75782456 & $2,67 \mathrm{E}-05$ \\
\hline & 4399,797 & 439,9797 & 213600 & 221100 & 13,15 & 13,35 & 12,25955469 & $2,67 \mathrm{E}-05$ \\
\hline & 4179,808 & 417,9808 & 221200 & 228700 & 13,35 & 13,5 & 11,78165372 & 0,00002 \\
\hline & 3970,817 & 397,0817 & 228800 & 236300 & 13,5 & 13,65 & 11,29037694 & 0,00002 \\
\hline & 3772,276 & 377,2276 & 236400 & 243900 & 13,65 & 13,75 & 10,82008108 & $1,33 \mathrm{E}-05$ \\
\hline & 3583,662 & 358,3662 & 244000 & 450000 & 13,75 & 13,8 & 10,33945634 & $2,43 \mathrm{E}-07$ \\
\hline & 3404,479 & 340,4479 & 450100 & 1450100 & 13,8 & 13,8 & 9,851367768 & 0 \\
\hline & 3500 & 350 & 1450200 & 2450200 & 13,8 & 13,8 & 10,12777102 & 0 \\
\hline & 3500 & 350 & 2450300 & 2460300 & 13,8 & 13,8 & 10,12777102 & 0 \\
\hline & 3500 & 350 & 2460400 & 2470400 & 13,8 & 13,9 & 10,12777102 & $1 \mathrm{E}-05$ \\
\hline & 3500 & 350 & 2470500 & 2480500 & 13,9 & 14 & 10,18758552 & $1 \mathrm{E}-05$ \\
\hline & 3500 & 350 & 2480600 & 2490600 & 14 & 14,2 & 10,24797451 & $2 \mathrm{E}-05$ \\
\hline & 3500 & 350 & 2490700 & 2500700 & 14,2 & 14,45 & 10,370513 & 0,000025 \\
\hline & 3500 & 350 & 2500800 & 2510800 & 14,45 & 14,7 & 10,52708533 & 0,000025 \\
\hline & 3500 & 350 & 2510900 & 2520900 & 14,7 & 15 & 10,68757831 & $3 \mathrm{E}-05$ \\
\hline & 3500 & 350 & 2521000 & 2531000 & 15 & 15,3 & 10,88557164 & $3 \mathrm{E}-05$ \\
\hline & 3500 & 350 & 2531100 & 2541100 & 15,3 & 15,7 & 11,0897332 & $4 \mathrm{E}-05$ \\
\hline & 3500 & 350 & 2541200 & 2551200 & 15,7 & 16,15 & 11,37207644 & $4,5 \mathrm{E}-05$ \\
\hline & 3500 & 350 & 2551300 & 2561300 & 16,15 & 16,6 & 11,70444119 & $4,5 \mathrm{E}-05$ \\
\hline & 3500 & 350 & 2561400 & 2571400 & 16,6 & 17 & 12,05355117 & $4 \mathrm{E}-05$ \\
\hline & 3500 & 350 & 2571500 & 2581500 & 17 & 17,5 & 12,37897362 & 0,00005 \\
\hline & 3500 & 350 & 2581600 & 2591600 & 17,5 & 18 & 12,8073036 & 0,00005 \\
\hline & 3500 & 350 & 2591700 & 2601700 & 18 & 18,5 & 13,26154968 & 0,00005 \\
\hline
\end{tabular}




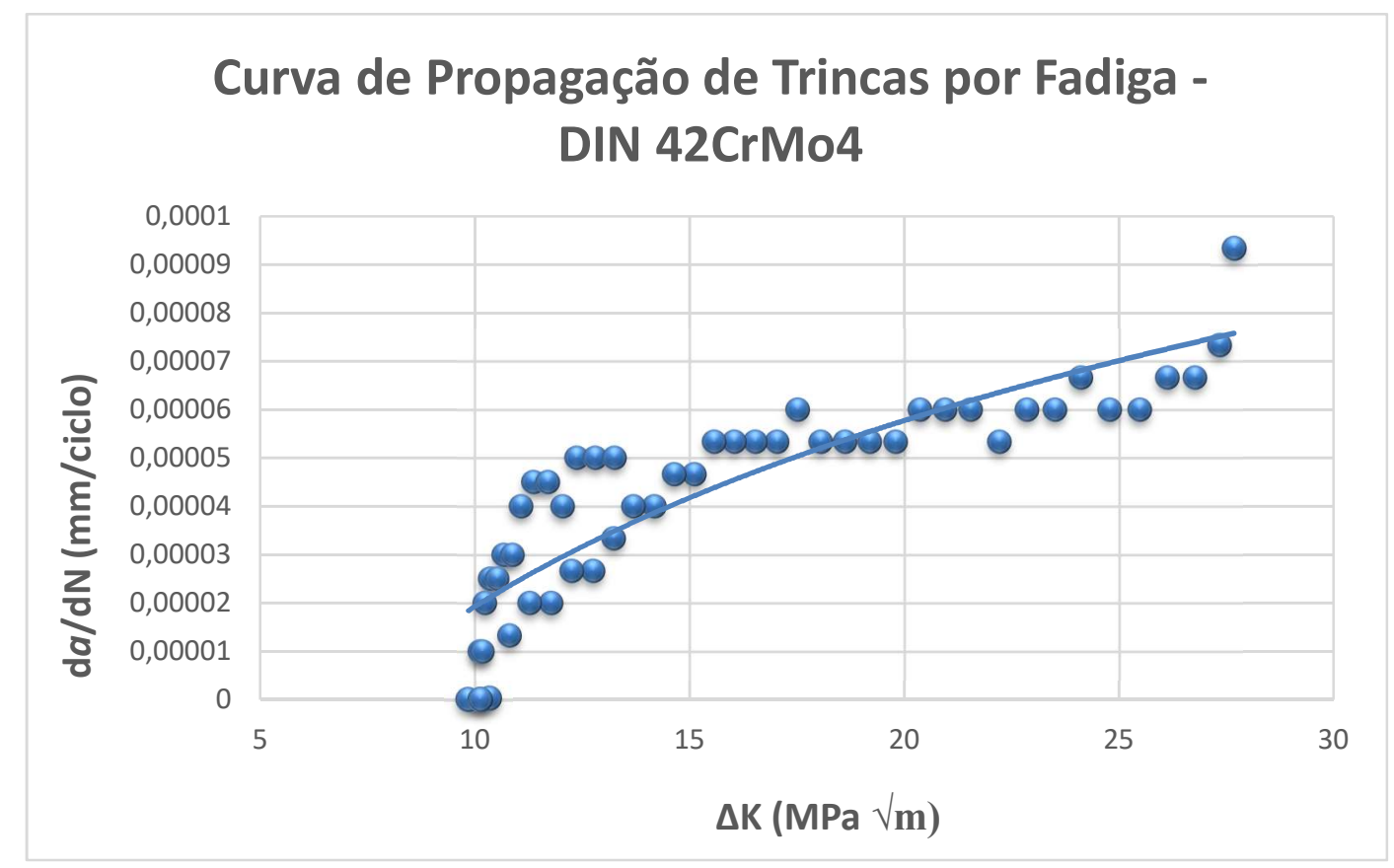

Figura 55: Nova curva $\mathrm{d} a / \mathrm{dN}$ versus $\Delta \mathrm{K}$ DIN $42 \mathrm{CrMo} 4$.

A figura 56 apresenta o valor obtido experimentalmente para o threshold para os quatro aços estruturais estudados.

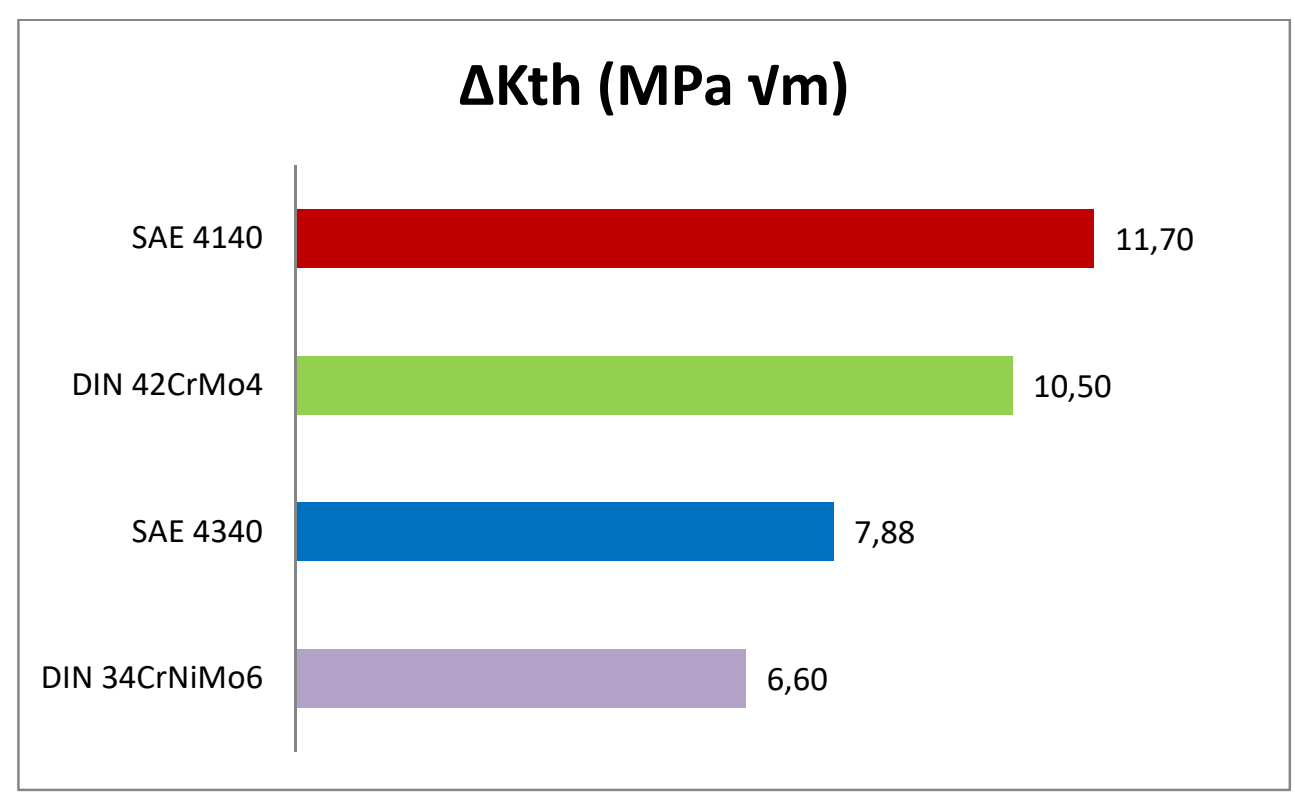

Figura 56: $\Delta \mathrm{K}_{\mathrm{th}}$ dos quatro aços estruturais estudados. 


\subsection{Microscopia}

A fim de facilitar a contagem das inclusões presentes numa área de $1 \mathrm{~mm}^{2}$ foi utilizado o programa de processamento digital de imagens Fiji. Primeiramente, foi feita a segmentação, que significa transformar a imagem obtida na microscopia (tons de cinza) numa imagem binária.

Cada imagem obtida pelo MEV englobou uma área de $200 \times 200 \mu \mathrm{m}^{2}$, sendo assim, para calcular as heterogeneidades metalúrgicas numa área de $1 \mathrm{~mm}^{2}$, um mosaico com 5 imagens de cada tipo de material estudado foi feito.

Essa quantidade de partículas presentes em $1 \mathrm{~mm}^{2}$ serviu de base para comparação dos aspectos metalúrgicos dos diferentes aços estudados e assumiu-se que esse cálculo é representativo para os materiais em sua totalidade.

A primeira imagem da microestrutura do eixo (DIN 34CrNiM06) com uma magnificação de 500x, é mostrada na figura 57:

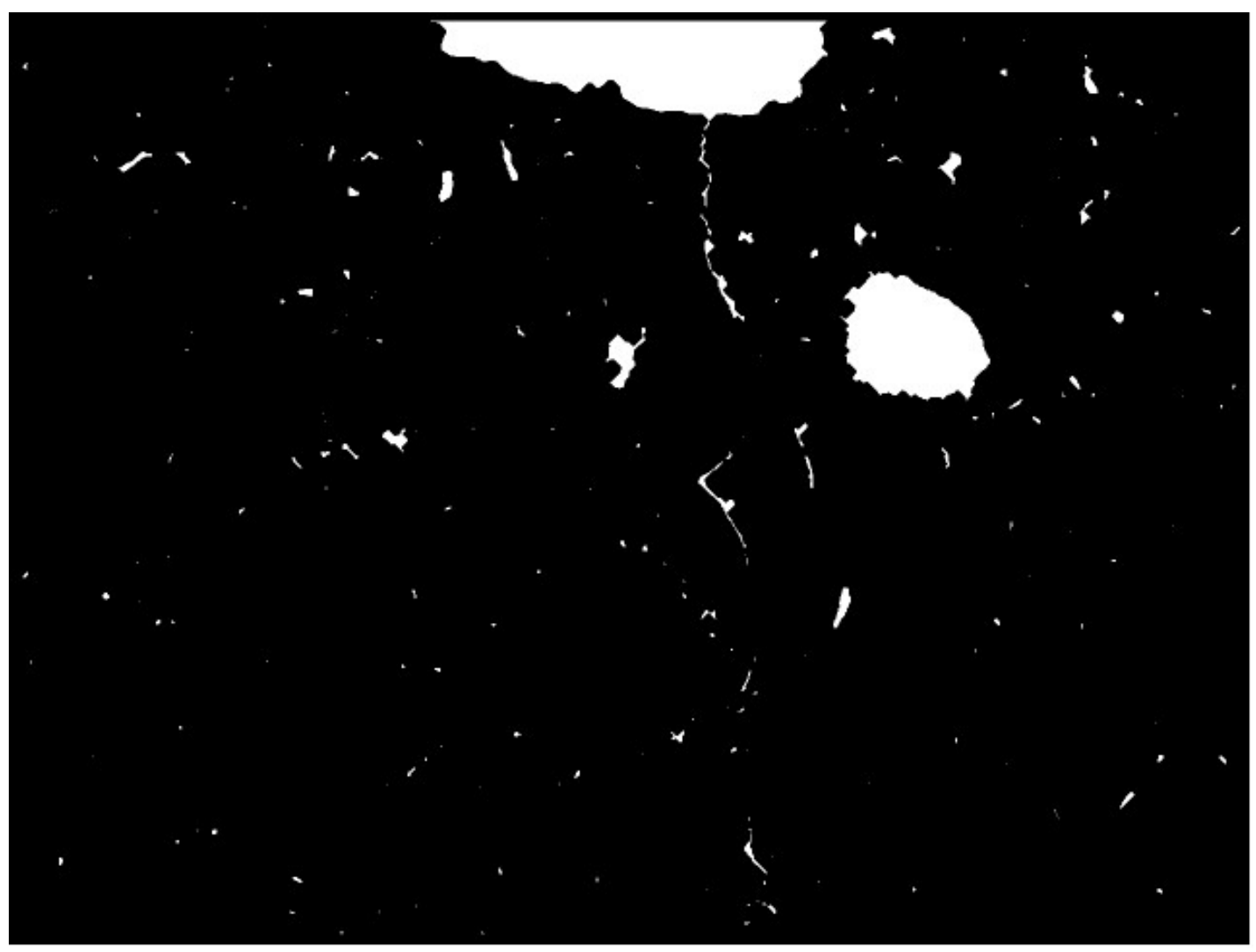

Figura 57: Imagem de MEV da amostra do aço DIN 34CrNiM0 6 segmentada. 
A etapa seguinte foi a extração de atributos, o que significou a quantificação dos aspectos microestruturais. O comando executado no Fiji foi o Analyze Particles, onde foi possível selecionar as partículas por tamanho e circularidade (fig.58).

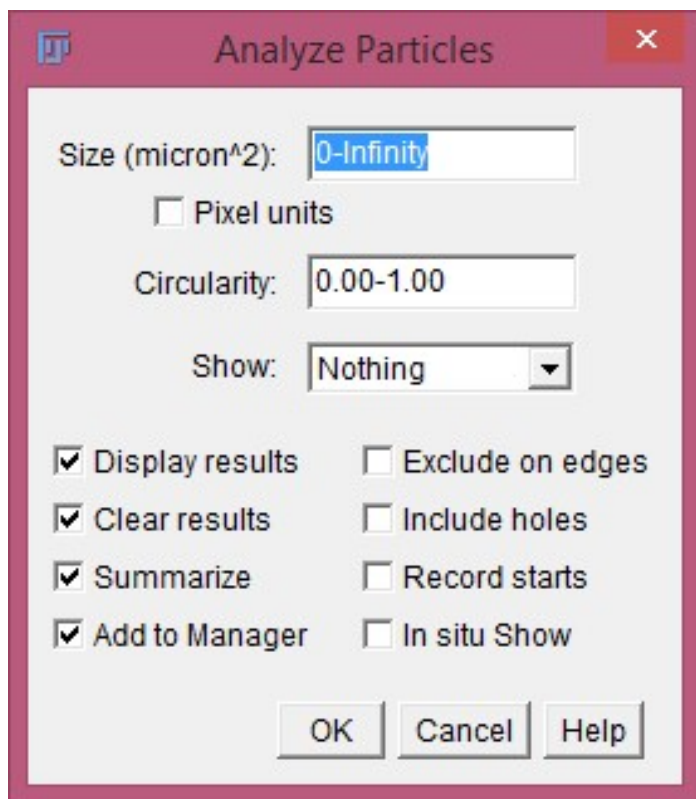

Figura 58: Comando Analyze Particles do Fiji.

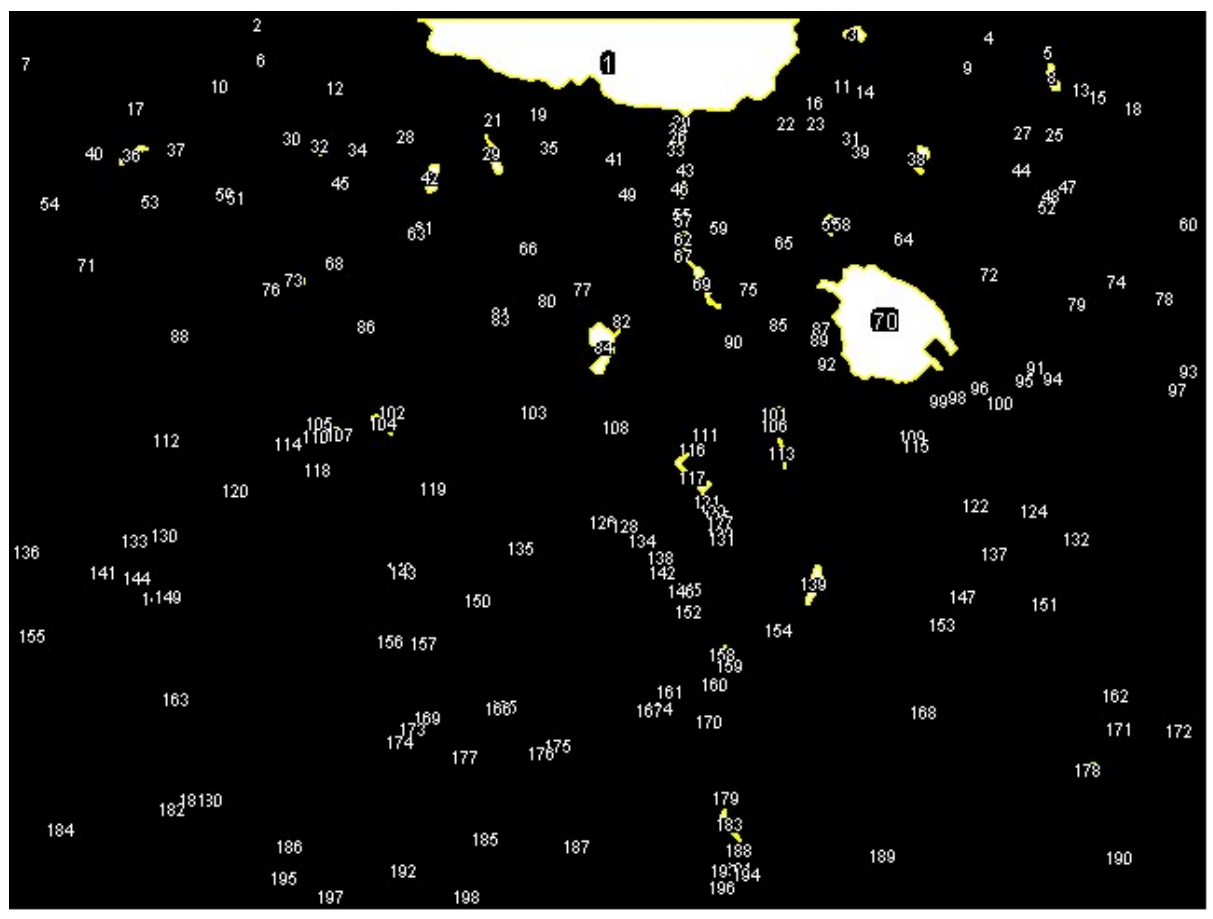

Figura 59: Resultado do comando Analyze Particles na imagem segmentada do aço DIN $34 \mathrm{CrNiM0}_{6}$. 
É importante ressaltar que o que foi medido foram os objetos brancos no fundo escuro, entretanto após a segmentação, havia objetos brancos que não faziam parte da análise, como por exemplo o entalhe (1) e um contaminante (70). Partes da trinca também não foram contabilizadas, gerando no total cerca de 165 partículas para $200 \mu \mathrm{m}^{2}$ de área (fig.59).
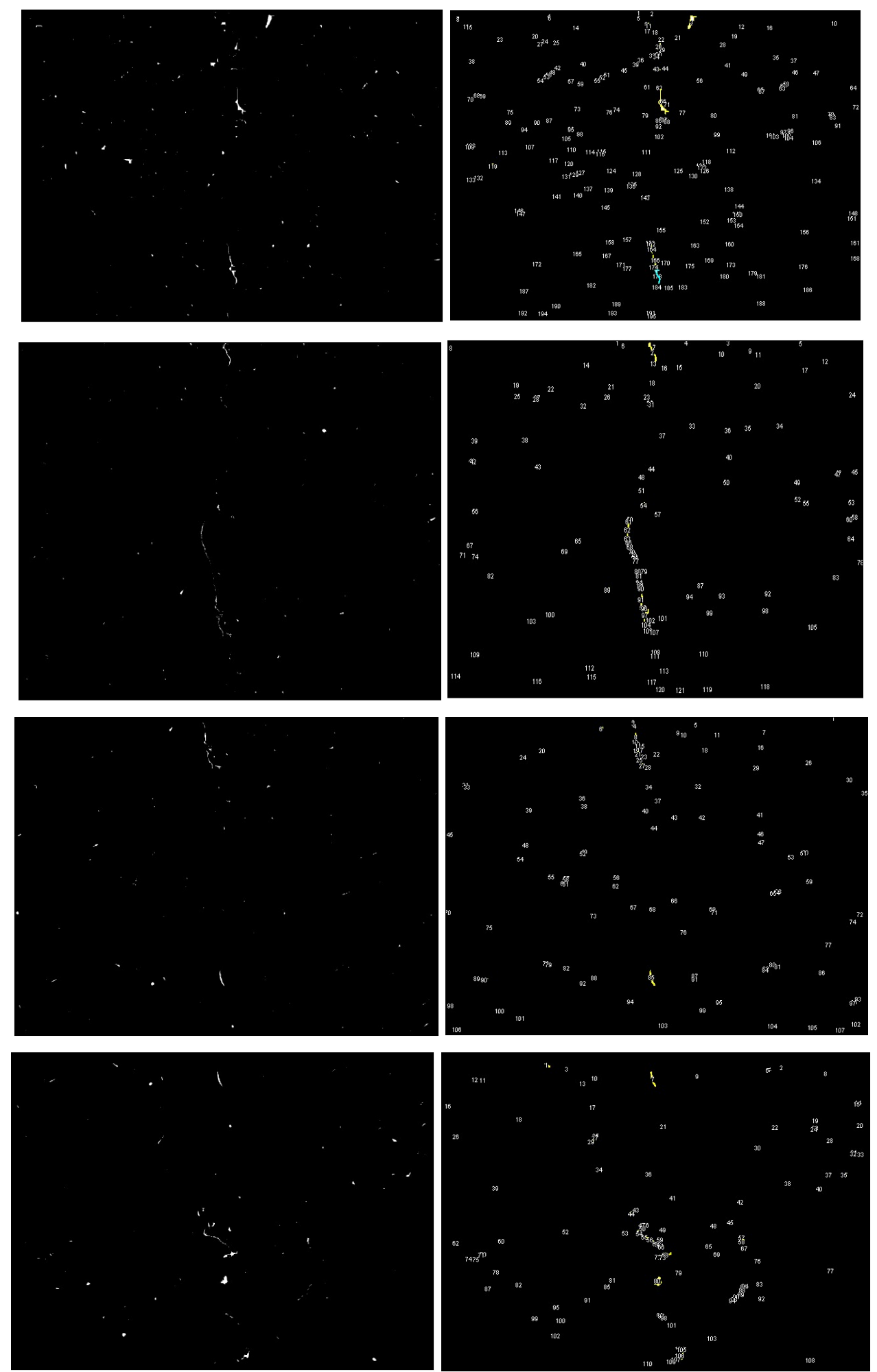

Figura 60: Mosaico formado por 4 imagens do aço DIN 34CrNiM06. 
Finalizando a contagem para 5 imagens extraídas do MEV (formando um mosaico do caminho percorrido pela trinca) para o material DIN 34CrNiM06 foram quantificadas cerca de 550 partículas $/ \mathrm{mm}^{2}$. Essa grande quantidade de heterogeneidades metalúrgicas explica, em certos aspectos, o baixo valor de $\Delta \mathrm{K}_{\text {th }}$ $(6,60 \mathrm{MPa} \mathrm{Vm})$ que esse material apresentou no ensaio de propagação de trincas por fadiga.

Análise de Espectroscopia por Energia Dispersiva (EDS) foi feita nas amostras de todos os aços, a fim de obter a composição química dessas partículas (fig.61) e o resultado para o DIN 34CrNiM06 pode ser observado nas figuras $62 \mathrm{e}$ 63.

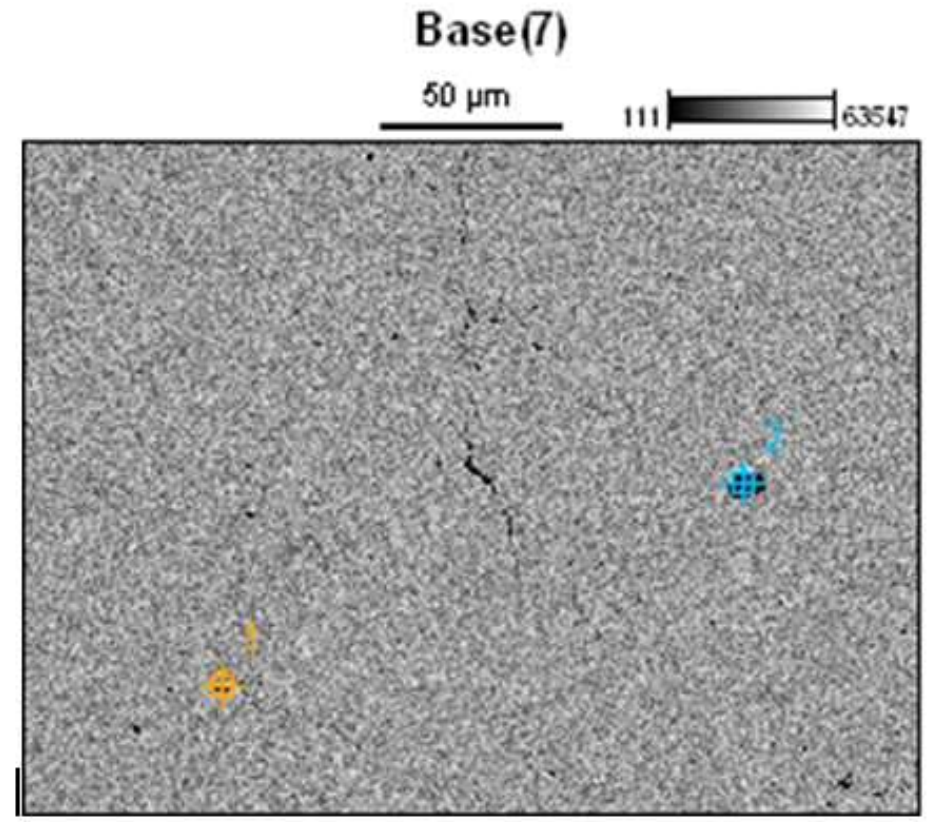

Figura 61: Imagem do MEV onde foi feito EDS no aço DIN 34CrNiM06.

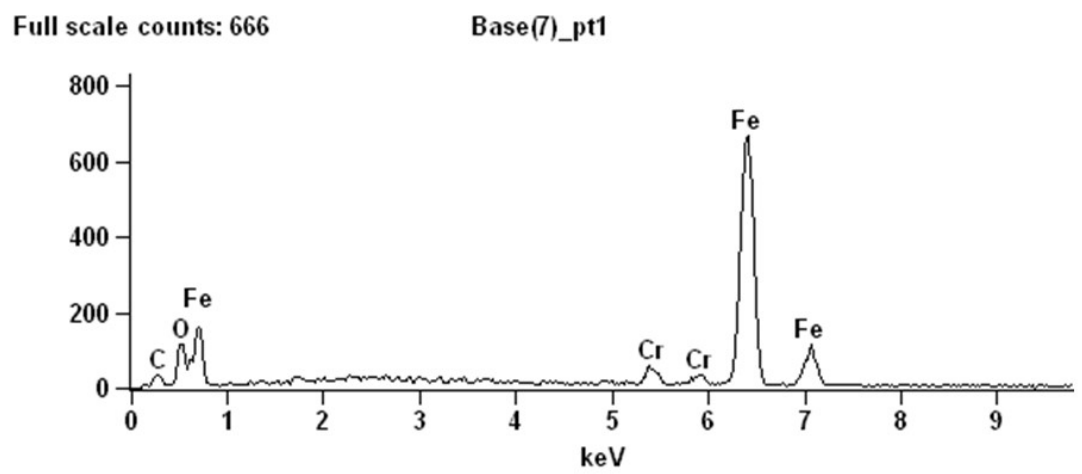

Figura 62: EDS na partícula 1 (Fig.61) indicando a presença de óxidos no aço DIN 34CrNiM06. 


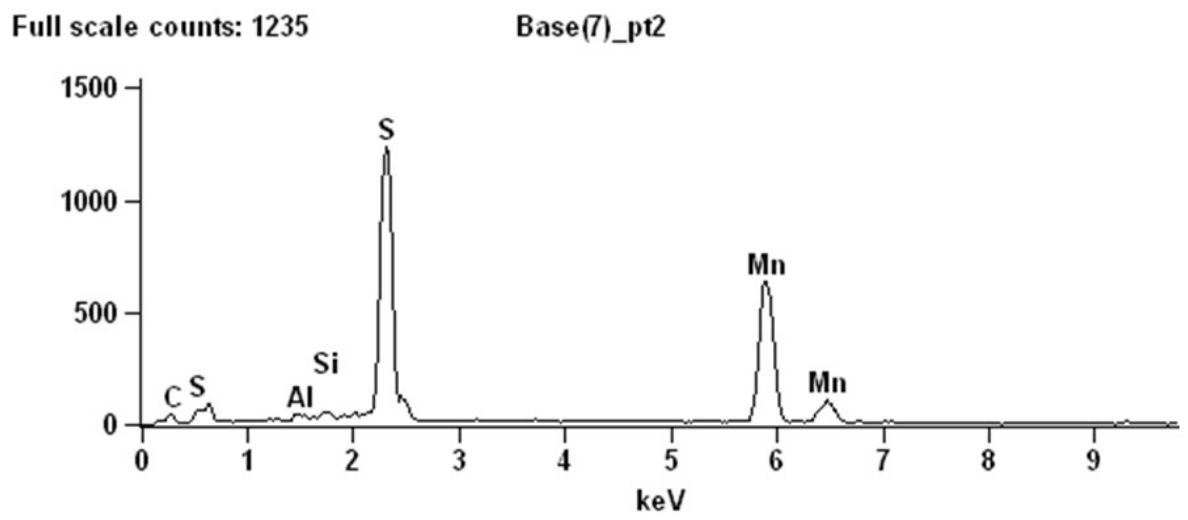

Figura 63: EDS na partícula 2 (fig.61) indicando a presença de sulfetos no aço DIN 34CrNiM06.

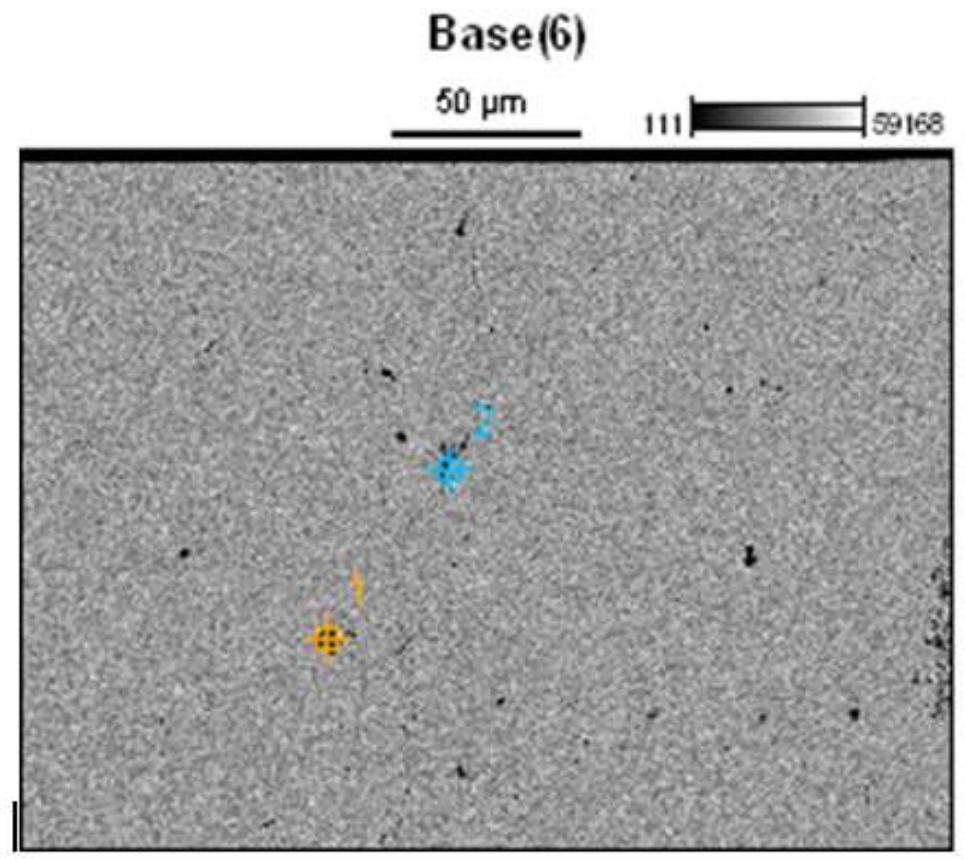

Figura 64: Outra imagem do MEV onde foi feito EDS no aço DIN 34CrNiM06.

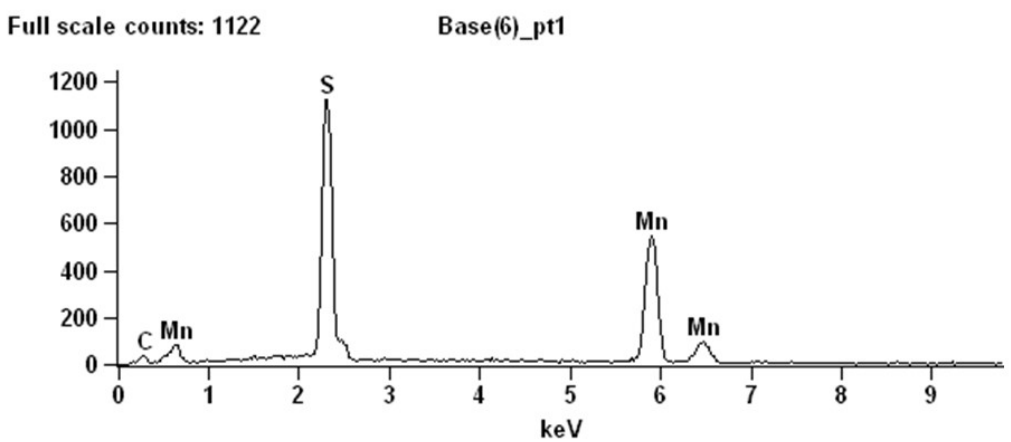

Figura 65: EDS na partícula 1 (fig.64) indicando mais sulfetos no aço DIN 34CrNiM06. 


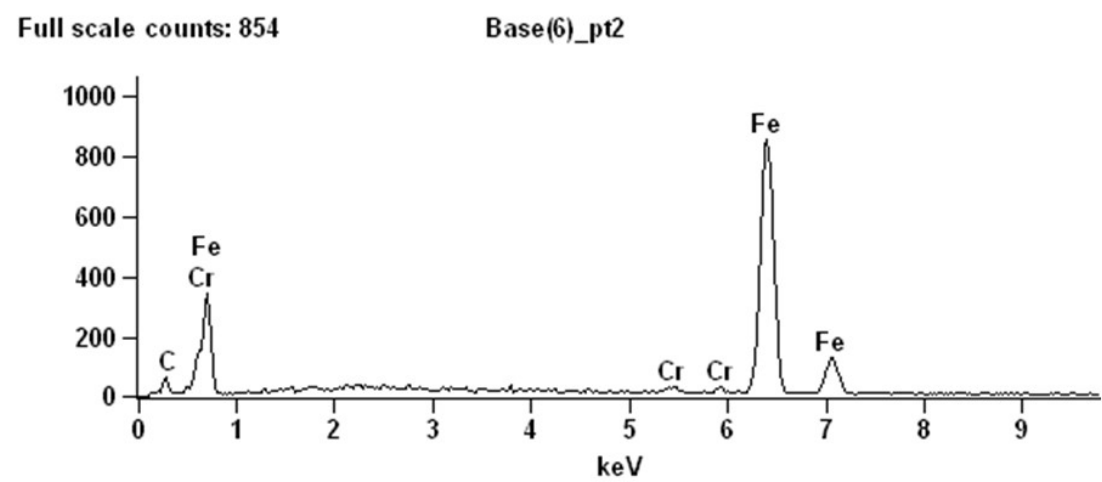

Figura 66: EDS na partícula 2 (fig.64) indicando a presença de vazios no aço DIN 34CrNiM0 ${ }_{6}$.

A média das áreas das partículas para o aço DIN 34CrNiM06 foi de 3,88 $\mu \mathrm{m}^{2}$ (fig.67). Ao substituir esse valor no parâmetro $(\sqrt{\text { area }})$ da equação 20 , o valor do limiar de propagação teórico de Murakami foi de $\left(\Delta \mathrm{K}_{\mathrm{th}}=1,77 \mathrm{MPa} \vee \mathrm{m}\right)$. Se ao invés da média, consideramos o maior tamanho de partícula como parâmetro $(\sqrt{\text { area }})$ o valor do thershold calculado foi de $\left(\Delta \mathrm{K}_{\mathrm{th}}=3,41 \mathrm{MPa} \mathrm{Vm}\right)$.

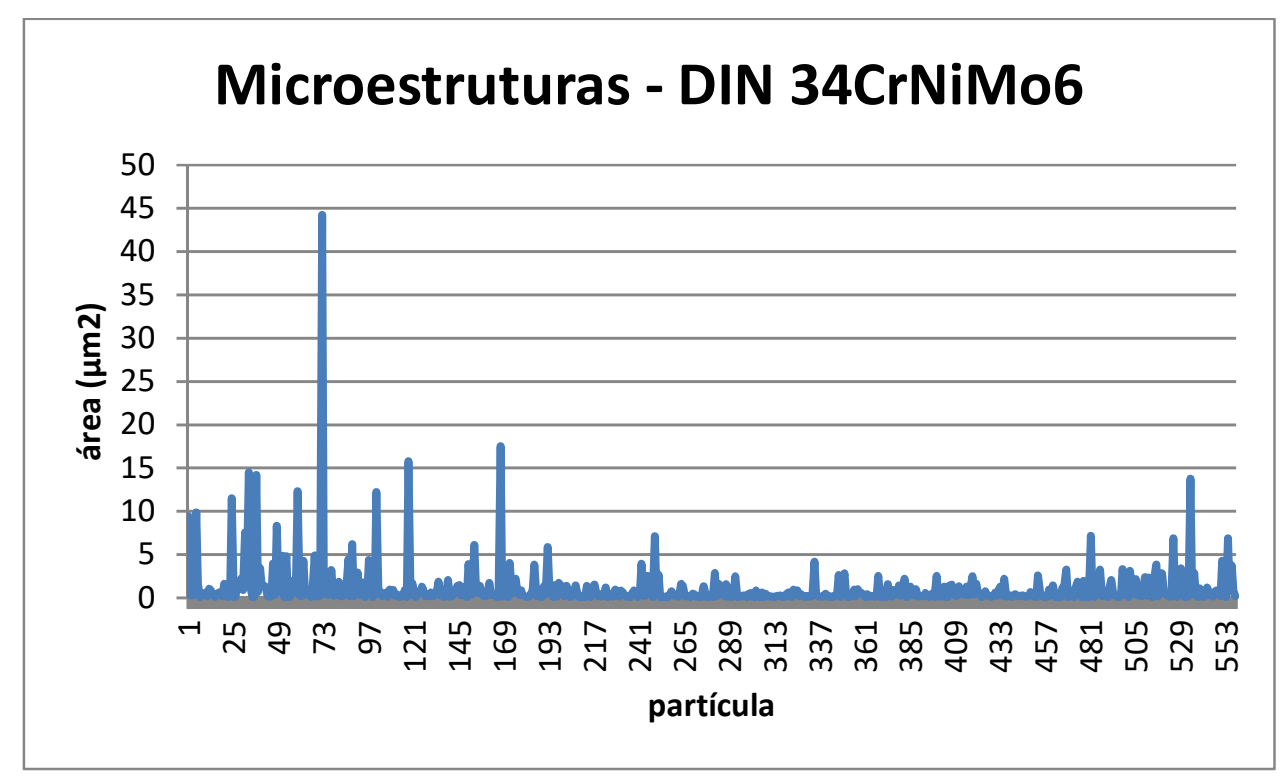

Figura 67: Área das partículas presente no aço DIN 34CrNiM06. 

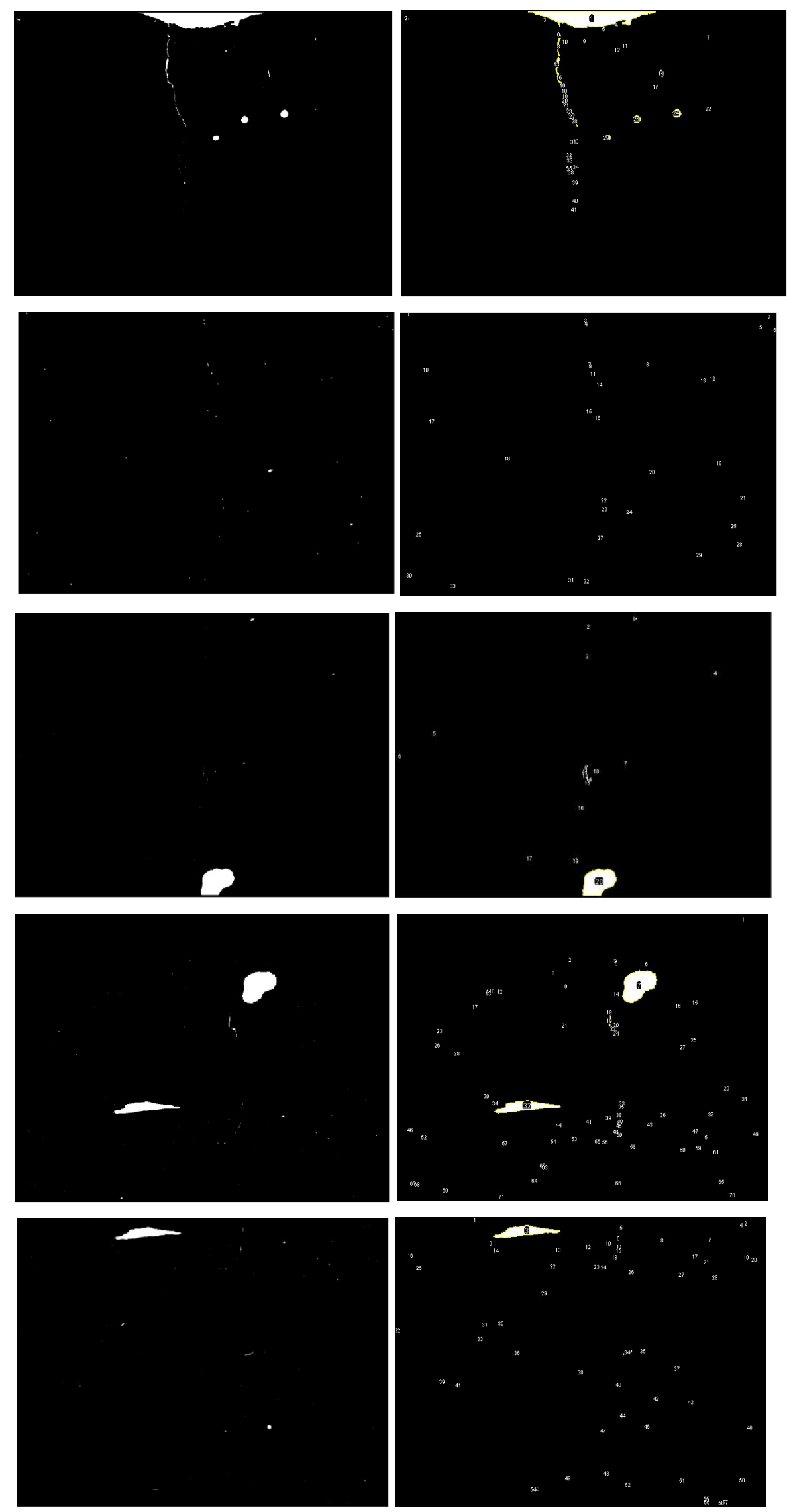

Figura 68: Mosaico formado por 5 imagens do aço SAE 4340 
O mosaico de imagens formado para o aço SAE 4340 (fig.68) indicou a quantidade de 110 partículas $/ \mathrm{mm}^{2}$. A média das áreas dessas partículas foi de $16,92 \mu \mathrm{m}^{2}$, um valor elevado devido principalmente, a presença de uma inclusão (sulfeto) e um vazio de tamanhos bem superiores quando comparado com as demais heterogeneidades metalúrgicas (fig.69).

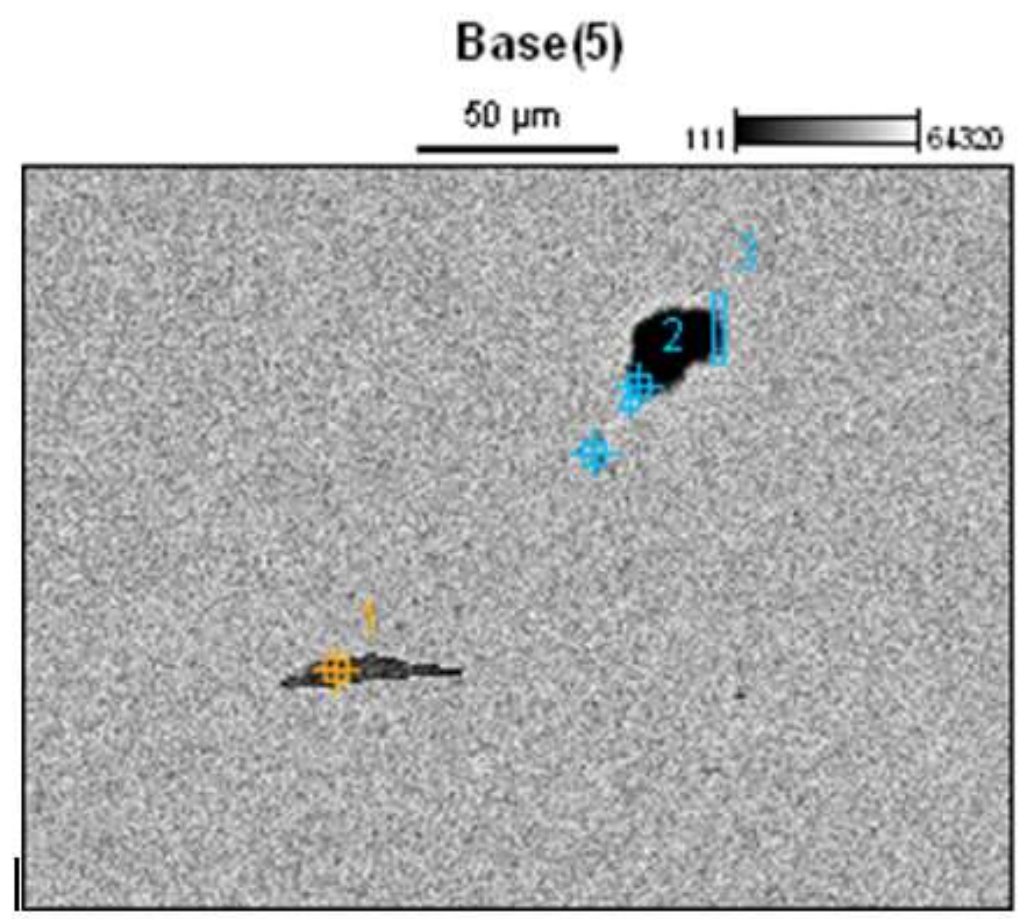

Figura 69: Imagem do MEV onde foi feito EDS no aço SAE 4340.

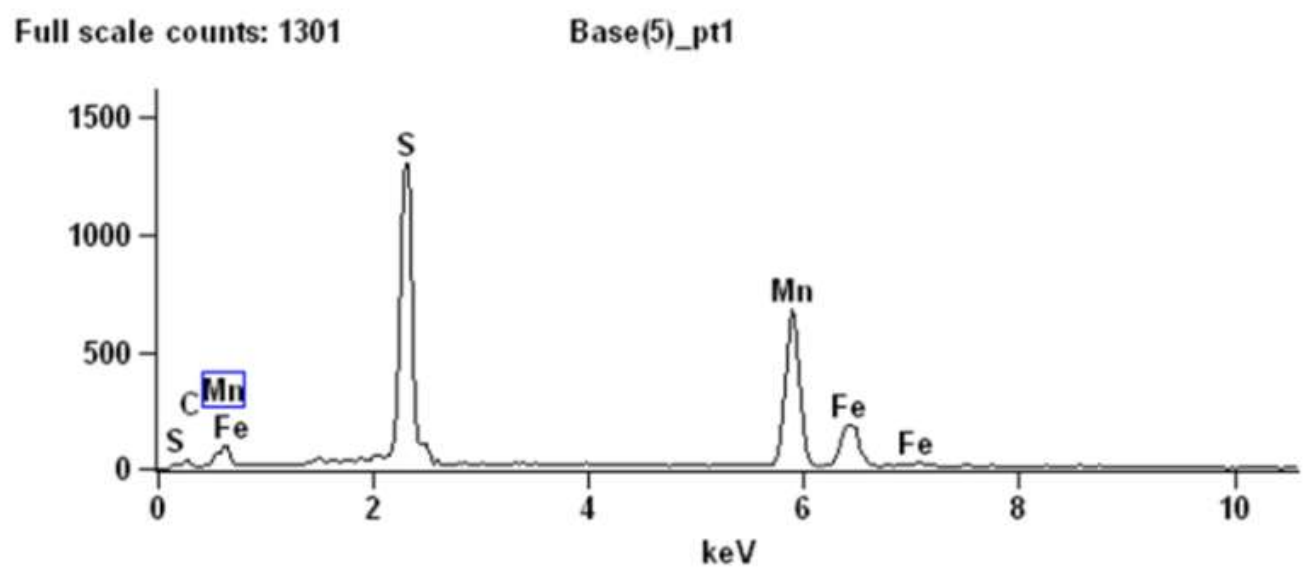

Figura 70: EDS na partícula 1 (fig.69) indicando sulfetos no aço SAE 4340. 


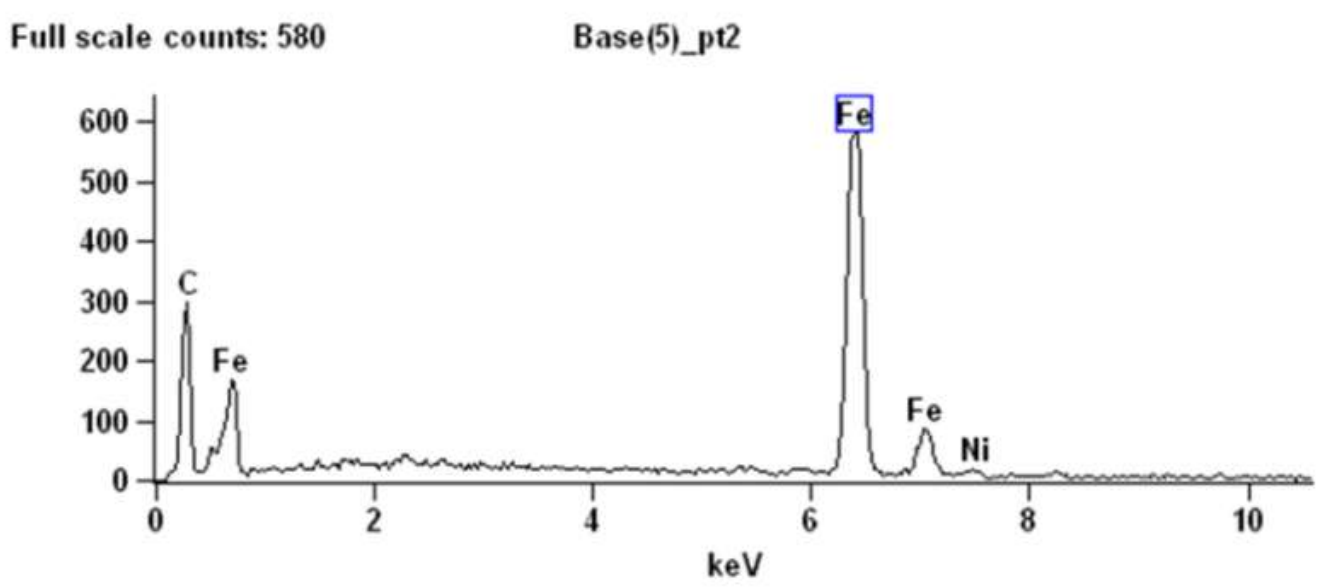

Figura 71: EDS na partícula 2 (fig.69) indicando vazios no aço SAE 4340.

Desconsiderando essas duas partículas, uma vez que não parecem exercer uma influência significativa no caminho preferencial das trincas de fadiga, a média das áreas dessas partículas passou a ser de $2,50 \mu \mathrm{m}^{2}$. Isso leva a $\Delta \mathrm{K}_{\text {th }}=1,55$ MPa $\sqrt{ }$ m (equação 20). Se ao invés da média, consideramos o maior tamanho de partícula como parâmetro $\sqrt{\text { area }}$ o valor do thershold calculado pela equação 20 foi de $\Delta \mathrm{K}_{\mathrm{th}}=3,21 \mathrm{MPa} \mathrm{Vm}$.

O mosaico formado pelas imagens do aço DIN 42CrMo4 (fig.72) indicou a quantidade de 95 partículas $/ \mathrm{mm}^{2}$. A média das áreas dessas partículas foi de 5,01 $\mu \mathrm{m}^{2}$. Com isso, $\Delta \mathrm{K}_{\mathrm{th}}=1,65 \mathrm{MPa} \vee \mathrm{m}$ (teórico), já para defeito como sendo o maior tamanho de partícula como parâmetro $\sqrt{\text { area }}$ o valor do thershold calculado foi de $\Delta K_{\text {th }}=3,12 \mathrm{MPa} V \mathrm{~m}$.

Com relação à amostra do aço SAE 4140, observa-se um comportamento diferente quando comparado aos demais aços estudados. Há a presença de quatro trincas que nuclearam em pontos diferentes, porém a que de fato continuou a se propagar foi aquela que estava no caminho onde tinha uma maior quantidade de partículas presentes, o que significa que essas partículas influenciaram na propagação da trinca, intensificando a tensão na ponta da mesma, aumentando o campo de tensões atuantes (fig.73). 

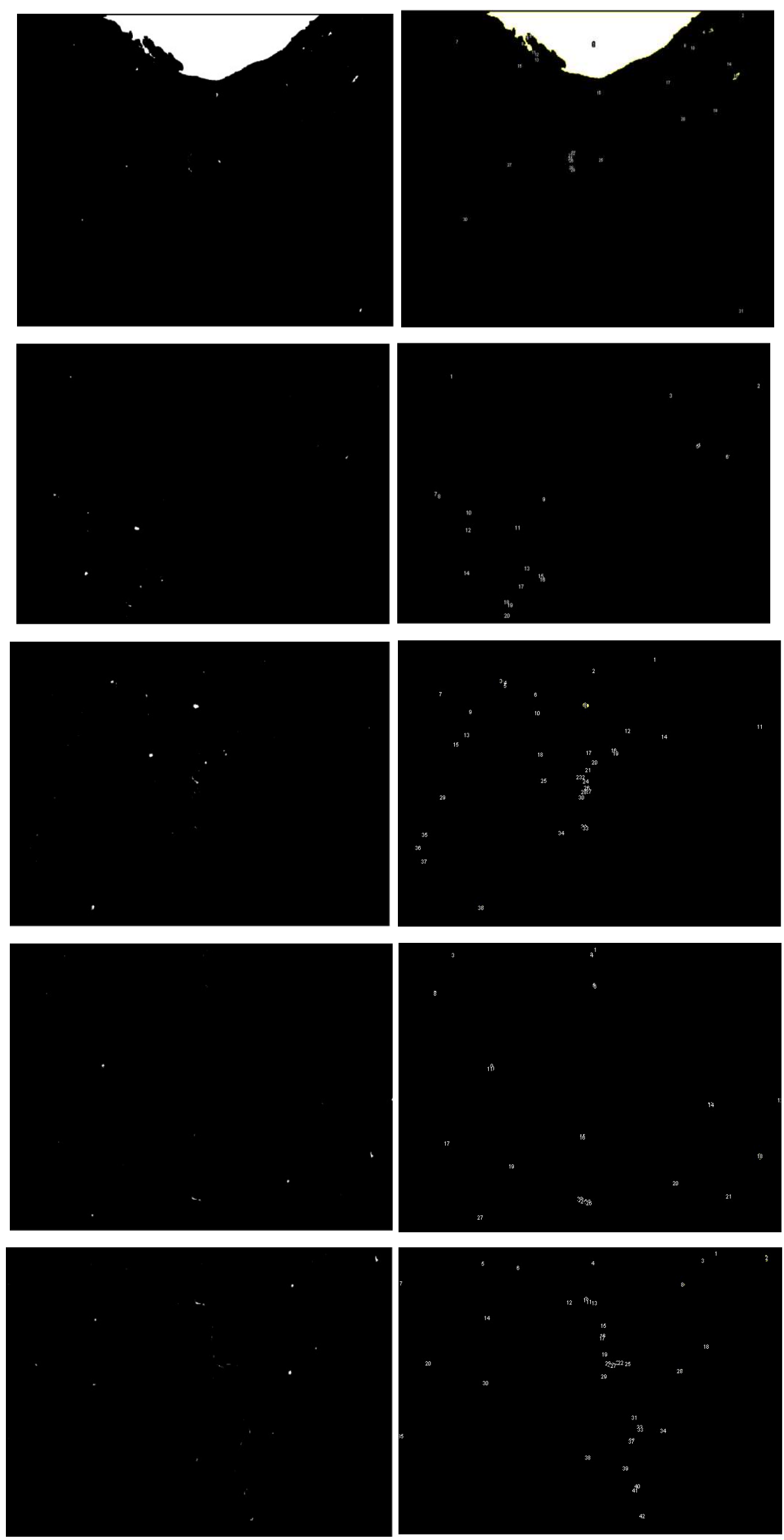

Figura 72: Mosaico formado por 5 imagens do aço DIN 42CrMo4 


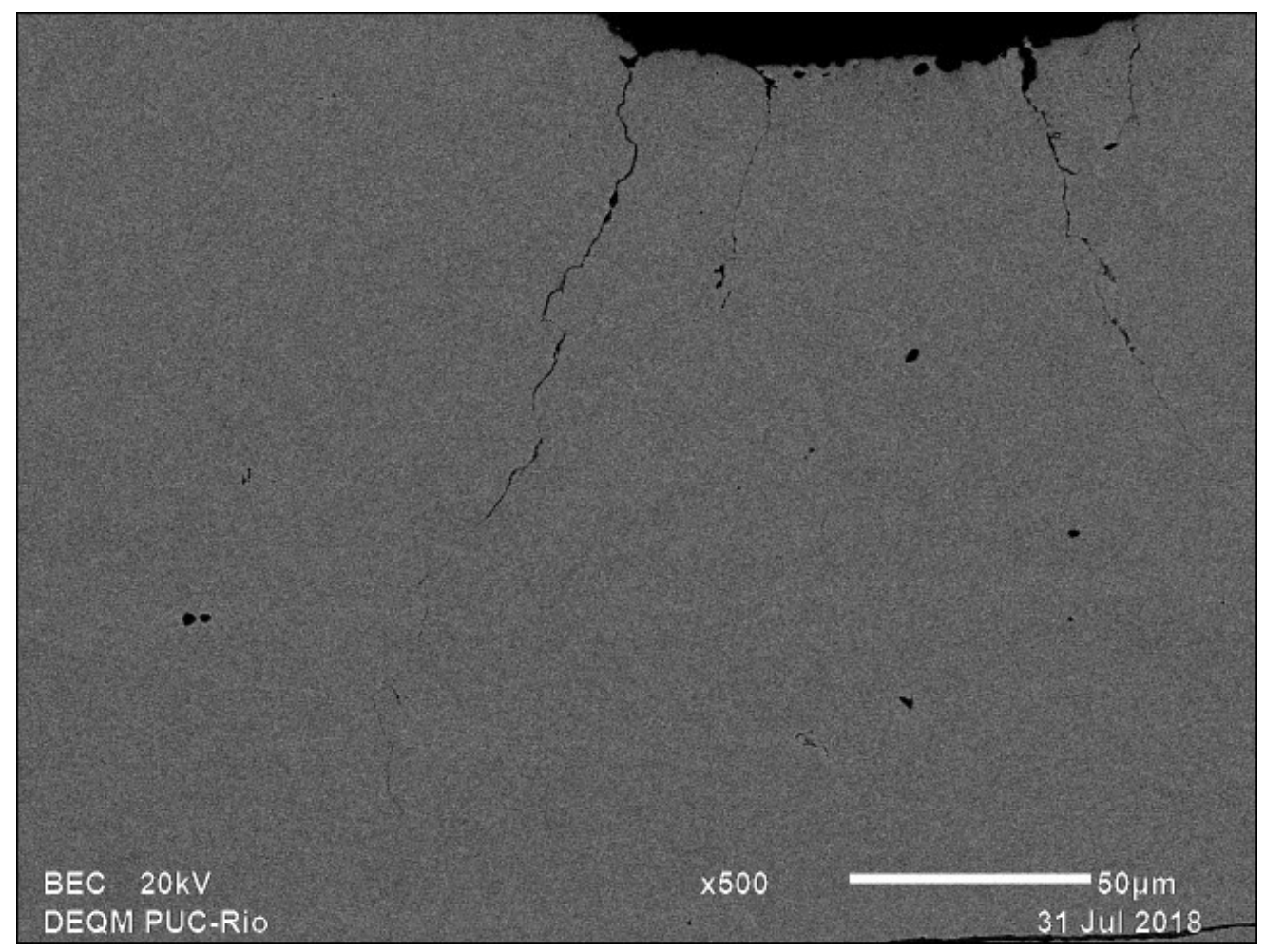

Figura 73: Imagem de MEV da amostra do aço SAE 4140 indicando múltipla nucleação de trincas de fadiga.

A segmentação das imagens do aço SAE 4140 (fig.74) mostrou-se mais difícil do que aquelas das outras amostras, pois como o caminho de propagação da trinca estava mais evidente, uma grande quantidade de partículas foi quantificada de maneira errada. Esses "pedaços" de trinca contabilizados erroneamente foram desconsiderados, onde foram eliminados manualmente um a um.

Também houve, de uma maneira mais evidente do que no caso das outras amostras, a sobreposição de uma mesma região entre duas imagens. Mais uma vez, as partículas que apareceram duplicadas não foram contabilizadas.

Um total de 125 partículas / $\mathrm{mm}^{2}$ foram contabilizadas para este aço, com a média das áreas valendo $10,54 \mu^{2}$. Essa média elevada deu-se a presença de uma maior quantidade de inclusões mais alongadas, portanto com áreas maiores. 

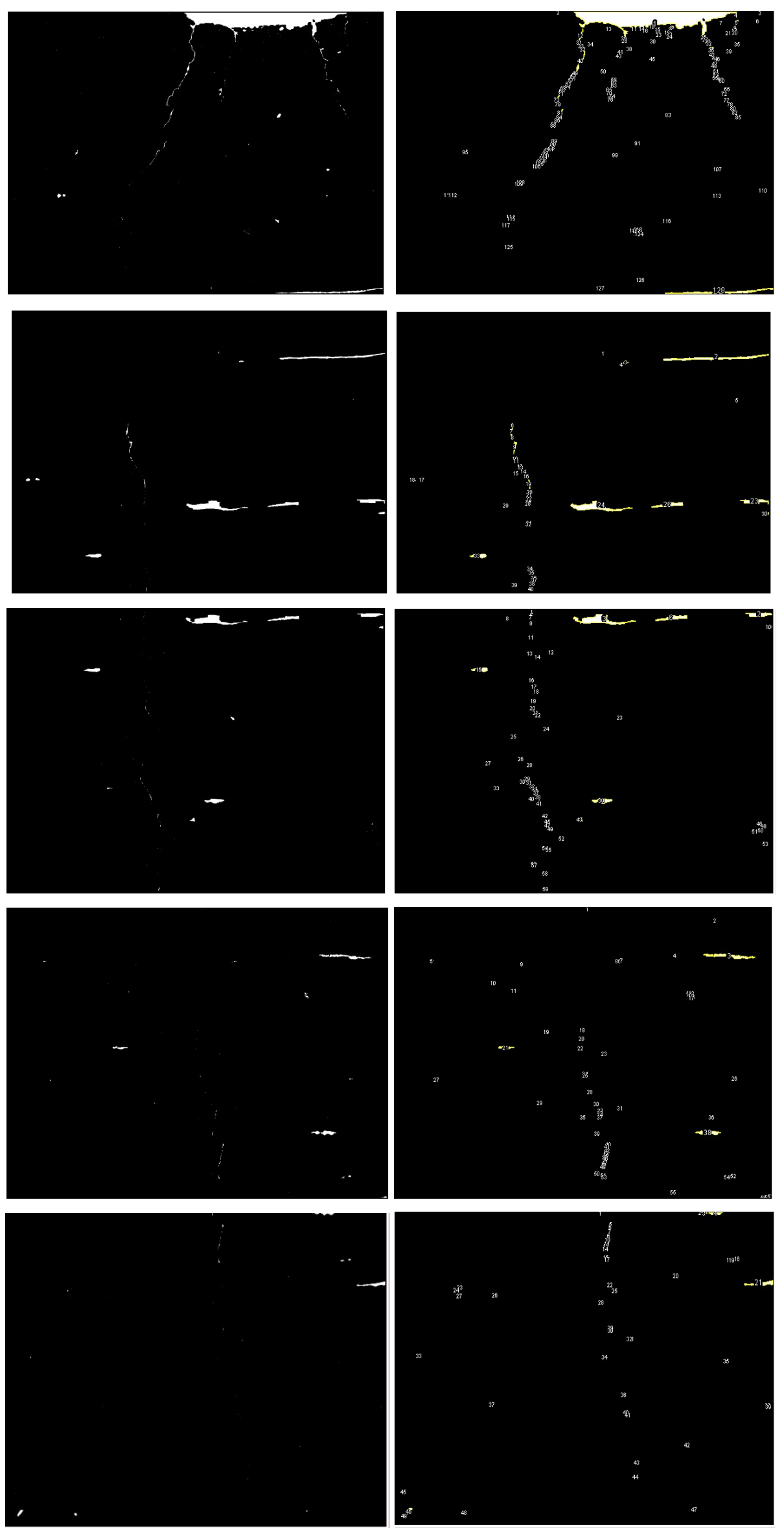

Figura 74: Mosaico formado por 5 imagens do aço SAE 4140. 
Como a direção de laminação do material onde os corpos de prova foram retirados foi na longitudinal, as inclusões alongadas nesta direção ficaram em posições paralelas em relação ao carregamento. Estudos indicam que nesta condição, as inclusões não exercem influência no caminho preferencial de propagação das trincas.

Se as oito inclusões mais alongadas na direção longitudinal não forem quantificadas, uma vez que na formulação proposta por Murakami o parâmetro ( $\sqrt{\text { area }}$ ) contempla defeitos em posições transversais aquelas do carregamento, a média da área das partículas passa a valer $5,43{\mu \mathrm{m}^{2}}^{2}$ o que leva a um limiar de propagação calculado (teórico) de 1,69 $\mathrm{MPa} \vee \mathrm{m}$. Se novamente, for considerado como parâmetro $(\sqrt{\text { area }})$ o maior defeito que exerça influência na propagação das trincas, o valor do threshold calculado foi de $\Delta \mathrm{K}_{\text {th }}=2,88 \mathrm{MPa} \sqrt{\mathrm{m}}$.

\section{Base(2)}

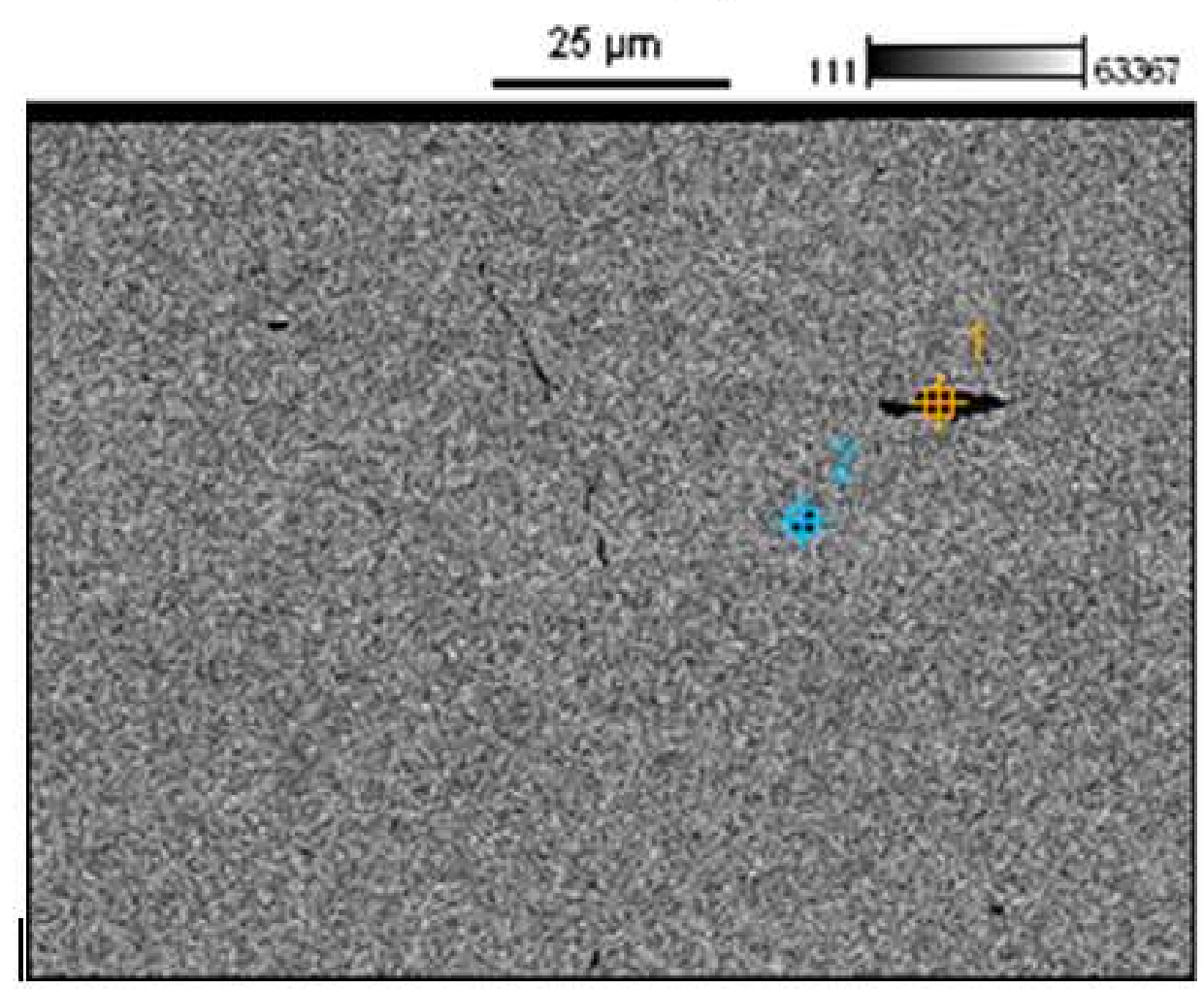

Figura 75: MEV onde foi feito EDS no aço SAE 4140. 


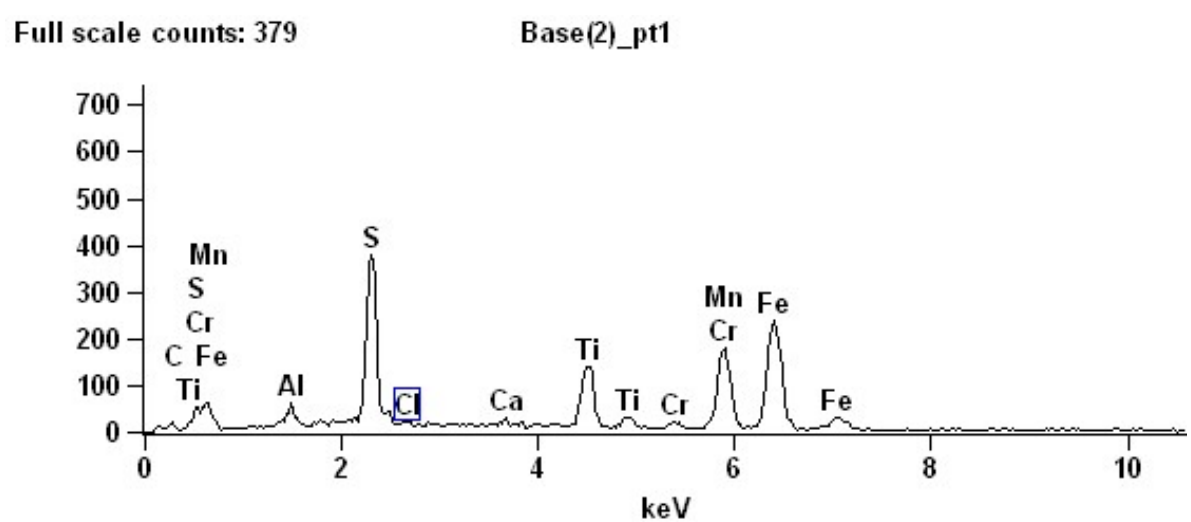

Figura 76: EDS indicando a presença de sulfetos no aço SAE 4140.

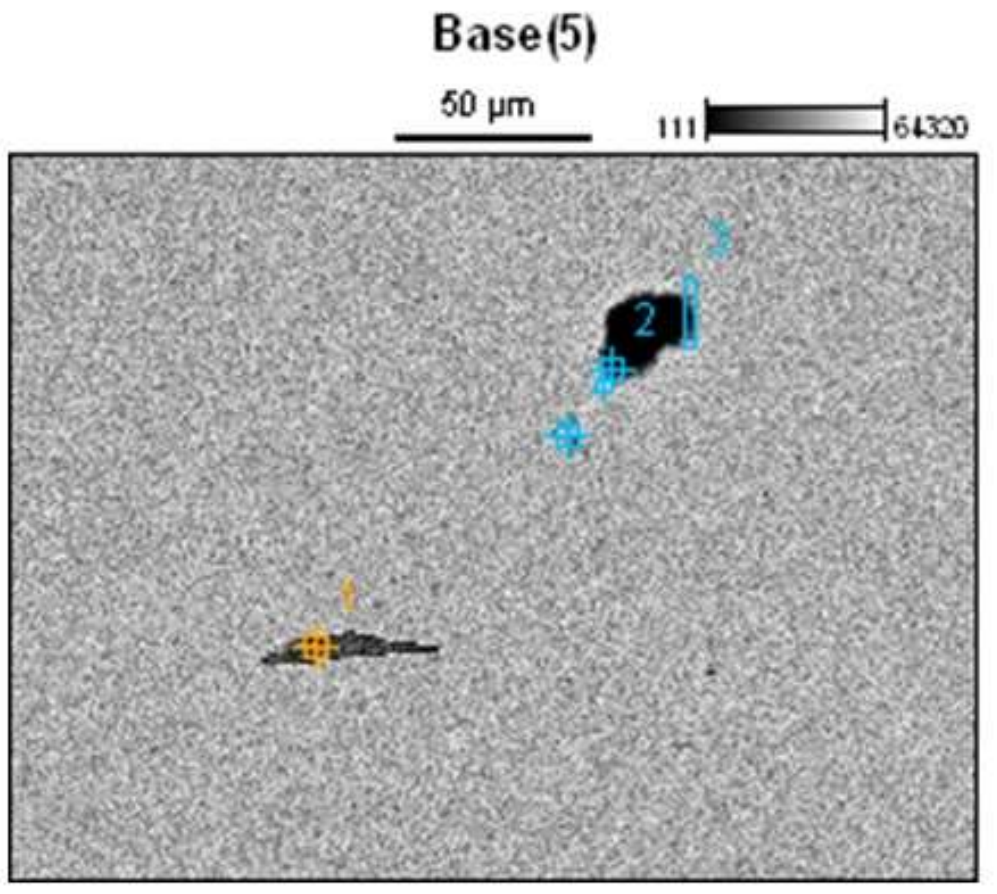

Figura 77: Outra imagem de MEV onde foi feito EDS no aço SAE 4140.

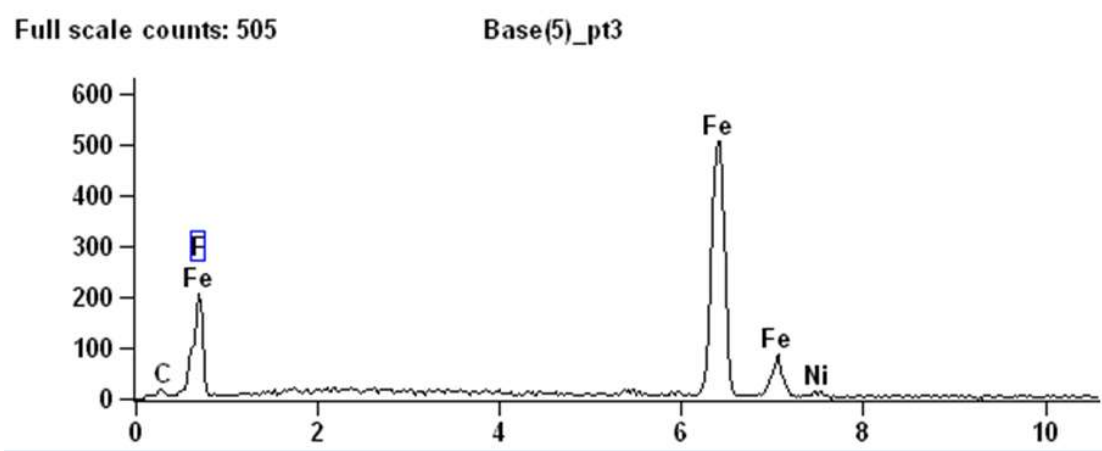

Figura 78: EDS indicando a presença de vazios no aço SAE 4140. 


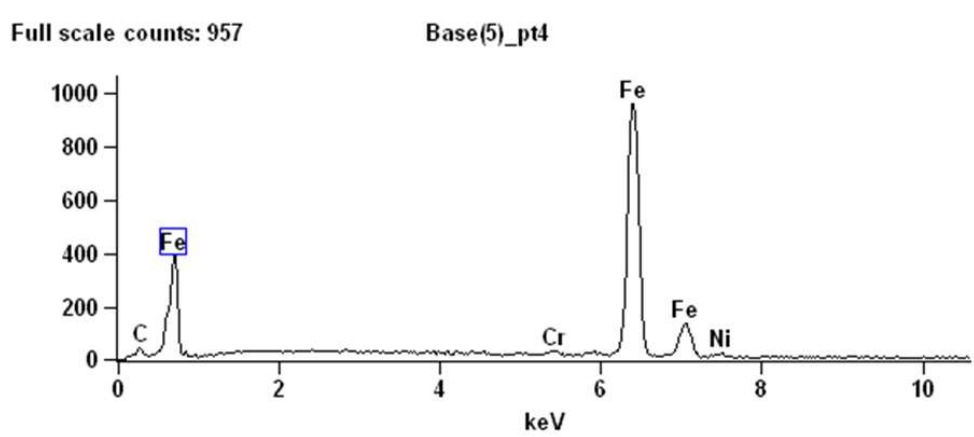

Figura 79: EDS indicando a presença de mais vazios no aço SAE 4140.

A tabela 14 indica a diferença entre o $\Delta K_{\text {th }}$ calculado através da equação 20 usando o parâmetro $(\sqrt{\text { area }})$ tanto pela média das áreas dos defeitos quanto pelo maior defeito encontrado, daquele medido experimentalmente, para os quatro diferentes tipos de aço estudados nesse trabalho. A figura 80 mostra graficamente a diferença entre o valor do threshold obtido experimentalmente, daqueles calculados usando Murakami.

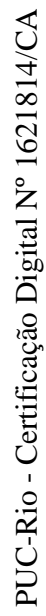

Tabela 14: $\Delta \mathrm{K}_{\text {th }}$ calculado e o medido experimentalmente para os aços estruturais estudados.

\begin{tabular}{|c|c|c|c|c|c|c|}
\hline Material & Dureza (HV) & $\begin{array}{c}\text { Varea }(\mu \mathrm{m}) \\
\text { (valor médio) }\end{array}$ & $\begin{array}{l}\Delta K \text { th (MPa Vm) } \\
\text { [Teór.] - Média }\end{array}$ & $\begin{array}{c}\text { Varea } \mu \mathrm{m} \\
\text { [maior] }\end{array}$ & $\begin{array}{l}\Delta \text { Kth (MPa Vm) } \\
\text { [Teór.] - Maior }\end{array}$ & $\begin{array}{c}\Delta \mathrm{Kth}(\mathrm{MPa} \mathrm{Vm}) \\
{[\text { Exper.] }}\end{array}$ \\
\hline 34CrNiMo6 & 285 & 1,97 & 1,77 & 16,65 & 3,41 & 6,60 \\
\hline 4340 & 282 & 1,58 & 1,55 & 16,34 & 3,21 & 7,88 \\
\hline $42 \mathrm{CrMo} 4$ & 263 & 2,24 & 1,65 & 12,98 & 3,12 & 10,50 \\
\hline 4140 & 266 & 2,33 & 1,69 & 11,58 & 2,88 & 11,70 \\
\hline Média & 274 & 2,03 & 1,67 & 14,39 & 3,16 & 9,17 \\
\hline DP & 11 & 0,34 & 0,09 & 2,50 & 0,22 & 2,34 \\
\hline
\end{tabular}

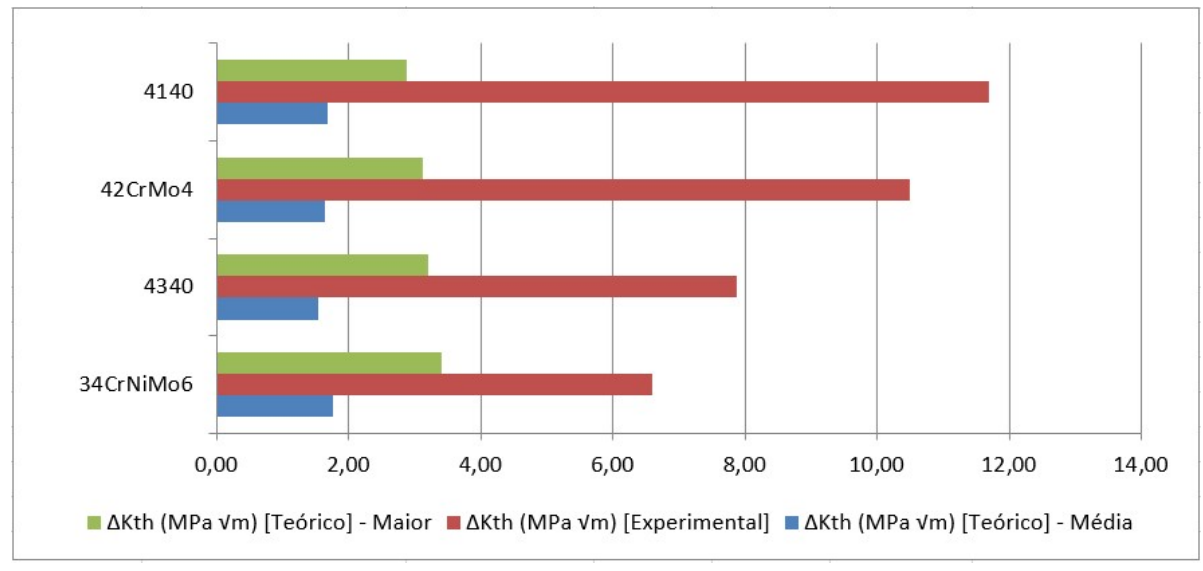

Figura 80: Comparação entre o $\Delta$ Kth teórico (Murakami) e o experimental para quatro diferentes aços estruturais. 


\section{Conclusões}

O presente trabalho avaliou nos materiais DIN 34CrNiMo6, SAE 4340, DIN 42CrMo4 e SAE 4140 a influência de heterogeneidades metalúrgicas sobre o limiar de propagação de trincas de fadiga. Os resultados obtidos nessa dissertação permitiram estabelecer as seguintes conclusões:

- O aço DIN 34CrNiMo6 foi aquele que apresentou no ensaio de propagação de trincas de fadiga o menor valor de $\Delta \mathrm{K}_{\text {th }}(6,60 \mathrm{MPa} \vee \mathrm{m})$.

- No ensaio mecânico de tração, o aço DIN 34CrNiMo6 teve o maior valor de tensão limite de escoamento $(728 \mathrm{MPa})$ e também de limite de resistência mecânica (897 MPa), o que dá indícios que aços com maiores valores de resistência mecânica, deslocam a curva $\mathrm{d} a / \mathrm{dN}$ versus $\Delta \mathrm{K}$ para a esquerda, levando a menores valores de $\Delta K_{\text {th }}$.

- Ensaios de microscopia óptica e eletrônica de varredura indicaram a presença de uma maior quantidade de heterogeneidades metalúrgicas (por exemplo, inclusões e vazios) no aço DIN 34CrNiMo6.

- Em contra-partida o aço SAE 4140 apresentou o maior valor de $\Delta K_{\text {th }}$ $(11,70 \mathrm{MPa} \vee \mathrm{m})$, menores valores de tensão limite de escoamento, de resistência mecânica (587 MPa e $802 \mathrm{MPa}$, respectivamente) e uma menor quantidade de heterogeneidades metalúrgicas.

- Os aços SAE 4340 e DIN 42CrMo4 apresentaram valores intermediários de $\Delta \mathrm{K}_{\text {th }}$, além de quantidades similares de heterogeneidades metalúrgicas.

- Com isso, no que se refere à iniciação de trincas de fadiga, o aço SAE 4140 apresenta-se como alternativa mais viável para substituição do aço 34CrNiMo6 na fabricação de eixos virabrequins para motores de usinas termoelétricas. 


\section{Sugestões para trabalhos futuros}

Para uma investigação mais completa, assim como para validar a metodologia aplicada nesta dissertação, são propostos para futuros trabalhos os seguintes tópicos:

- Obtenção das curvas de propagação de trincas de fadiga completas, ou seja, traçar também os pontos localizados na fase de propagação instável da trinca;

- Fraturar os corpos de prova, analisar a superfície de fratura dos mesmos e fazer ensaios não destrutivos por líquidos penetrantes buscando outra forma de avaliar a influência dos aspectos microestruturais na propagação das trincas de fadiga.

- Fazer polimento eletrolítico nas amostras feitas desses aços em novos corpos de prova, uma vez que o polimento mecânico "arranca" material e fica difícil de mensurar se os "vazios" presentes nas amostras são devidos à fabricação do material ou ao polimento mecânico.

- Analisar dentro dos aspectos microestruturais presentes nas amostras, quais são aqueles que exercem uma maior influência na propagação das trincas de fadiga.

- Relacionar o tamanho dos grãos das amostras dos aços estruturais estudados com o limiar de propagação de trincas por fadiga.

- Avaliar as condições em que a equação do cálculo de limiar de propagação de trincas de fadiga, proposta por Murakami e Endo, acarreta em valores de $\left(\Delta \mathrm{K}_{\mathrm{th}}\right)$ mais próximos daqueles obtidos experimentalmente.

- Avaliar a influência que as heterogeneidades metalúrgicas exercem em aços estruturais quando ensaiados num regime de altíssimo ciclo de fadiga. Verificar se os aspectos responsáveis pela nucleação das trincas para esse caso serão os mesmos. 


\section{Referências bibliográficas}

[1] ANDERSON, T. L. 2005. Fracture Mechanics: Fundamentals and Applications, 3rd ed., CRC Press, Boca Raton, FL.

[2] BARSOM, J. M., ed. 1987. Fracture Mechanics Retrospective: Early Classic Papers (1913-1965), RPS-1, ASTM International, West Conshohocken, PA.

[3] DIETER, E. G. Metalurgia Mecânica, 2rd ed. Guanabara Dois.

[4] IRWIN, G. R.; DE WIT, R. A summary of fracture mechanics concepts. Journal of testing and evaluation, v. 11, n. 1, p. 56-65, 1993.

[5] DOWLING NE (2007), Mechanical Behavior of Materials, 3rd ed. Prentice Hall, Inc. New Jersey, USA.

[6] ROSA, E. 2002. Análise de Resistência Mecânica (Mecânica da Fratura e Fadiga), 1rd Ed., UFSC.

[7] HERTZBERG, R., Deformation and Fracture Mechanics of Engineering Materials, $3^{\text {a }}$ ed. Wiley, New York, 1989.

[8] ME3 Fundamentals of Fracture Mechanics, Lecture notes 2014-15, Shaun Crofton Imperial College, London - UK.

[9] SURESH, S. 2006. Fatigue of Materials, $2^{\text {nd }}$ ed., Cambridge University Press, Cambridge, UK.

[10] Jorge Arturo Hinostroza Medina, Avaliação de Previsões de Fratura Elastoplástica - Tese de Doutorado, PUC-RJ, 2014.

[11] WELLS, A. A., "Unstable Crack Propagation in Metals - Cleavage and Fast Fracture", Crack Propagation Symposium Proc., Cranfield College of Aeronautics, 1, p. 210, 1961.

[12] COTTRELL, A. H., "Theoretical Aspects of Radiation Damage a Brittle Fracture in Steel Pressure Vessels", Iron and Steel Institute Spec. Report., n 69, p.281, 1961.

[13] Castro JTP, Meggiolaro MA (2009), Fadiga: Técnicas e Práticas de Dimensionamento Estrutural sob Cargas Reais de Serviço - Volume 1, Create Space (in portuguese). 
[14] Yamashita Y, Murakami Y. "Small crack growth model from low to very high cycle fatigue regime for internal fatigue failure of high strength steel". International Journal of Fatigue. 2016; 93(2):406-414.

[15] Murakami Y, Yamashita Y. "Prediction of life and scatter of fatigue failure originated at non-metallic inclusions". Procedia Engineering. 2014; 74:6-11.

[16] Wang QY, Berard JY, Rathery S, Bathias C. "High-cycle fatigue crack initiation and propagation behavior of high-strength spring steel wires". Fatigue FractEng Mater Struct 1999; 22:673-7.

[17] Paris PC, Marines-Garcia I, Hertzberg RW, Donald JK. "The relationship of effective stress intensity, elastic modulus and burger-vector on fatigue crack growth as associated with "Fish-eye" gigacycle fatigue phenomena". In: Proceedings of the international conference on very high cycle fatigue III, Kyoto, Japan; September 2004.

[18] Marines-Garcia I, Paris PC, Tada H, Bathias C, Lados D. "Fatigue crack growth from small to large cracks on very high cycle fatigue with fisheye failures". Eng Fract Mech 2008; 75:1657-65.

[19] Pyttel B, Schwerdt D, Berger C. "Very high cycle fatigue - Is there a fatigue limit?" International Journal of Fatigue. 2011; 33(1):49-58.

[20] Castro JTP, Meggiolaro MA (2009), Fadiga: Técnicas e Práticas de Dimensionamento Estrutural sob Cargas Reais de Serviço - Volume 2, Create Space (in portuguese).

[21] P.G. Forrest (1962), Fatigue of Metals, Pergamon Press Ltd., Headington Hill Hall, Oxford 4 \& 5 Fitzroy Square, London W.1.

[22] William D. Callister, JR. Ciência e Engenharia de Materiais: Uma Introdução, $5^{\text {a }}$ edição. Rio de Janeiro, LTC2002.

[23] Kwai S. Chan, "Roles of microstructure in fatigue crack initiation". International Journal of Fatigue 32 (2010) 1428-1447.

[24] C. Bathias, L. Drouillac, P. Le François. "How and why the fatigue S-N curve does not approach a horizontal asymptote". International Journal of Fatigue 23 (2001) S143-S151.

[25] Norton, R.L. (2006). Machine Design: An Integrated Approach (3rd Ed.). Worcester, Massachusetts, EUA: Pearson Prentice Hall.

[26] Meyers, M.A. \& Chawla, K.K. (2009). Mechanical Behavior of Materials (2 ed.). Nova York, EUA: Cambridge University Press. 
[27] Mentley, J. (2013). Fatigue \& durability. Technical report, HBM Code, São Paulo, SP, Brasil. Apresentado na Altair Technology Conference 2013, Brasil.

[28] Schijve, J. (2008). Fatigue of Structures and Materials (2nd Ed.). Springer.

[29] LIU, Y; MAHADEVAN, S. "Multiaxial high-cycle fatigue criterion and life prediction for metals". International Journal of Fatigue. v.27, n.7, julho, 2005.

[30] RITCHIE, R. O., “Intern. Met. Rev.”, 1979, R. 245, p. 205.

[31] INVING, P. E. and BEEVERS, C. J., “Metal. Trans.”, 1974, 5, p. 391.

[32] BUCCI, R. J., PARIS, P. C. and HERTZBERG, R. W., ASTM STP $513,1972$.

[33] SCMITH, R. A. and PARIS, P. C., “ASTM STP 536”, 1973, p. 79.

[34] Kujawski D, Ellyin F. "A unified approach to mean stress effect on fatigue threshold conditions". Int J Fatigue 1995;17(2):101-106.

[35] Lal DN, Namboodhiri TKG. "A model for the effect of mean stress on the threshold condition for fatigue crack propagation". Mater Sci Eng A $1990 ; 130: 37-49$.

[36] Kloster V, Richard HA, Kullmer G. "Experimental characterization of the threshold and fatigue crack growth behavior regarding negative stress ratios". Ann NuclEnerg 2013; 40(1):14-24.

[37] Walker K. "The effect of stress ratio during crack propagation and fatigue for 2024-T3 and 7075-T6 aluminum". In: Effect of environment and complex load history on fatigue Life. ASTM International 1970:1-14.

[38] Mann T. "The influence of mean stress on fatigue crack propagation in aluminum alloys". Int J Fatigue 2007; 29:1393-1401.

[39] Radhakrishan VM. Endurance diagram. Int J Fatigue 1990; 12(6):513-517.

[40] Doker H. "Fatigue crack growth threshold: implications, determination and data evaluation". Int J Fatigue 1997; 19(93):145-149. 
[41] Miller KJ, de los Rios ER. "The behavior of short fatigue cracks"; EGF (ESIS), 1986 Publication 1.

[42] Tokaji K, Ogawa T, Harada Y. "The growth of small fatigue cracks in a low carbon steel”. FFEMS 1986; 9:205-17.

[43] Zheng X, Hirt MA. "Fatigue crack propagation in steels". Eng. Fract. Mech. 1983; 18:965-73.

[44] Klesnil M, Lukáš P. "Fatigue of metallic materials". Mater Sci Monogr 1980;7.

[45] Carlos A. Molina, Mirco D. Chapetti. "Estimation of high cycle fatigue behavior using a threshold curve concept", International Journal of Fatigue 108 (2018) 47-52.

[46] McEvily AJ, Minakawa K. "Crack closure and the growth of short and long fatigue cracks". ScrMetall 1984; 18:71.

[47] El Haddad MH, Topper TH, Smith KN. "Prediction of nonpropagating cracks". Eng. Fract. Mech. 1979; 11:573-84.

[48] Chapetti MD. "Fatigue propagation threshold of short cracks under constant amplitude loading”. Int J Fatigue 2003; 25:1319-26.

[49] Tanaka K, Nakai Y, Yamashita M. "Fatigue growth threshold of small cracks". Int J Fract 1981;17(5):519-33.

[50] Kitagawa H, Takahashi S. "Applicability of fracture mechanics to very small cracks in the early stage". In: Proceedings of the Second International Conference on mechanical behavior of materials ASM; 1976. p. $627-631$.

[51] PARKER, A. P., The Mechanics of Fracture and Fatigue, Spon, London, 1983.

[52] Metals Handbook, "Failure Analysis and Prevention”, vol. 11, ASM, 1980.

[53] Bruno Ximenes Takahashi, Metodologia Moderna para Análise de Fadiga baseada em Elementos Finitos de Componentes Sujeitos a Fadiga Uni e Multiaxial - Tese de Mestrado, USP-SP, 2014.

[54] P. L. TEED, "The Influences of Metallographic Structure on Fatigue". Symp. Fatigue and Fracture of Metals M.I.T. John Wiley, New York (1950) 252. 
[55] P. H. FRITH, "Fatigue Tests on Rolled Alloy Steels". Iron and Steel Inst.Special Report No. 50 (1954).

[56] J. T. RANSOM and R. F. MEHL, "Anisotropy of the Fatigue Properties of SAE 4340 Steel Forgings". Proc. Amer. Soc. Test. Mat. 52 (1952) 779 .

[57] W. C. STEWART and W. L. WILLIAMS, "Effect of Inclusions on the Endurance Properties of Steels". J. Amer. Soc. Naval Engrs. 60 (1948) 475.

[58] H. N. CUMMINGS, F. B. STULEN and W. C. SCHULTE, "Tentative Fatigue Strength Reduction Factors for Silicate-Type Inclusions in HighStrength Steels”. Proc. Amer. Soc. Test. Mat. 58 (1958) 505.

[59] M. ATKINSON, "Influence of Non-Metallic Inclusions on Fatigue Properties". J. Iron and Steel Inst. 195 (1960) 64.

[60] E. EPREMIAN and R. F. MEHL, "Statistical Behavior of Fatigue Properties and the Influence of Metallurgical Factors". Amer. Soc. Test. Mat. Spec.Tech. Publ. 137 (1953).

[61] H. STYRI, "Fatigue Strength of Bail-Bearing Races and HeatTreated 52100 Steel Specimens". Proc. Amer. Soc. Test. Mat. 51 (1951) 682.

[62] J. I. FISHER and J. P. SHEEHAN, "Effect of Metallurgical Variables on the Fatigue Properties of AISI 4340 Steel". Wright Air Development Center Tech. Rpt. 58-289 (1959).

[63] Murakami Y. "Metal fatigue: effects of small defects and nonmetallic inclusions". Oxford: Elsevier Science Ltd; 2002.

[64] Y. Nadot, C. Nadot-Martin, A. Dragon and M. Vincent. "Competition between surface defect and grain size under fatigue loading - ARMCO iron". Procedia Structural Integrity 7 (2017) 530-535.

[65] Murakami Y, Endo M. "Effects of defects, inclusions and inhomogeneities on fatigue strength". Int J Fatigue 1994;16h16min-82. 
[66] Tokaji, K., Ogawa, T. and Osako, S. (1988). Fatigue Fracture Engineering Material Structure, Vol. 11, No. 5, pp.331-342.

[67] Mirco D. Chapetti. "Hardness as a tool for the estimation of the microstructural threshold". Procedia Structural Integrity 7 (2017) 229-234.

[68] Letícia Bueno Nogueira, Estudo da Influência de Defeitos Microestruturais no Limiar de Fadiga de aços estruturais - Tese de Mestrado, PUC-RJ, 2017.

[69] A.L.V. da Costa e Silva e P.R. Mei, Aços e Ligas Especiais. Editora Edgard Blücher, São Paulo (2014).

[70] Patrícia de Oliveira C. Neubauer, Determinação Experimental de Curvas de Resistência do aço DIN 42CrMo4 - Tese de Mestrado, PUC-RJ, 2018.

[71] Silva Telles, Pedro, Materiais para Equipamentos de Processo. Editora Interciência, Rio de Janeiro (2003).

[72] Berenice Anina Dedavid, Carmem Isse Gomes e Giovanna Machado, Microscopia Eletrônica de Varredura - Aplicação e Preparação de Amostras - Apostila, EdiPUC-RS, Porto Alegre (2007).

[73] J. H. Bulloch. Fatigue threshold in steels Mean stress and microstructure influences. Int. J. Pres. Ves. \& Piping 58 (1994) 103-127. 